\title{
MARGENS DE COMERCIALIZAÇÃO E CAUSALIDADE DE PREÇOS AGRÍCOLAS
}

\author{
JOĀO GOMES MARTINES FILHO
}

Orientador: Prof. Dr. GERALDO S. A. DE CAMARGO BARROS

Dissertação apresentada à Escola Superior de Agricultura "Luiz de Queiroz", da Universidade de São Paulo, para obtenção do título de Mestre em Agronomia, Área de Comcontração: Economia Agrária.

PIRACICABA

Estado de São Paulo - Brasil

Maio - 1988 


\section{Martines Filho, João Gomes}

$M 385 m$ Margens de comercialização e causali dade de preços agricolas. Piracicaba, 1988 .

$146 \mathrm{p}$.

Diss. (Mestre) - ESALQ

Bibliografia.

1. Causalidade de preços agrícolas 2. Comercilização agrícola I. Escola Su perior de Agricultura Luiz de Queiroz, Piracicaba.

$$
\text { CDD } 338.14
$$




\title{
MARGENS DE COMERCIALIZACGÃO E CAUSALIDADE DE PREÇOS AGRICOLAS
}

\author{
JOÃO GOMES MARTINES FILHO
}

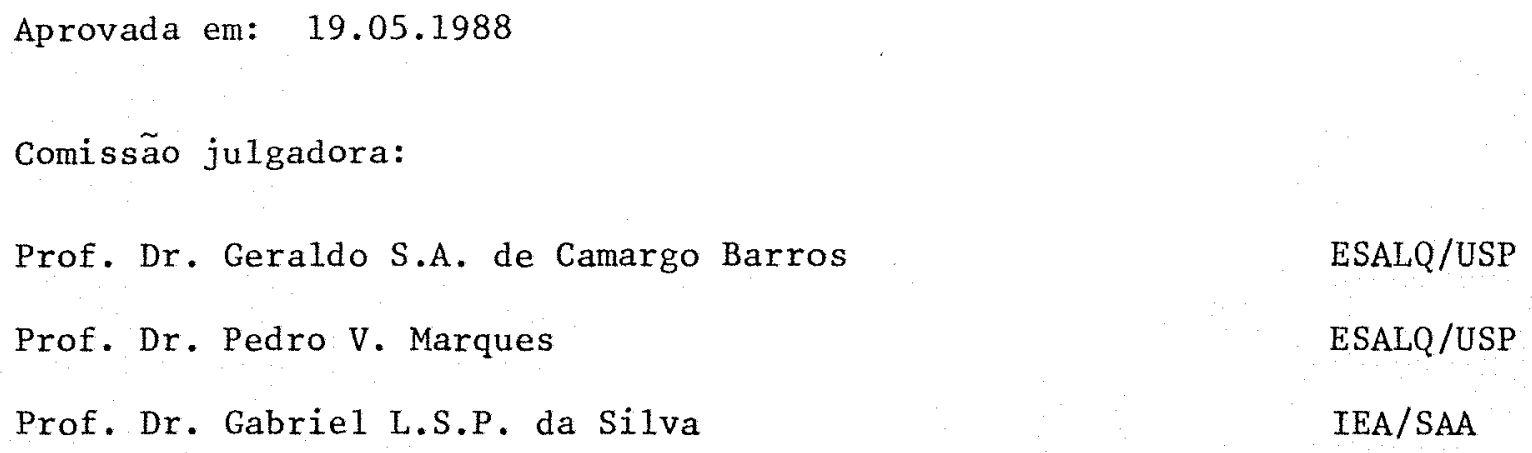


Aos meus pais

e irmãos

OFEREÇO

$\bar{A}$ minha esposa

Ana Lücia

DEDICO 
Ao amigo, professor e orientador Geraldo S. A. de Camargo Barros, meu sincero agradecimento.

A todos os professores e funcionários do Departamento de Economia e Sociologia Rural da ESALQ, que direta ou indiretamente colaboraram para a realização desta pesquisa.

Ao convênio IPEA/FEALQ, que viabilizou o desenvolvimento deste trabalho.

Ao Centro de Pesquisa em Economia Agrícola, da. Fundação de Estudos Agrārios Luiz de Queiroz, pela infraestrutura oferecida.

$\bar{A}$ Ana Lücia Kassouf, Fernando C. Peres, Gabriel L.S.P. da Silva e Pedro V. Marques, pelas críticas e sugestões.

As datilögrafas Maria Aparecida Zani e Elisa da Silva Peron, pelo excelente trabalho realizado. 
SUMĀRIO

Pāgina

LISTA DE TABELAS $\ldots \ldots \ldots \ldots \ldots \ldots \ldots \ldots \ldots \ldots \ldots \ldots \ldots \ldots \ldots \ldots \ldots$

LISTA DE FIGURAS $\ldots \ldots \ldots \ldots \ldots \ldots \ldots \ldots \ldots \ldots \ldots \ldots \ldots \ldots \ldots \ldots \ldots \ldots \ldots \ldots$

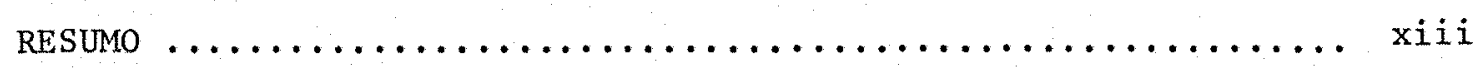

SUMMARY $\ldots \ldots \ldots \ldots \ldots \ldots \ldots \ldots \ldots \ldots \ldots \ldots \ldots \ldots \ldots \ldots \ldots \ldots \ldots \ldots \ldots \ldots$

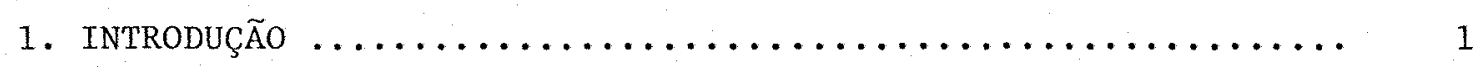

2. MATERIAL E METODOS ........................ 6

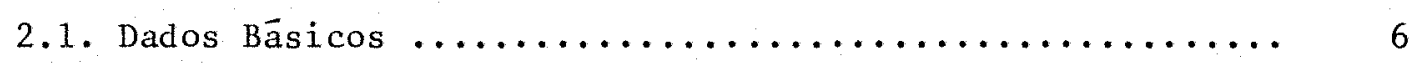

2.1.1. Formas dos produtos a serem estudados ......... 7

2.1.2. Regiões de produção selecionadas $\ldots \ldots \ldots \ldots \ldots \ldots$

2.1.3. Equipamentos atacadistas selecionados $\ldots \ldots \ldots \ldots .9$

2.1.4. Equipamento varejista selecionado $\ldots \ldots \ldots \ldots . \ldots 10$

2.1.5. Fonte dos dados $\ldots \ldots \ldots \ldots \ldots \ldots \ldots \ldots \ldots \ldots \ldots \ldots$

2.2. Relação entre Preços em Mercado Competitivo .......... 13

2.2.1. Variação na demanda primāria (Dx) .......... 17

2.2.2. Variação na oferta primäria (Sa) ............ 19

2.2.3. Variação na oferta de insumos de comercia-

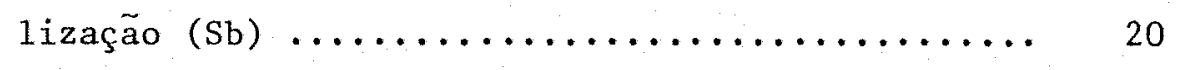

2.3. Anälise de Causalidade ................... 21

2.4. Cālculo das Margens de Comercialização ............. 29

2.5. Anälise das Margens e Preços .................. 33

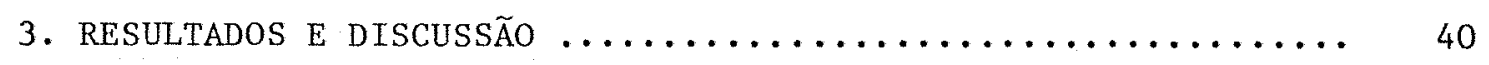

3.1. Anālise de Causalidade $\ldots \ldots \ldots \ldots \ldots \ldots \ldots \ldots \ldots \ldots \ldots \ldots$

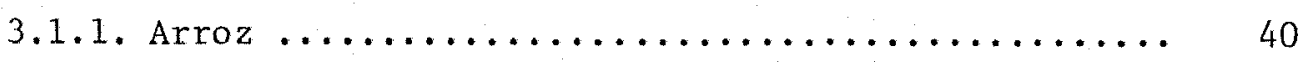


Pägina

3.1.2. Milho $\ldots \ldots \ldots \ldots \ldots \ldots \ldots \ldots \ldots \ldots \ldots \ldots \ldots \ldots \ldots \ldots \ldots \ldots$

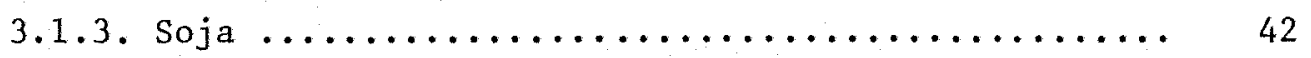

3.1.4. Laranja de mesa .................. 44

3.2. Anālise da Transmissão de Preços ............... 45

3.2.1. Arroz $\ldots \ldots \ldots \ldots \ldots \ldots \ldots \ldots \ldots \ldots \ldots \ldots \ldots \ldots \ldots \ldots \ldots \ldots$

3.2 .2 . Milho $\ldots \ldots \ldots \ldots \ldots \ldots \ldots \ldots \ldots \ldots \ldots \ldots \ldots \ldots \ldots \ldots \ldots$

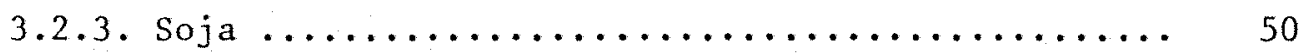

3.2.4. Laranja de mesa .................. 55

3.3. Anälise das Margens de Comercialização ........... 55

3.3.1. Arroz sem casca .................... 59

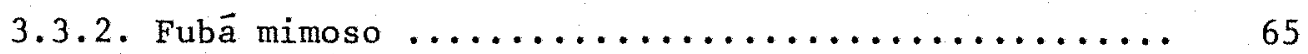

3.3.3. סleo de soja $\ldots \ldots \ldots \ldots \ldots \ldots \ldots \ldots \ldots \ldots \ldots \ldots \ldots$

3.3.4. Laranja de mesa $\ldots \ldots \ldots \ldots \ldots \ldots \ldots \ldots \ldots \ldots$

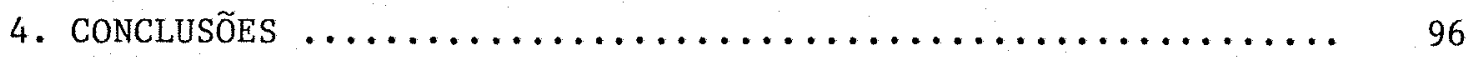

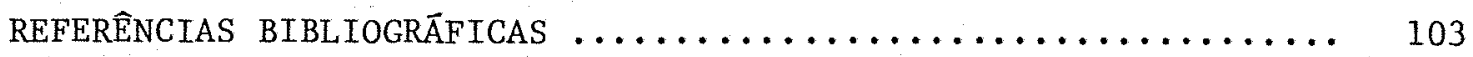

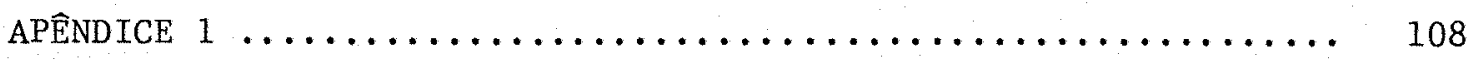

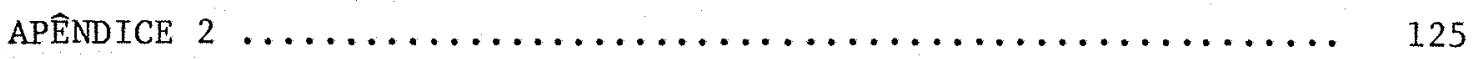


1 Fatores de ponderação de preços mëdios no varejo, cidade de São Paulo, 1971/72 e 1981/82 (percenta-

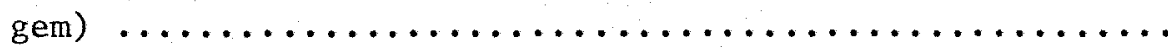

2 Testes para exclusão das variāveis futuras na anālise de causalidade do arroz ................ 41

3 Testes para exclusão das variäveis futuras na anälise de causalidade do milho ................ 42

4. Testes para exclusão das variāveis futuras na anālise de causalidade da soja $\ldots \ldots \ldots \ldots \ldots \ldots \ldots \ldots \ldots \ldots$

5 Testes para exclusão das variáveis futuras na anālise de causalidade da laranja ................. 44

6 Nümero de defasagens consideradas na anālise de transmissão de preços ..................... 46

7. Equação de transmissão de preços do arroz, dos pro dutores de Goiás (APRG) para o varejo (APV), no

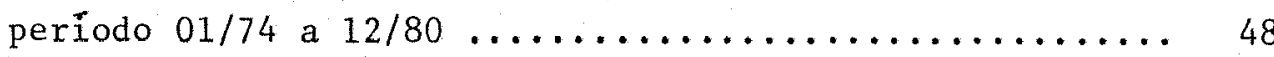

8 Equação de transmissão de preços do milho, dos pro dutores do Estado de São Paulo (MPRS) para o varejo (MPV), no período $01 / 75$ a $12 / 85 \ldots \ldots \ldots \ldots \ldots \ldots \ldots$

9. Equação de transmissão de preços do milho, dos pro dutores do Estado do Paranä (MPRP) para o varejo (MPV), no período $01 / 74$ a $12 / 85 \ldots \ldots \ldots \ldots \ldots \ldots \ldots$ 
10 Equação de transmissão de preços do milho, dos produtores do Estado de Minas Gerais (MPRM) para o varejo (MPV), no período $01 / 75$ a $12 / 84 \ldots \ldots \ldots \ldots \ldots \ldots . \ldots . \ldots$

11 Equação de transmissão de preços da soja, do ataca do (SPA) para o varejo (SPV), no período 01/72 a $12 / 85$

12. Equação de trasnmissão de preços da soja, dos produtores do Estado de São Paulo (SPRS) para o atacado (SPA), no período $01 / 85$ a $12 / 85 \ldots \ldots \ldots \ldots \ldots \ldots \ldots$

13 Equação de transmissão de preços da soja, dos produtores do Estado de Mato Grosso/Mato Grosso do Sul (SPRT) para o atacado (SPA), no período $01 / 74$

14 Equação simultânea de transmissão de preços da soja, dos produtores do Estado de Minas Gerais (SPRM) para o atacado (SPA) no período de $01 / 74$ a 12/84

15 Equação de transmissão de preços da laranja, do va rejo (LPV) para o atacado (LPA), no período $01 / 72$

16 Equação de transmissão de preços da laranja, dos produtores do Estado de São Paulo (LPRS) para o atacado (LPA), no período $01 / 78$ a $12 / 85 \ldots \ldots \ldots \ldots \ldots$ 


\section{LISTA DE FIGURAS}

Figura no

pāgina

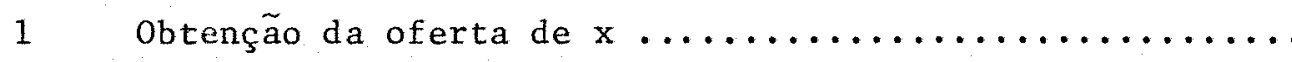

2 Obtenção da demanda derivada de $\underline{a} \ldots \ldots \ldots \ldots \ldots \ldots \ldots$

3 Equilíbrio nos mercados do bem final e da matériaprima

4 Efeito da variação na demanda primāria (Dx) $\ldots \ldots \ldots \ldots$

5 Efeito da variação na oferta primäria (Sa) $\ldots \ldots \ldots \ldots$

6 Efeito da variação na oferta de insumos de mercado $(\mathrm{Sb})$

7 Preço médio mensal e anual do arroz em casca ao pro dutor e do arroz sem casca no varejo/SP, em $\mathrm{Cz} \$$ de Dez/1987, no período 1973 a $1985 \ldots \ldots \ldots \ldots \ldots \ldots \ldots$

8 Margem corrente total de comercialização do arroz sem casca, tendo como região de produção o Estado de São Paulo (DIRAs de São Josē do Rio Preto e Ribeirão Preto), no período 1973 a 1985 .............

9. Margem corrente total de comercialiação do arroz sem casca, tendo como região de produção o Estado de Goiās, no período 1976/1980 ..................

10. Margem corrente total de comercialiação do arroz sem casca, tendo como região de produção o Estado do Rio Grande do Sul, no período 1981 a 1984 ......... 
11 Preço médio mensal e anual do milho em grão ao pro dutor, e do fubä mimoso no varejo/SP, em $\mathrm{Cz} \$$ de Dez/1987, no período 1976 a 1985 ...............

12 Margem corrente total de comercialização do fubā mimoso, tendo como região de produção o Estado de São Paulo (DIRAs de Ribeirão Preto e Sorocaba), no período 1976 a 1985 . . . . . . . . . . . . . . . .

13 Margem defasada (preço ao produtor defasado de 01 mês) total de comercialização do fubā mimoso, tendo como região de produção o Estado de São Paulo,

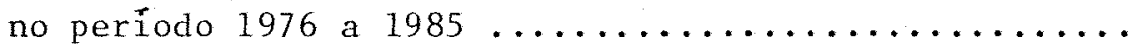

14 Margem corrente total de comercialização do fubā mimoso, tendo como região de produção o Estado do

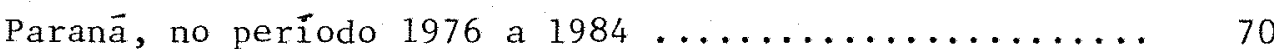

15 Margem corrente total de comercialização do fubä mimoso, tendo como região de produção o Estado de Minas Gerais, no periodo 1976 a $1984 \ldots \ldots \ldots \ldots \ldots \ldots$

16 Preço médio mensal e anual da soja em grão ao produtor, em Cz\$ de Dez/1987, no período 1975 a $1985 \ldots . .74$

17 Preço mëdio mensal e anual do ỏleo de soja refinado enlatado $(900 \mathrm{ml})$ no atacado/sP e varejo/sP, em Cz\$ de Dez/1987, no período 1973 a $1985 \ldots \ldots \ldots \ldots \ldots \ldots$

18 Margem corrente do varejo de comercialização do óleo de soja, no período de 1972 a $1985 \ldots \ldots \ldots \ldots \ldots$ 
19 Margem defasada (preço ao atacado defasado de 06 me ses) do varejo de comercialização do óleo de soja,

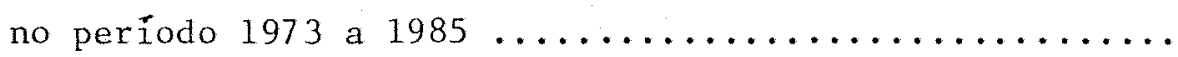

20 Margem corrente do atacado de comercialização do oleo de soja, tendo como região de produção o Estado de São Paulo (DIRAs de Marília e Ribeirão Pre

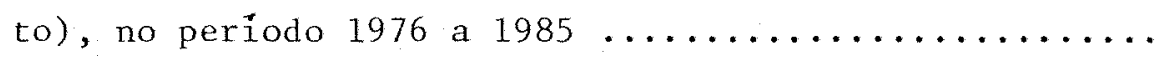

21 Margem corrente do atacado de comercialização do óleo de soja, tendo como região de produção o Esta do de Mato Grosso/Mato Grosso do Sul, no período

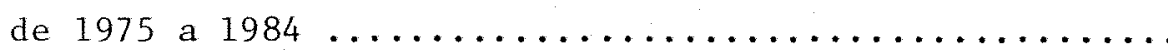

22 Margem corrente do atacado de comercialização do óleo de soja, tendo como região de produção o Esta do de Minas Gerais, no período 1975 a 1984 ...........

23 Margem defasada (preço ao produtor defasado de 01 mês) do atacado de comercialização do ōleo de soja, tendo como região de produção o Estado de Minas Ge rais, no período 1975 a $1984 \ldots \ldots \ldots \ldots \ldots \ldots \ldots \ldots \ldots$. . . . . . . . . . .

24 Margem defasada (preço ao atacado defasado de 01 mês) do atacado de comercialização do ôleo de soja, tendo como região de produção o Estado de Minas Gerais, no período 1975 a $1984 \ldots \ldots \ldots \ldots \ldots \ldots \ldots \ldots$

25 Margem corrente total de comercialização do óleo de soja, tendo como região de produção o Estado de São Paulo (DIRAs Marília e Ribeirão Preto), no pe-

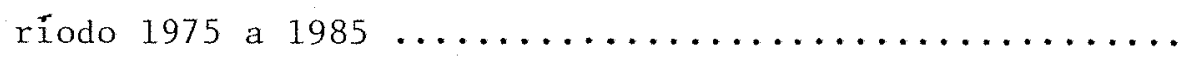


26 Margem corrente total de comercialização do öleo de soja, tendo como região de produção o Estado de Mato Grosso/Mato Grosso do Sul, no período 1975 a 1984

27 Margem corrente total de comercialização do öleo de soja, tendo como região de produção o Estado de Minas Gerais, no período 1975 a $1984 \ldots \ldots \ldots \ldots \ldots \ldots$

28 Preço médio mensal e anual da laranja de mesa ao produtor, atacado/SP e varejo/SP, em Cz\$ de Dez/ 1987, no período 1972 a 1985 ................... 90

29 Margem corrente do varejo de comercialização da laranja, no período 1972 a $1985 \ldots \ldots \ldots \ldots \ldots \ldots \ldots \ldots$

30 Margem defasada (preço ao varejo defasado de 12 me ses) do varejo de comercialização da laranja, no

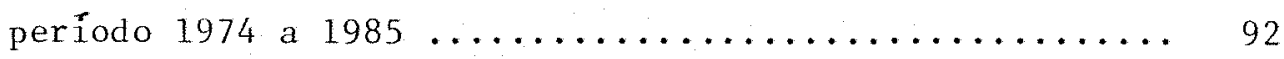

31 Margem corrente do atacado de comercialização da laranja, tendo como região de produção o Estado de São Paulo, no período 1978 a 1985 ................ 93

32 Margem corrente total de comercialização da laranja, tendo como região de produção o Estado de São Paulo, no período de 1978 a $1985 \ldots \ldots \ldots \ldots \ldots \ldots \ldots$ 
MARGENS DE COMERCIALIZAÇÃO E CAUSALIDADE DE

PREÇOS AGRICOLAS

João Gomes Martines Filho

Orientador: Prof.Dr. Geraldo S.A.de Camargo Barros

RESUMO

As oscilações dos preços agrícolas podem estar associadas a variações na demanda interna e externa, ou a fatores ligados à produção e à comercialização. Assim sendo, nesta pesquisa analisaram-se o sentido de causalidade de séries de preços agrícolas entre os níveis de produtor, ata cado e varejo, bem como a elasticidade com que os preços são transmitidos entre esses níveis de mercado e o comportamento das margens de comercialização em relação às variações nos preços exỏgenos.

Os produtos estudados foram o arroz em casca, milho em grão, soja em grão e laranja de mesa, a nível de produtor e arroz sem casca, fubá mimoso, ỏleo de soja refinado enlatado e laranja de mesa, a nível de varejo, no período de 1972 a 1985.

$$
\text { Utilizando-se as definições de causalidade de GRANGER }
$$
(1969), subjacentes ao fenômeno que SIMS (1972) denominou exogeneidade, pode-se observar que na maioria dos casos estudados os choques nos preços iniciaram-se a nível de produção, possivelmente face às variaçōes climäticas. Para os produtos relacionados ao mercado externo, como o óleo de soja e a laranja de mesa, acredita-seque as exportações podem desencadear, 
inicialmente, variações de preços diretamente ao produtor, por ser este, em geral, o elo de ligação entre os mercados externo e interno. Em outros casos, como no da laranja de mesa, a variação pode originar-se a nível de varejo, pois, aparentemente, este produto apresenta a demanda fortemente influenciada por variações de renda e clima, por exemplo.

A anālise de transmissão de preços revelou, de uma forma geral, que o aumento de $10 \%$ no preço aos produtores provocaria um aumento em torno de 6,0\% nos preços ao varejo para o arroz e fubä, e, ao redor de $5,5 \%$ nos preços ao atacado para o óleo de soja e laranja de mesa. Um aumento de $10 \%$ nos preços ao atacado de ōleo de soja refletiria num aumento de igual intensidade nos preços ao varejo, e um aumento de $10 \%$ nos preços ao varejo de laranja levaria tambēm a igual aumento ao atacado.

As margens correntes porcentuais mensais totais de comercia 1ização referente à produção do Estado de São Paulo, para o arroz sem casca, fubả mimoso, ôleo de soja refinado enlatado e laranja de mesa giraram em torno de $42,3 \% ; 71,5 \% ; 27,7 \%$ e $77,5 \%$ do preço de varejo, respectivamente. As margens correntes anuais totais não apresentaram tendência definida. Para os produtos que apresentaram defasagem significativa no processo de transmissão de preços, procedeu-se à anälise da margen defasada, com resultados semelhantes às margens correntes.

o comportamento das margens face às variações nos preços exōgenos foi analisado, levando-se em consideração as elasticidades de transmissão de preços. De um modo geral, pode-se dizer que a margem porcentual e o preço exógeno movimentaram em sentido contrārio, enquanto a mar gem absoluta e o preço exógeno apresentaram um comportamento bastante variävel entre os produtos e os níveis de comercialização. 
MARKETING SPREADS AND AGRICULTURAL

PRICE CAUSALITY

João Gomes Martines Filho

Adviser: Prof.Dr. Geraldo S.A.de Camargo Barros

SUMMARY

Agricultural price variations may be attributed to changes on domestic and external demands and to factors associated with production and marketing sectors. Analysis of causality was applied to producer, wholesale and retail price series. The elasticities of price transmission as well as the behavior of marketing spreads as related to exogenous prices were analysed.

The following products were studied: rice, corn (grain and flour), soybean (grain and oil), and orange. The period of analysis run from 1972 to 1985.

Applying GRANGER's definition of causality and using SIMS's procedure for testing exogeneity, it was observed that the majority of products presented causality from production level to wholesale and retail levels. This effect is probably due to weather variability. Products trad ed internationally (such as soybean and orange) may also present price variations originating at production leve1 since, in most cases, this is the linkage point between domestic and external markets. Still in other situations, price variations may begin at retail or consumer level provided 
that demand is significantly affected by such factors as income or weather. This was the case of orange.

The analysis of price transmission indicated that, in general, an increase of $10 \%$ in producer's price would lead to increase of about $6 \%$ in retail price of rice and corn flour and $5.5 \%$ in wholesale price of soybean oil. A $10 \%$ increase in soybean oil wholesale price sould lead to an equal price increase at the retail level. An increase of $10 \%$ in orange retail price would also be associated to a $10 \%$ increase at the wholesale level.

Current monthly spreads for products shipped from the State of São Paulo were $42.3 \%$ for rice; $71.5 \%$ for corn flour; $27.7 \%$ for soybean oil and $77.5 \%$ for orange. No definite trend was detected for these spreads during the period analysed. Lagged marketing spreads were estimated and revealed equivalent results.

The relationships between marketing spreads and elasticities of price transmission were determined. In general, relative spreads and exogenous prices moved in opposite directions. 


\section{INTRODUÇÃO}

Os preços agrícolas estão continuamente variando em decorrência de choques associados a diversas causas. Entre elas, pode-se citar as oscilações de demanda interna e externa, a nível de produção e a nível de comercialização. Para melhor conhecer esses fenômenos, decidiuse estudar o sentido de causalidade dos preços agrícolas entre os níveis de produtor, atacado e varejo. Tal conhecimento $\vec{e}$ importante porque, sen do a economia brasileira marcada por elevados níveis de inflação, nela se verificam frequentes alterações de preços relativos da agricultura, as quais tem sido interpretadas como provocadores de inflação. Com isso generaliza-se a impressão de que os intermediärios ou comerciantes auferem grandes e crescentes margens, que são sempre capazes de repassar mais do que proporcionalmente os aumentos de preços das mercadorias que comercializam. Face a tal interpretação, os responsāveis pelas políticas agrícolas estão continuamente buscando o controle dos mercados agrícolas, ora pelo tabelamento, ora pela formação de estoques reguladores, ora por impedimentos ou contingenciamentos à exportação, ora pela importação subsidiada, ora pela fixação de margens e assim por diante, em pontos no 
processo de comercialização que, na grande maioria das vezes, não são res ponsäveis pelo início dos choques nos preços agrícolas.

A formação dos preços agrícolas se passa num contexto do qual participam produtores, intermediārios e consumidores. Compondo este cenário estả um nümero considerâvel de mercados de produtos agrícolas ou industrializados, incluindo os mercados de insumos utilizados na produção e comercialização.

Conforme BARROS \& XAVIER (1979), o mecanismo de formação e determinação de preço opera sob a dependência de uma superestrutura institucional. Esta superestrutura é definida, principalmente, pelo grau de competitividade do mercado e pelo grau de intervenção governamental no mesmo, condicionando um mecanismo de transmissão de preços do consumidor ao produtor e vice-versa, atravës do setor de intermediação, o qual apropria-se de uma margem como contrapartida pela prestação de serviços.

Dessa forma, a anālise de preços agrícolas envolve três aspectos bäsicos:

a) por um lado, o processo pelo qual os preços se transmitem de um nível para outro de mercado - produtor, atacado e varejo - associa-se intimamente aos procedimentos de apropriação dos intermediários. Ou seja, ao mesmo tempo em que os intermediários cobram certa margem pelos seus serviços, concretiza-se um processo de transmissão de preços, cuja intensidade necessita ser conhecida;

b) por outro lado, torna-se relevante determinar a origem das oscilações de preços que serão transmitidas simultaneamente à apropriação das margens, e 
c) por fim, as magnitudes apropriadas no processo de comercialização e sua tendência precisam ser conhecidas.

Neste trablaho cuida-se fundamentalmente da transmissão de preços entre os níveis de varejo, atacado e produtor, envolvendo dois aspectos básicos: a direção e a intensidade com que os choques de preços agrícolas são transmitidos entre os níveis de mercado, e posteriormente, calcula-se o valor das margens correntes/defasadas (absolutas e porcentuais) de comercialização.

$\mathrm{Na}$ literatura depara-se com estudos envolvendo mercados con correnciais e mercados de estrutura concentrada. Nestes ültimos, principalmente, considera-se que variações nos preços de compra são transmitidas aos preços de venda, através da aplicação de "markups". O aumento da demanda a nível de varejo, por exemplo, pode levar inicialmente à redução dos estoques unicamente. Somente quando a variação da demanda alcançar o produtor, iniciar-se-à o aumento de preços nesse nível de mercado, o qual será transmitido ao atacado e varejo, pela aplicação de "markups". HEIEN (1980) e TEIXEIRA (1982) discutiram tal enfoque dinâmico, em que o sentido de causalidade prevalescente $\vec{e}$ do produtor para o atacado e des te para o varejo, como resultado da aplicação de "markup" em mercados competitivos.

Outro modelo teórico, relacionado com mercados competitivos, foi desenvolvido anteriormente, por GARDNER (1975). Neste trabalho, de natureza estático-comparativa, variações na demanda ao varejo ou na oferta a nível de produção podem dar origem a variações de preços no respectivo nível de mercado, que são, posteriormente, transmitidos aos demais 
níveis. Neste modelo competitivo pode-se considerar que o preço de compra causa o preço de venda, o preço de venda causa o preço de compra, ou, pode existir um "feedback" entre esses preços. A determinação do sentido de causalidade, implica diagnosticar a ocorrência de alterações na oferta ao produtor, na demanda ao varejo, ou em ambos simultaneamente. Este modelo, além de ser mais abrangente, proporciona algumas hipóteses adicionais, como, por exemplo, a de que uma variação relativa dos preços a nĩvel de produtor, em condições normais, será maior, ou quando muito igual, à dos demais níveis (atacado e varejo) de mercado.

A anảlise de causalidade é de grande valia pois indica onde se inicia a variação dos preços, dada a estrutura vigente de comercialização.

O teste de causalidade a ser utilizado nesta pesquisa baseia-se em procedimento desenvolvido por GRANGER (1969) e implementado por SIMS (1972), sendo tambëm discutido, entre outros, por BISHOP (1979), HEIEN (1980), TEIXETRA (1982), CIBANTOS (1983), BESSLER (1984), CHAMBERS (1984), BURNQUIST (1986) e BARROS \& MARTINES Fo (1987).

Vários são os trabalhos que calcularam as margens de comercialização para alguns produtos agrícolas, sendo um dos pioneiros no Brasil realizado por JUNQUEIRA \& CANTO (1971). A maioria dos estudos de mar gens de comercialização realizados em nosso País, pressupõe a exogeneidade dos preços ao nível de produtor, em relação ao nível de varejo. São exemplos deste enfoque: JUNQUETRA et a $i$ i (1968), HOFFMANN (1969), BRANDT (1971), BARBOSA (1974), ADABO (1978), RUAS (1978), SAYAD (1980), FIALLOS (1981) e SOARES (1981). 
Neste trabalho consideram-se o arroz em casca, milho em grão, soja em grão e laranja de mesa, a nível de produtor, e arroz sem casca empacotado, fubä mimoso, öleo de soja refinado enlatado e laranja de mesa, como os seus correspondentes a nível de varejo. Inicialmente, procura-se avaliar o comportamento do setor de comercialização agrícola em termos do mecanismo de transmissão de preços, isto é, a intensidade com que o setor tende a atenuar ou exacerbar as oscilações de preços a nivel de produtor ou varejo. Isto envolve, preliminarmente, a determinação do sentido de causalidade entre os preços, considerando-se os vārios níveis de mercado. Apōs essa anālise, passa-se a estimar o nümero de defasagens envolvidas na transmissão de preços, e as respectivas elasticidades de transmissão de preços. Essas informações, juntamente com outras relativas aos coeficientes tëcnicos de processamento, permitem a determinação das margens de comercialização, em especial, as defasadas.

As principais regiões de produção, os mercados atacadistas e varejistas relevantes foram definidos levando em consideração que o cen tro final de abastecimento è a cidade de São Paulo.

As defasagens envolvidas na transmissão de preços entre níveis de mercado, bem como as regiões responsäveis pelo abastecimento do mercado, são levadas em consideração no cālculo das margens de comercialização. Alëm disso, realizou-se, finalmente, a anälise do comportamento das margens face às variações nos preços exógenos, observando-se as elasticidades de transmissão de preços. 
2. MATERIAL E MËTODOS

2.1. Dados Bāsicos

Com base no Estudo Nacional da Despesa Familiar - despesas das famílias - ENDEF (1978) para a Ärea Metropolitana de São Paulo, consideram-se, dentro dos grandes itens cereais/derivados e frutas, os produtos que representaram maior despesa (monetāria e não monetāria) anual em alimentação por família, que foram arroz, fubá mimoso, óleo de soja re finado enlatado e laranja de mesa.

Através de entrevistas junto a agentes de comercialização, como os supermercados, atacadistas, entidades de classes representativas, Bolsa de Cereais de São Paulo, Instituto de Economia Agrícola - IEA e Com panhia de Entrepostos e Armazēns Gerais de São Paulo - CEAGESP diagnosticou-se o fluxo de comercialização dos produtos, considerando que o mercado consumidor é a cidade de São Paulo, no período 1972 a 1985. 
2.1.1. Formas dos produtos a serem estudados

Ao longo da cadeia de comercialização, o produto pode sofrer algum processamento, resultando na alteração de sua forma.

Desta maneira, define-se, a seguir, as formas relevantes dos produtos em cada nível de mercado.

Arroz

A nivel de produtor considera-se o arroz em casca, e ao varejo, arroz sem casca, longo, tipo 2, empacotado.

Dado que a principal forma de comercialização do arroz para os supermercados na cidade de São Paulo é realizada basicamente por re presentantes, o mercado atacadista tradicional tornou-se irrelevante nesse caso. Por isso são considerados apenas es níveis de produtor evarejo. Mitho

A nível de produtor considera-se milho em grão, e ao varejo, fubá mimoso. Por deficiência de dados, o nível de atacado tambëm não foi considerado para este produto.

Soja

A nível de produtor considera-se soja em grão, e ao atacado e varejo, o ôleo de soja refinado enlatado (900 m1).

Laranja de mesa

Nos três níveis de mercados, produtor, atacado e varejo, consideram-se a laranja de mesa. 
2.1.2. Regiões de produção selecionadas

Utilizando-se os resultados finais de produção de safras realizados pelo IEA, identificaram-se, no período 1972-1985, as principais regiões produtoras a nível de Divisão Regional Agrícola (DIRA) do Es tado de São Paulo.

Entretanto, sabe-se que a cidade de são Paulo è tambëm abastecida com produtos oriundos de outros Estados. As regiões de produção selecionadas são indicadas a seguir.

Arroz em casca

Dentre as principais regiões de produção destacam-se os Estados de São Paulo (DIRAs de São José do Rio Preto e Ribeirão Preto), Coiās e Rio Grande do Sul.

o abastecimento até o final da década de 70 foi realizado predominantemente pelo arroz amarelão do Estado e dos Estados Centrais. A partir daí, iniciou-se a introdução do arroz agulhinha do Rio Grande do Sul, que é responsävel, atualmente, por cerca de $85 \%$ do arroz empacotado a nível de supermercado na cidade de São Paulo.

\section{Mi tho em grão}

Como região de produção consideram-se os Estados de São Paulo (DIRAs de Ribeirão Preto e Sorocaba), Parana e Minas Gerais.

Trata-se de um produto cuja principal utilização $\vec{e}$ o arraçoamento animal, ficando difícil a definição das regiões produtoras que abastecem à agroindūstria de fubà mimoso. Na tentativa de obter-se maior 
representatividade das regiões de produção, os Estados do Paraná e Minas Gerais tambèm foram considerados como importantes supridores.

$$
\text { Soja em grão }
$$

Como região de produção consideram-se os Estados de São Paulo (DIRAs de Marília e Ribeirão Preto), Minas Gerais e Mato Grosso/Mato Grosso do Sul.

O Estado de São Paulo possui o terceiro parque esmagador de soja no Brasil, apōs o Rio Grande do Sul e Paraná. As duas DIRAs contempladas no Estado de São Paulo, além de representarem as principais regiões de produção do Estado, possuem um parque agroindustrial representativo, responsävel pelo abastecimento do centro varejista de São Paulo.

Devido à localização geogräfica e à disponibilidade de vias de acesso, os Estados de Minas Gerais e Mato Grosso/Mato Grosso do Sul são importantes fontes supridoras do parque agroindustrial do Estado de São Paulo.

Laranja de mesa.

Como região de produção considera-se o Estado de São Paulo como um todo, e, assim, dada a inexistência de dados a nível de DIRA, a análise baseia-se no preço mëdio recebido pelos fruticultores do Estado de São Paulo.

2.1.3. Equipamentos atacadistas selecionados

Os equipamentos atacadistas selecionados devem integrar a cadeia de comercialização, ligando as regiões de produção aos equipamentos varejistas considerados no trabalho. 
o arroz não possui mercado atacadista definido, pois é adquirido do produtor através do maquinista/engenho ou cooperativa, que possui um representante na cidade de São Paulo, o qual realiza as vendas diretamente aos supermercados. Dada a inexistência de estatísticas na interface maquinista/supermercado, engenho/supermercado ou cooperativa/su permercado, analisam-se apenas as margens totais de comercialização, omitindo o nível de atacado.

Para o milho, tendo em vista a indisponibilidade de dados do mercado atacadista do fubá mimoso, pois as agroindüstrias realizam as vendas diretamente aos supermercados, desconsidera-se também este elo da cadeia de comercialização.

No caso da soja, o preço ao atacado faz referência ao mercado atacadista da cidade de São Paulo, que não é importante integrante do processo de comercialização do qual participavam os supermercados. Nes te caso, a análise envolvendo o preço ao atacado é realizada apenas para se ter uma indicação indireta das distribuições das margens.

Com referência à laranja de mesa define-se a CEAGESP, da cidade de São Paulo, como mercado atacadista representativo.

\subsubsection{Equipamento varejista selecionado}

o IEA implantou, em maio de 1970, o acompanhamento mensal dos preços médios praticados no varejo da cidade de São Paulo.

Os fatores de ponderação dos preços ao varejo para os diferentes equipamentos varejistas (empório, feira-livre, quitanda e supermercado) foram obtidos através do trabalho de Pesquisa de Orçamentos 
Familiares - PoF, realizado pela Fundação Instituto de Pesquisas Econômicas - FIPE, inicialmente em $1971 / 72$ e, posteriormente, em 1981/82. Esta pesquisa indicou o häbito de compra da família que possui uma renda familiar modal de dois a seis salärios mínimos.

A importância relativa desses equipamentos $\vec{e}$ mostrada na Tabela 1, em que aparecem os fatores de ponderação que o IEA utiliza para o cälculo do preço médio ao varejo.

Com base nesta pesquisa evidenciam-se häbitos de compra do consumidor paulistano, que contribuiram na definição do equipamento varejista a ser considerado neste trabalho. Para o arroz em casca, fubá mimoso e óleo de soja refinado enlatado, considera-se como equipamento varejista representativo o supermercado e, para a laranja de mesa, a feira-livre.

2.1.5. Fonte dos dados

Os dados de preços a nível de produtor para o Estado de São Paulo foram obtidos junto ao IEA e os referentes aos outros Estados, junto à Fundação Getủ1io Vargas - FGV (Apêndice 1).

o preço ao atacado para o óleo de soja refinado enlatado foi obtido no IEA (Apêndice 1), e para a laranja de mesa na CEAGESP de São Paulo (Apêndice 1). No caso do arroz e do milho não foram considerados mercados atacadistas, pois os preços encontrados na literatura não se referem aos sistemas de comercialização analisados. 
Tabela 1. Fatores de ponderação de preços mëdios no varejo, cidade de São Paulo, 1971/72 e 1981/82 (percentagem)

\begin{tabular}{|c|c|c|c|c|c|c|c|c|}
\hline \multirow{2}{*}{ Produto } & \multicolumn{2}{|c|}{ Empörio } & \multicolumn{2}{|c|}{ Feira-livre } & \multicolumn{2}{|c|}{ Quitanda } & \multicolumn{2}{|c|}{ Supermercado } \\
\hline & $71 / 72$ & $81 / 82$ & $71 / 72$ & $81 / 82$ & $71 / 72$ & $81 / 82$ & $71 / 72$ & $81 / 82$ \\
\hline Arroz (pacote) & 16 & 13 & 6 & 4 & - & - & 78 & 83 \\
\hline Fubá mimoso & 34 & 13 & 14 & 6 & - & - & 52 & 81 \\
\hline ôleo de soja & 29 & 9 & 15 & 2 & - & - & 56 & 89 \\
\hline Laranja & - & - & 83 & 93 & 7 & 3 & 10 & 4 \\
\hline
\end{tabular}

Fonte: Instituto de Economia Agricola (IEA), a partir dos dados de Pesquisa de Orçamentos Familiares (POF) de 1971/72 e 1981/82 da Fundação Instituto de Pesquisas Econômicas (FIPE).

Os dados de varejo referem-se, especificamente, ao equipamento considerado (supermercado ou feira-livre), que foram obtidos junto ao IEA (Apêndice 1).

Os preços foram corrigidos com base no İndice Geral de Pre ços - disponibilidade interna (IGP - DI), elaborado pela Fundação Getülio Vargas, com base em 1977 e Dezembro/1987. 
2.2. Relação entre Preços em Mercado Competitivo

o modelo apresentado a seguir, desenvolvido por GARDNER (1975) supõe a existência de um equilíbrio competitivo simultâneo e instantâneo no mercado agrícola e no setor de comercialização. Suas implicações são derivadas por meio de anälise estático-comparativa.

A utilização desse modelo envolve limitações, pois um modelo competitivo de equilíbrio nos três níveis de mercado - produtor, ata cado e varejo - não representa necessariamente a nossa realidade. Entretanto, visa-se, especificamente, analisar teoricamente os efeitos de choques de oferta e de demanda sobre os preços e margens de comercialização. Alguns esforços no sentido de explicitar efeitos dinâmicos e de ordem estrutural podem ser encontrados na literatura. HEIEN (1980), por exemplo, introduziu algumas modificações no modelo de CARDNER (1975), no sentido de considerar os aspectos dinâmicos do ajustamento de preços, admitindo a possibilidade de desequilíbrio a nível de varejo, onde os preços se alterariam somente face a variações de custos, sendo os ajustes de quantidade realizados atravês de variações de estoques. Em casos de estrutura oligopolísticas, o modelo da curva de demanda quebrada tem sido largamente utilizado, especialmente, para o setor industrial, conforme trabalho de CONSTDERA (1981), por exemplo.

o modelo analítico de GARDNER (1975) a ser apresentado con sidera um produto final $(x)$ e dois insumos utilizados em sua produção: a matéria prima agrícola (a) e o insumo de comercialização (b). Este ültimo representa um agregado das atividades de comercialização (transporte, beneficiamento, armazenamento, etc.), agregação esta que necessita da 
pressuposição de que os preços relativos dos componentes sejam constantes.

$$
\begin{aligned}
& \text { O modelo representativo dessa indústria será: } \\
& x=f(a, b) \\
& x=D(P x, N) \\
& P b=P x \cdot f b \quad, \frac{\partial x}{\partial b}=f b \\
& P a=P x \cdot f a, \frac{\partial x}{\partial a}=f a \\
& P b=g(b, T) \\
& P a=h(a, W)
\end{aligned}
$$

onde:

(2.1) representa a função de produção do agregado de firmas de comer cialização, com retornos constantes à escala;

(2.2) representa a função de demanda $x$, sendo Px o preço ao varejo e N uma variāvel exögena (população, por exemplo);

$(2.3)$ e (2.4) representam as igualdades dos preços dos fatores Pa e $\mathrm{Pb}$, aos seus valores do produto marginal, condição necessária para maximização do lucro das firmas;

(2.5) e (2.6) representam as ofertas dos dois insumos considerados, sendo $\mathrm{T}$ e $\mathrm{W}$ variāveis exógenas (por exemplo, um imposto fixo e clima, respectivamente).

O sistema de seis equações $(2.1$ a 2.6$)$ a seis incógnitas possuirâ, sob certas condições gerais, uma ünica solução de equilíbrio nos três mercados $(x, a, b)$. 
Abaixo, abstëm-se da resolução algëbrica do modelo, limitando-se à apresentação gräfica dos värios casos envolvidos conforme apre sentados em BARROS (1987). Para possibilitar a anālise gräfica, pressupõe-se que a elasticidade de substituição ( $\left.\sigma_{a b}\right)$ é igual a zeról/. Especificamente, considera-se que cada unidade de $\underline{x}$ seja produzida usando-se uma unidade de a e duas de $\underline{b}$, ou seja:

$$
\mathrm{x}=\min \left\{\mathrm{a}, \frac{\mathrm{b}}{2}\right\}
$$

Na Figura 1 e apresentada a demanda por $x(D x)$ e as ofertas de a (Sa) e b (Sb) separadamente. Dada a proporção fixa entre insumos, o preço de oferta de $x(S x)$ é igual à soma correspondente do preço de uma unidade de a mais o preço de duas unidades de $\underline{b}$. A intersecção de Dx e Sx fornece o preço e a quantidade de equilíbrio de $x$.

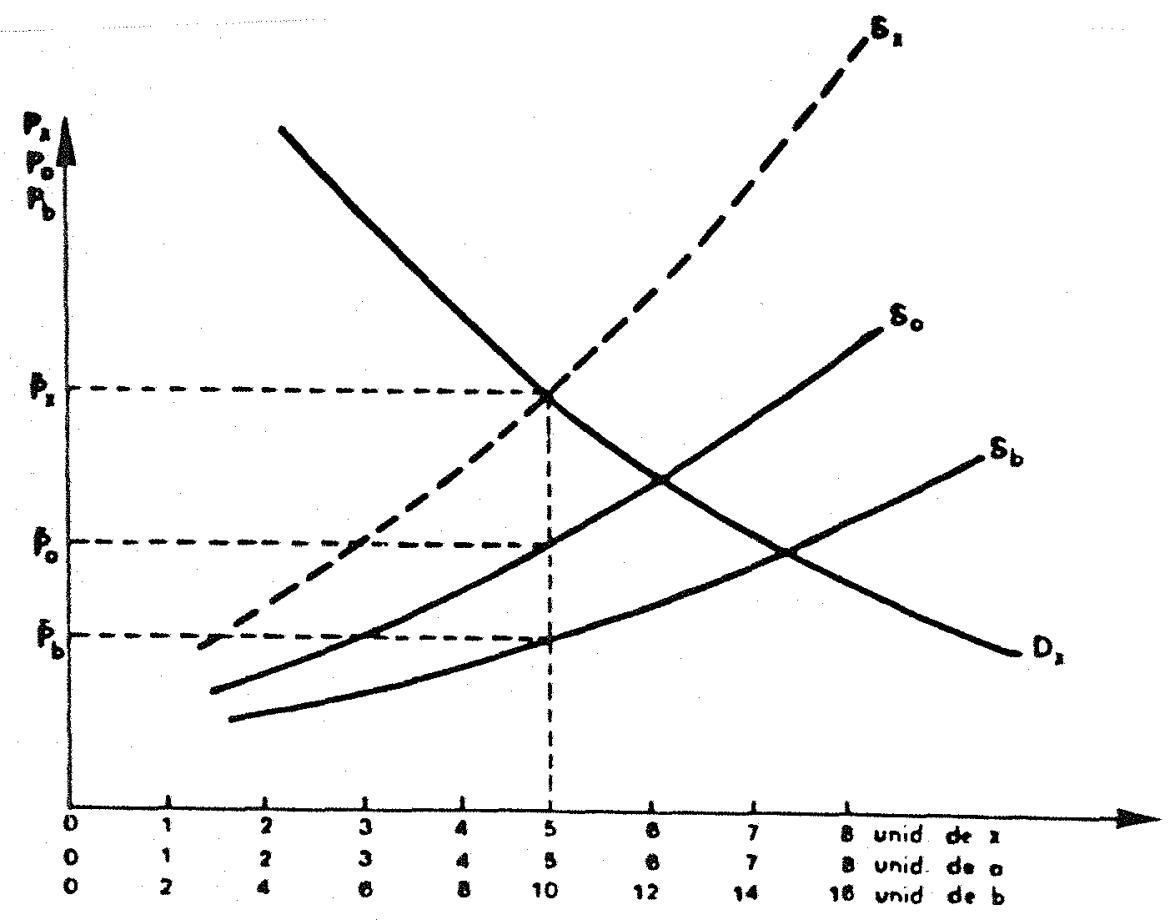

Figura 1. Obtenção da oferta de $x$

I/ BARROS (1987) mostra que os resultados obtidos não se alteram qualitativamente desde que o valor de oab não seja igual ou superior à unidade. 
Para a obtenção da demanda derivada de a consideram-se como dadas, a demanda pelo produto final $x(\mathrm{Dx})$ e a oferta do insumo $b$ (Sb). A demanda (a oferta) de qualquer bem relaciona a quantidade desejada e o preço māximo (mínimo) que se está disposto a pagar (receber) por essaquan tidade. Assim, o preço mäximo a ser pago por uma unidade de a serā a diferença entre o preço mäximo a ser pago por $x$ (dado em Dx) e o preço míni mo a ser pago por 2 unidades de b (dado em Sb). Portanto, para se obter a demanda derivada de a (Da), deve-se tomar a distância vertical entre Dx e Sb, como o preço de demanda correspondente à cada quantidade, conforme pode ser observado na Figura 2. De modo semelhante pode-se obter a demanda derivada de b.

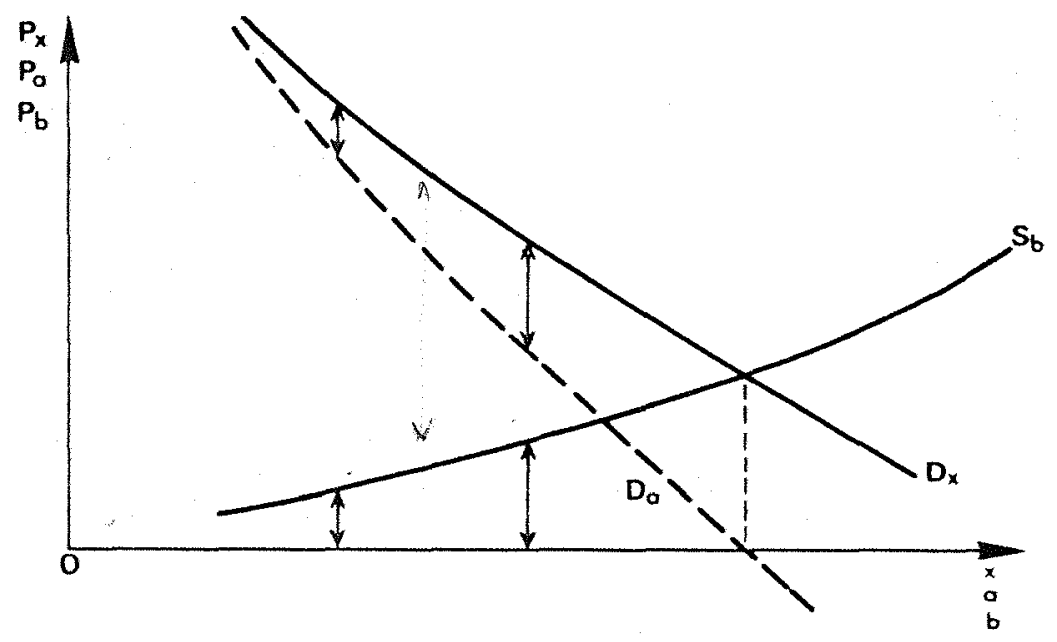

- Figura 2. Obtenção da demanda derivada de a

Na Figura 3 encontra-se o ponto de equilibrio de $x(\bar{x}, P x)$, através do encontro de Sx e Dx. Verticalmente abaixo desse ponto tem-se o equilíbrio a nível de produção de a, e $\bar{M}$ e a margem corrente absoluta 
de comercialização.

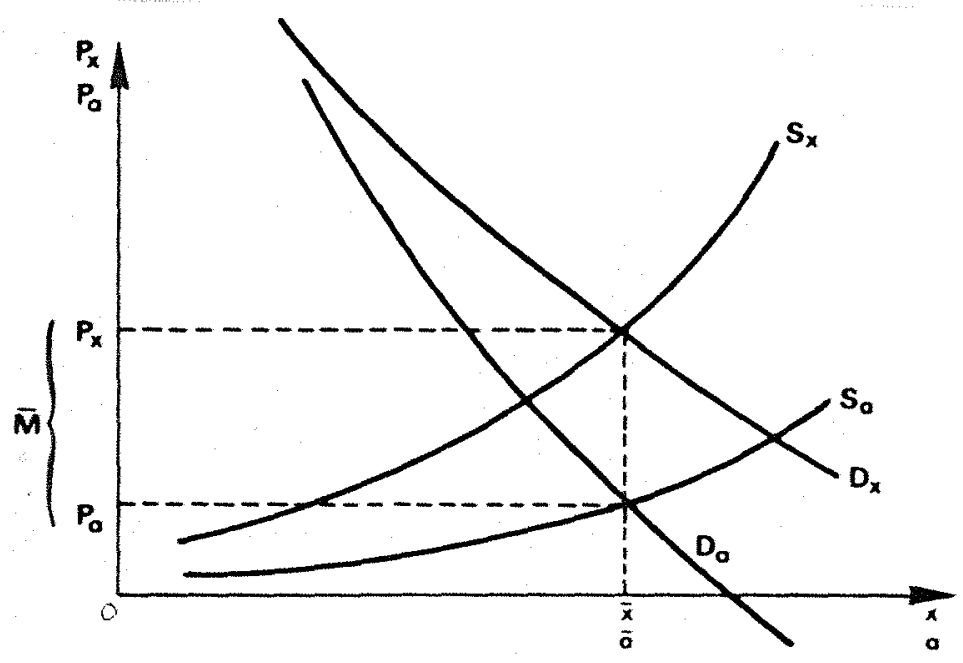

Figura 3. Equilíbrio nos mercados do bem final e da matëria-prima

A seguir, apresenta-se uma breve discussão referente aos efeitos de choques na demanda primāria, oferta primāria e na oferta de insumos de comercialização sobre o equilíbrio nos mercados considerados.

\subsubsection{Variação na demanda primäria (Dx)}

Considere-se que ocorra um acréscimo na demanda pelo produto final $\mathrm{x}$, dado, por exemplo, por um aumento populacional $(\Delta N)$. Observando-se a Figura 4, inicialmente, ter-se-ä um deslocamento para a direita da demanda de $x\left(D^{\prime} x\right)$, e deslocamento para a direita da demanda da matéria-prima agrícola a (D'a), mantendo-se a mesma distância vertical a Dx, dado que a oferta de insumos de comercialização não se alterou. 


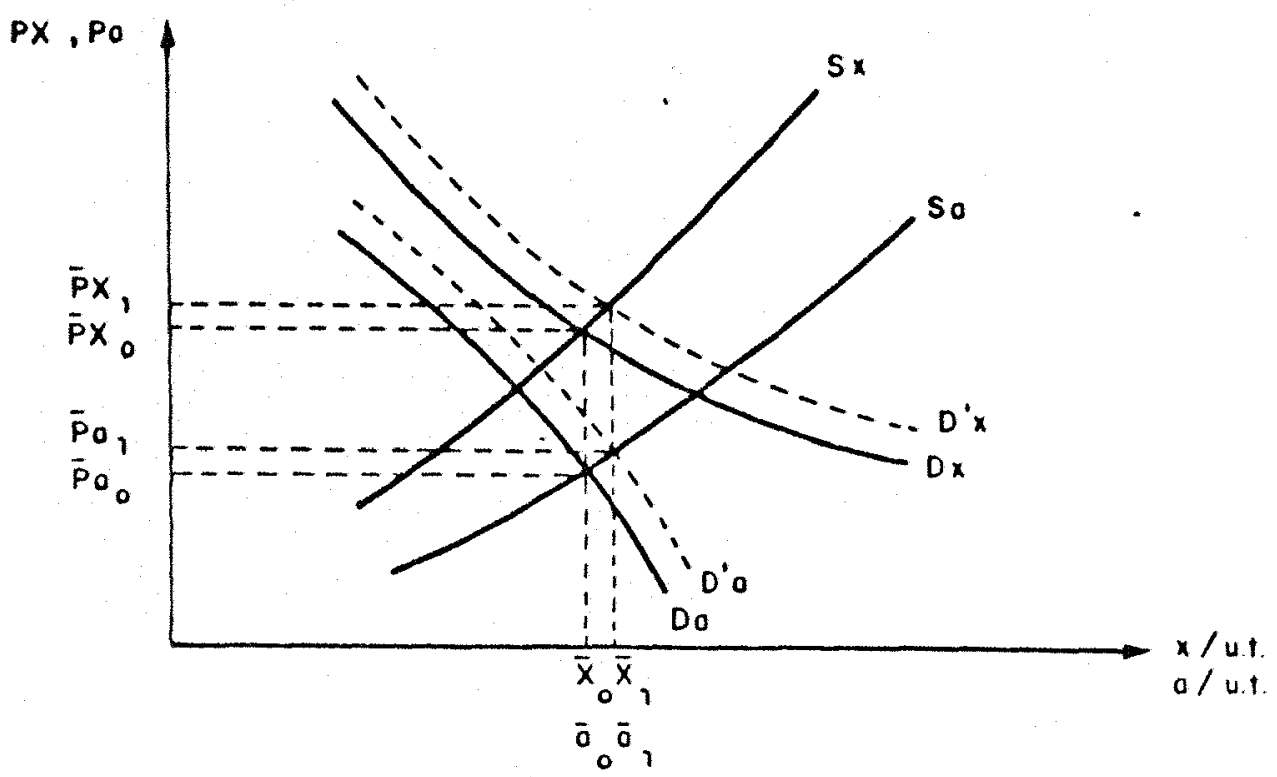

Figura 4. Efeito da variação na demanda primāria (Dx)

Deverä ocorrer um aumento em Px e Pa, entretanto, a intensidade de aumento destes preços dependerá das elasticidades de oferta de a (ea) e de b (eb), dado que, havendo retornos constantes à escala, terse-à:

$$
\frac{\mathrm{dPx}}{\mathrm{Px}}=\mathrm{ka} \frac{\mathrm{dPa}}{\mathrm{Pa}}+\mathrm{kb} \frac{\mathrm{dPb}}{\mathrm{Pb}}
$$

Pode-se observar que a variação relativa em $\operatorname{Px}\left(\frac{\Delta \mathrm{Px}}{\mathrm{Px}}\right)$ serä menor que em $\mathrm{Pa}\left(\frac{\Delta \mathrm{Pa}}{\mathrm{Pa}}\right)$, quando ea $<\mathrm{eb}$, pois o aumento proporcional em $\mathrm{Pa}$ serā maior que em $\mathrm{Pb}$, e a variação proporcional em Px serä uma ponderação entre variações proporcionais entre $\mathrm{Pa}$ e Pb (BARROS, 1987).

Observa-se tambëm, que argumenta-se neste caso, que o aumento de preços no varejo causou o aumento a nível de produtor, ou seja, a causalidade será do preço de venda ( $\mathrm{Px}$ ) para o preço de compra (Pa). 


\subsubsection{Variação na oferta primäria (Sa)}

Considere-se que ocorra uma redução na oferta de matériaprima agrícola (Sa), dado, por exemplo, por uma variação climätica $(\Delta W)$. Assim, a função de oferta de matéria-prima agrícola deslocar-se-ã para a esquerda (S'a), fazendo com que a oferta de $x$ (Sx) tambëm se desloque para a esquerda $\left(S^{\prime} x\right)$, conforme a Figura 5 .

Assim sendo, Px e Pa sofrerão aumentos entretanto, a quantidade demandada de $x$ se reduzira $\vec{a}$ com redução na quantidade e no preço de $b$, dado que eb $>0$.

Neste caso, pode-se interpretar que os preços a nivel de produtor causaram alterações nos preços a nível de varejo, ou seja, a cau salidade será do preço de compra ( $\mathrm{Pa}$ ) para o preço de venda (Px).

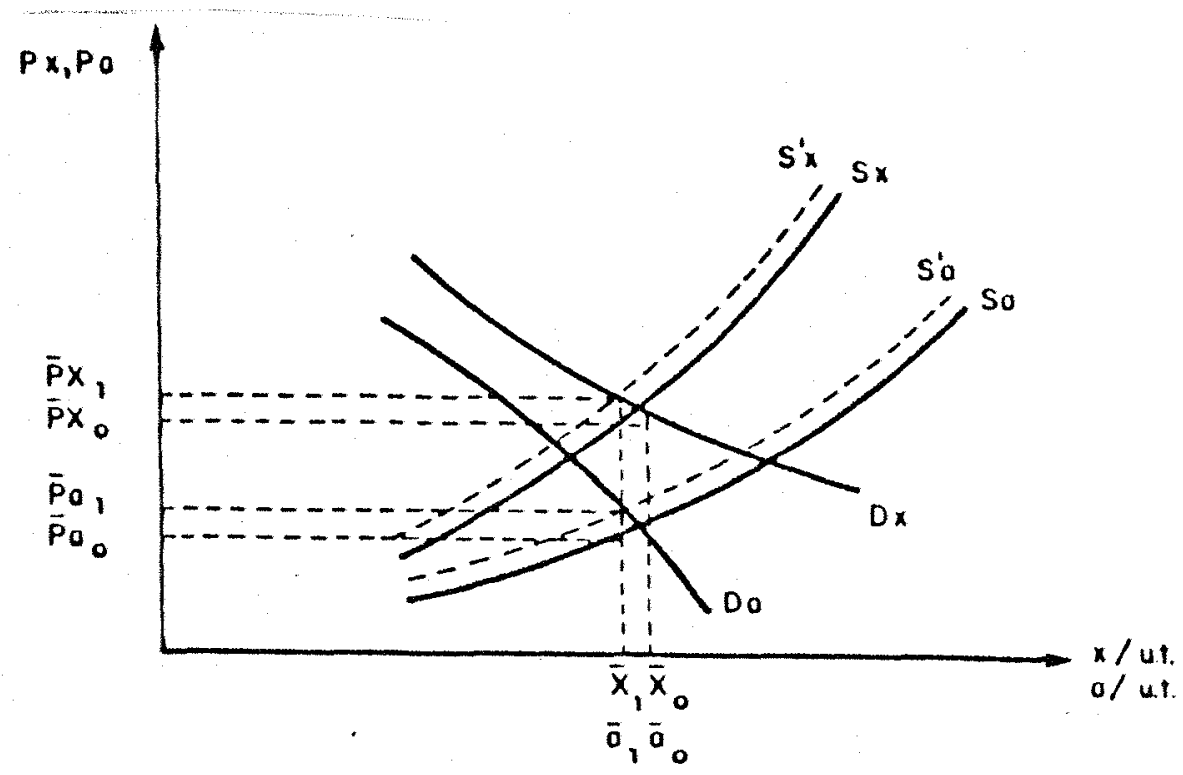

Figura 5. Efeito da variação na oferta primäria (Sa) 
2.2.3. Variação na oferta de insumos de comercialização (Sb)

Considere-se um efeito de redução na oferta de insumos de comercialização, dado por exemplo por aumento nos impostos $(\Delta \mathrm{T})$. Isto pro vocarā um deslocamento para a esquerda da oferta de x (S'x), e um deslocamento para baixo da demanda de matéria-prima agrícola ( $\left.{ }^{\prime} a\right)$, conforme Figura 6 .

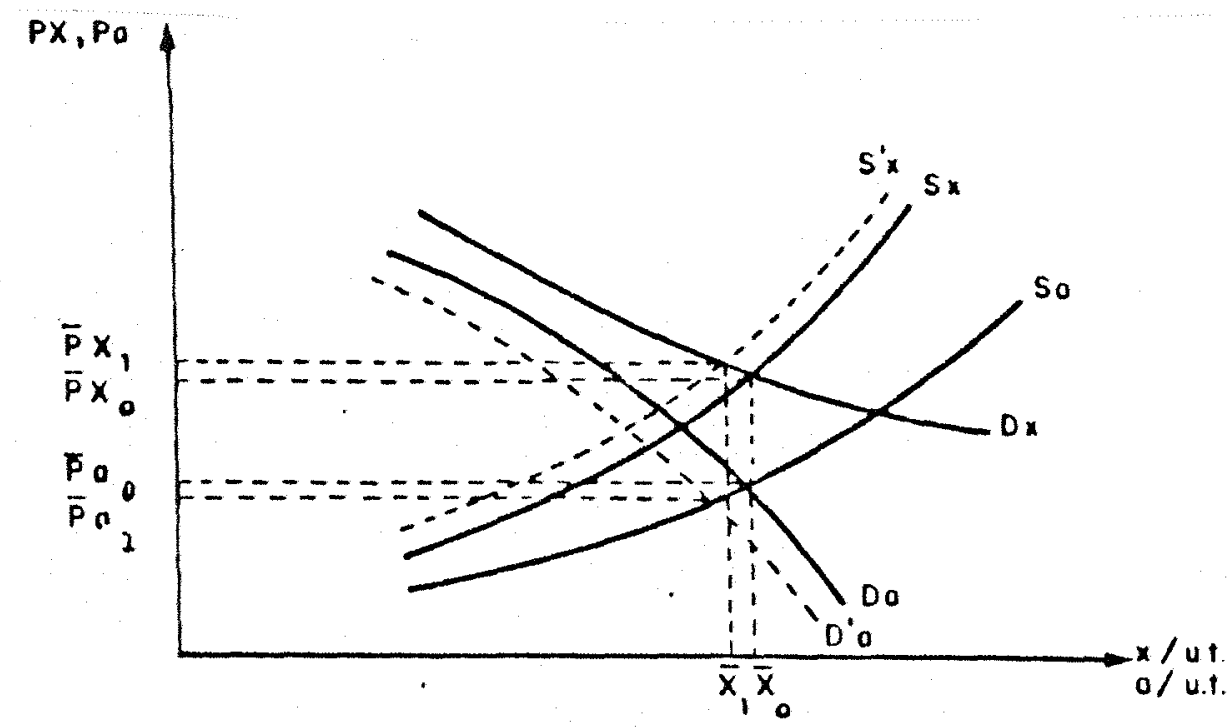

Figura 6. Efeito da variação na oferta de insumos de mercado (Sb)

Assim, fica evidenciado que umâ redução na oferta de insumos de comercialização, provoca uma redução no preço a nível de produtor e aumento no preço a nível de varejo.

Nesse caso não haverả relação causal entre os preços a nível de produtor (Pa) e a nível de varejo (Px). 


\subsection{Anälise de Causalidade}

A anālise de causalidade de preços foi realizada utilizando-se, apenas, as sêries de preços referentes ao mercado interno, podendo-se observar variações provenientes da produção ou da demanda a nível de consumidor. Para certos produtos, no entanto, as variações de preço podem originar-se no mercado externo, o qual não foi incluido explicitamente na anālise. Supões-e nesses casos, que o efeito dessas variações faça-se sentir inicialmente, a nível de produção, por ser este, em geral, o elo de ligação entre os mercados externo e interno.

De um modo geral, as variações de preços agrícolas devem originar-se, predominantemente, a nível de produção, face às variações climāticas. Entretanto, em alguns casos, essas variações podem originarse a nível de varejo, principalmente, no caso de produtos cujo consumo se ja fortemente influenciado por variações de renda ou clima, por exemplo.

Ao contrārio de alguns outros trabalhos, prefere-se não formular hipōteses ou pressupostos quanto ao sentido de causalidade esperado. $\overrightarrow{\mathrm{E}}$ o caso de HEIEN (1980) que ao admitir que os preços são ajustados pela prätica de "markup", restringe o sentido de causalidade àquele dos preços de compra para os preços de venda.

0 teste do sentido de causalidade aqui empregado foi desen volvido inicialmente por GRANGER (1969) e SIMS (1972), sendo, posteriormente, apresentado por BISHOP (1979) sob uma forma mais aplicativa. No Brasil, alguns trabalhos utilizaram-se deste instrumental como TEIXEIRA (1982), CIBANTOS (1983), BURNQUIST (1986) e BARROS \& MARTINES Fo (1987). 
SIMS (1972) desenvolveu um teste empírico para a anälise da direção causal entre variáveis econômicas, cuja relação básica considera que se, e somente se, o sentido de causalidade for unicamente dos valores presentes e passados de uma série de variāveis exögenas para uma dada variāvel endōgena, têm-se que, numa regressão de variável endógena, com valores passados, correntes e futuros das variäveis exōgenas, resultariam valores nulos para os coeficientes futuros das variáveis exógenas.

No presente estudo, adotaram-se as definições de causalidade de GRANGER (1969) subjacentes ao fenômeno que SIMS (1972) denominou exogeneidade.

As possíveis relações de causalidade entre duas variäveis, Pa e Px, são:

(a) $\mathrm{Pa}$ causa $\mathrm{Px}(\mathrm{Pa} \rightarrow \mathrm{Px})$;

(b) $\mathrm{Px}$ causa $\mathrm{Pa}(\mathrm{Px} \rightarrow \mathrm{Pa})$;

(c) Pa e Px são mutuamente relacionados quanto à direção de causalidade $(\mathrm{Pa} \leftrightarrow \mathrm{Px}) ; \mathrm{e}$

(d) ausência de causalidade entre as duas variāveis.

Assim sendo, verificou-se qual o sentido de causalidade entre os preços - produtor/atacado, atacado/varejo, e nos casos em que não houve mercado atacadista representantivo, elaborou-se a análise na "in terface"produtor/varejo.

O teste de causalidade proposto por SIMS (1972) requer pre viamente a realização de uma filtragem das séries de variäveis, quando for detectada a autocorrelação entre os resíduos. A realização dessa fi 1 tragem consiste num esquema empírico para remover a autocorrelação entre 
os resíduos (obtenção de séries que apresentem "ruídos brancos", ou seja, sêries com resíduos desprovidos de tendência na mëdia e na variância), conforme BISHOP (1979). A fundamentação teórica desta filtragem estā em que os procedimentos econométricos a serem utilizados envolvem a realização sistemática de testes $F$ envolvendo variâncias, cujos vieses associados a problemas de correlação serial entre os erros devem ser evitados, (STMS, 1972).

Para a filtragem das séries de preços utilizou-se o filtro compreendido na tëcnica iterativa que se segue $1 /$ :

a) Obtem-se as estimativas ordinärias dos mínimos quadrados (MQO) de, por exemplo,

$$
P x_{t}=\sum_{k=-4}^{8} \alpha_{k} P_{t-k}+e_{t}
$$

onde:

$$
\begin{aligned}
& \mathrm{Px}_{t}=\text { preço do produto final } \\
& \mathrm{Pa}_{t}=\text { preço a nível de produtor }
\end{aligned}
$$

e calcula-se os residuos $\hat{\mathrm{e}}_{1}, \hat{\mathrm{e}}_{2}, \ldots, \hat{\mathrm{e}}_{\mathrm{n}}$, utilizando-se a estimativa de $\rho$, dada por:

$$
\hat{\rho}=\frac{\sum \hat{e}_{t} \hat{e}_{t-1}}{\sum \hat{e}_{t-1}^{2}} \quad, \quad(t=2, \ldots, n)
$$

If A filtragem e demais procedimentos econométricos foram realizados atra vés do "software" RATS (DOAN \& LITTERMAN, 1981). 
b) a partir disto, constroem-se novas variäveis:

$$
P x_{t}^{*}=\left(\mathrm{Px}_{t}-\hat{\rho} \mathrm{Px}_{t-1}\right) \text { e } P a_{t}^{*}=\left(\mathrm{Pa}_{t}-\hat{\rho} \mathrm{Pa}{ }_{t-1}\right) \text {, para obter-se }
$$

as estimativas por MQO:

$$
\mathrm{Px}_{t}^{*}=\sum_{\mathrm{k}=-4}^{8} \alpha_{k} \mathrm{~Pa}_{t-\mathrm{k}}^{*}+\mathrm{u}_{t} \quad(t=2,3, \ldots, \mathrm{n})
$$

e,

$$
u_{t}=e_{t}-\widehat{\rho}_{t-1}
$$

A verificação da eficācia em se utilizar o valor de $\hat{\rho}$ como filtro foi realizado pelo exame das propriedades autorregressivas dos re síduos $\left(u_{t}\right)$, estimando-se $\theta$ na equação a seguir, por MQO, (BISHOP, 1979):

$$
u_{t}=\theta\left(u_{t-1}\right)+v_{t}
$$

Deve-se verificar se o coeficiente $\theta$ não $\vec{e}$ significativo estatisticamente, considerando-se um nível de $5 \%$ de probabilidade, pela uti lização do teste $t$-student. Tal observação fornece uma evidência de que com a utilização do filtro estimado $(\hat{\rho})$, obteve-se valores de $u_{t}$ não autocorrelacionados.

$\mathrm{Na}$ eventualidade do teste $t$-Student apresentar-se signifí cativo com relação à variāvel estimada $\hat{\theta}$, realiza-se uma nova filtragem da sērie com $\mathrm{Px}_{t}^{*}$ e $\mathrm{Pa}_{\mathrm{t}}^{*}$.

Adicionalmente, a eficácia do filtro foi acompanhado pela observação do valor do teste de Durbin-Watson (DW) e teste Q1/.

I/ Teste Q - estatística de Box-Pierce, que ē dado por:

$$
Q=n \sum_{k=1}^{K} r_{k}^{2}(\hat{e}) \text { onde: } r_{k}(\hat{e})=\frac{\sum_{t=k+1}^{n} \hat{e}_{t} \hat{e}_{t-k}}{\sum_{t=1}^{n} \hat{e}_{t}^{2}} \text {. A estatistica } Q \text { apresen }
$$

ta distribuição de Qui-quadrado com $\underline{K}$ graus de liberdade. 
0 procedimento estatístico utilizado no trabalho, para a realização do teste de causalidade proposto por SIMS consiste em estimar equações da seguinte forma:

$$
\begin{aligned}
\mathrm{px}_{t}=\mathrm{a}_{1} \mathrm{pa}_{t}+\sum_{i=1}^{4} \mathrm{a}_{2 i} \mathrm{pa}_{t+i}+\sum_{k=1}^{8} \mathrm{a}_{3 k} \mathrm{pa}_{t-k}+\sum_{j=1}^{11} \mathrm{a}_{4 j} \mathrm{D}_{j}+\mathrm{a}_{5} \mathrm{~T}+\mathrm{e}_{1 t} \\
\mathrm{pa}_{t}=\mathrm{b}_{1} \mathrm{px}_{t}+\sum_{i=1}^{4} \mathrm{~b}_{2 i} \mathrm{px}_{t+i}+\sum_{k=1}^{8} \mathrm{~b}_{3 k} \mathrm{px} t-k+\sum_{j=1}^{11} \mathrm{~b}_{4 j} \mathrm{D} j+\mathrm{b}_{5} \mathrm{~T}+\mathrm{e}_{2 t}
\end{aligned}
$$

onde:

$$
\begin{aligned}
& \text { px - preço nominal do produto final } \\
& \text { pa - preço nominal a nível do produtor } \\
& D_{j} \text { - variāveis binārias para controle dos efeitos de sazonalidade } \\
& T \text { - variävel tendência }
\end{aligned}
$$$$
a_{1}, a_{2 i}, a_{3 k}, a_{4 j} \text { e } a_{5}-\text { parâmetros a serem estimados na equação }
$$$$
(2.7)
$$$$
b_{1}, b_{2 i}, b_{3 k}, b_{4 j} \text { e } b_{5} \text { - parâmetros a serem estimados na equação }
$$$$
e_{1 t}, e_{2 t}-\text { erros aleatórios }
$$

os valores de $i$ e $k$ considerados na pesquisa foram baseados em metodologia sugerida por BISHOP (1979) e utilizadas por TEIXEIRA (1982) e BURNQUIST (1986), mantendo-se as variāveis com 8 (oito) defasagens e 4 (quatro) valores futuros.

Para efeito do teste de causalidade consideram-se as duas hipöteses seguintes: 


$$
a_{21}=a_{22}=a_{23}=a_{24}=0
$$

e

$$
\mathrm{b}_{21}=\mathrm{b}_{22}=\mathrm{b}_{23}=\mathrm{b}_{24}=0
$$

Para testar estas hipóteses utilizou-se o procedimento apresentado por KMENTA (1978), atravēs da estatística F, aplicando-se nas expressões $(2.7)$ e $(2.8)$.

$$
F=\frac{S Q E_{r}-S Q E_{u} /(q-p)}{S Q E_{u} /(n-q)}
$$

onde:

$\mathrm{SQE}_{\mathrm{r}}$ - Soma dos quadrados do resíduo da regressão com restrição, com $a_{2 i}=0(i=1, \ldots, 4)$ em $(2.7)$ e $b_{2 i}=0(i=1, \ldots, 4)$ em (2.8) $\mathrm{SQE}_{\mathrm{u}}$ - Soma dos quadrados do resíduo da regressão sem restrição;

q - Número de parâmetros estimados na regressão sem restrição $=25$

$\mathrm{p} \quad$ - Nümero de parâmetros estimados na regressão restrita $=21$

n - Número total de observações

- Se a hipótese (I) for rejeitada e a hipótese (II) não for, tem-se condições necessārias e suficientes para estabelecer-se causalidade de $\mathrm{Px}$ para $\mathrm{Pa}(\mathrm{Px} \rightarrow \mathrm{Pa})$. Se ao conträrio rejeitar-se (II) e não fazêlo com relação a (I), conclui-se que a causalidade flui de $\mathrm{Pa}$ para Px $(\mathrm{Pa} \rightarrow \mathrm{Px})$. Caso as duas hipóteses sejam rejeitadas, estabelece-se uma re lação bicausal $(\mathrm{Px} \leftrightarrow \mathrm{Pa})$. Finalmente, se ambas as hipóteses não forem rejeitadas, conclui-se pela ausência de causalidade entre Px e Pa. 
Uma vez determinado o sentido de causalidade entre os preços, procede-se à estimativa das elasticidades de transmissão de preços, considerando-se o sentido de causa-efeito determinado.

A elasticidade de transmissão de preços consiste na relação entre as variações proporcionais nos preços:

$$
E(P x, P a)=\frac{\partial P x}{\partial P a} \cdot \frac{P a}{P x}
$$

onde:

Px - Variāvel preço determinada como endōgena, e

Pa - Variäve1 preço determinada como exögena.

Considerando-se que o sentido de causalidade seja unidirecional, para se obter as estimativas das elasticidades de transmissão de preços foram estimadas as equações ünicas de transmissão de preços. Se a direção de causalidade for detectada de $\mathrm{Pa} \rightarrow \mathrm{Px}$, a equação de transmissão de preços serā estimada por ${ }^{1 /}$ :

$$
\ln \mathrm{Px}_{t}=\ln \mathrm{A}+\sum_{i=0}^{\mathrm{d}} \alpha_{i} \ln \mathrm{Pa}_{t-i}+\mathrm{u}_{t}
$$

onde:

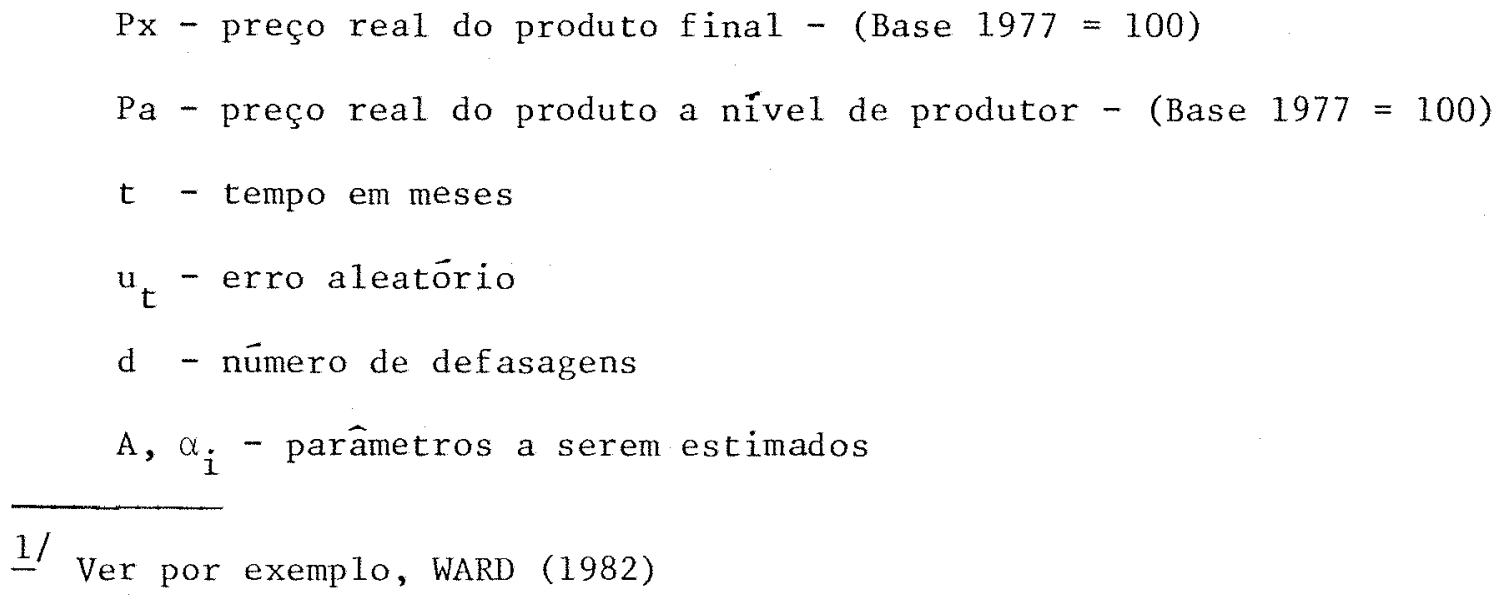


Tendo em vista que as regressões foram estimadas nos logarítmos naturais dos preços, os valores da elasticidade de transmissão de preços correspondem aos parâmetros a serem estimados da regressão.

A determinação do nümero de defasagens foi realizada atravēs de um teste de exclusão de defasagens da variāvel exōgena ( $\mathrm{Pa}$ ) não significativas na explicação da variāvel endōgena (Px).

0 procedimento do teste de exclusão consiste em avaliar, a partir de um modelo com 12 defasagens, a significância estatística dos testes F, a um nível de significância de $5 \%$ de probabilidade, à medida em que se excluem as defasagens $(d=1$ a $d=12),(d=2$ a $d=12), \ldots$, até $(\mathrm{d}=12)$, sucessivamente.

Nos casos em que detectou-se causalidade bidirecional, considerou-se o seguinte sistema de equações simultâneas:

$$
\begin{aligned}
& \ln \mathrm{Px}_{t}=\mathrm{a}_{0}+\mathrm{a}_{1} \operatorname{lnPa_{t}}+\mathrm{a}_{2} \operatorname{lnPa_{t-1}}+\mathrm{a}_{3} \operatorname{lnPa_{t-2}}+\mathrm{u}_{1 t} \\
& \ln \mathrm{Pa}_{t}=\mathrm{b}_{0}+\mathrm{b}_{1} \operatorname{lnPx_{t}}+\mathrm{b}_{2} \operatorname{lnPx_{t-1}}+\mathrm{b}_{3} \operatorname{lnPx_{t-2}}+\mathrm{u}_{2 t}
\end{aligned}
$$

onde:

$$
\begin{aligned}
& a_{0}, a_{1}, a_{2}, a_{3}, b_{0}, b_{1}, b_{2}, b_{3}-\text { parāmetros a serem estimados } \\
& u_{1 t}, u_{2 t}-\text { erros aleatórios }
\end{aligned}
$$

o nümero de defasagens incluídas foi determinado de maneira "ad hoc", examinando-se a significancia dos coeficientes. Neste trabalho utiliza-se basicamente duas defasagens, não se considerando mais que três defasagens. Para fins de estimação emprega-se o método de mínimos quadrados de dois estägios (MQDE), admitindo-se que os erros não sejam auto-correlacionados. 
2.4. Cálculo das Margens de Comercialização

Conforme observou BARROS (1987), a margem absoluta de comercialização è a diferença entre os preços pagos pelos consumidores e os valores recebidos pelos produtores pela quantidade equivalente na fazenda $\left(\mathrm{Pa}^{*}\right) \stackrel{1 /}{ }$. Por margem de atacado e varejo entende-se a diferença entre os preços pagos e recebidos pelos referidos comerciantes, ou seja:

- Margem absoluta total de comercialização (MC)

$$
\mathrm{MC}=\mathrm{Px}-\mathrm{Pa}^{*}
$$

- Margem absoluta do atacado (MA)

$$
M A=P c^{*}-P^{*}
$$

- Margem absoluta do varejo (MV)

$$
\mathrm{MV}=\mathrm{Px}-\mathrm{PC}^{*}
$$

sendo:

$$
\begin{aligned}
& \mathrm{Px} \text { - preço real de venda a nível de varejo } \\
& \mathrm{Pc}^{*} \text { - preço real equivalente de venda a nível de atacado } \\
& \mathrm{Pa}^{*} \text { - preço real equivalente a nível de produtor } \\
& \text { As margens porcentuais são: } \\
& - \text { Margem porcentual total de comercialização (MC') } \\
& \mathrm{MC}^{\prime}=\frac{\mathrm{Px}^{\prime} \mathrm{Pa}^{*}}{\mathrm{Px}^{*}} \cdot 100
\end{aligned}
$$

If Quando o produto final receber processamento durante a cadeia de comercialização, o preço ao produtor è transformado em quantidade equivalente na fazenda. 
- Parcela porcentual do produtor (MP')

$\mathrm{MP}^{\prime}=\frac{\mathrm{Pa}^{*}}{\mathrm{Px}} \cdot 100$

- Margem porcentual do atacado (MA')

$\mathrm{MA}^{\prime}=\frac{\mathrm{Pc}^{*}-\mathrm{Pa}^{*}}{\mathrm{Px}} \cdot 100$

- Margem porcentual do varejo (MV')

$\mathrm{MV}^{\prime}=\frac{\mathrm{Px}_{\mathrm{P}} \mathrm{Pc}^{*}}{\mathrm{PX}} \cdot 100$

A margem porcentual total de comercialização (MC') è a soma da margem porcentual do atacado (MA') e a margem porcentual do varejo $\left(M V^{\prime}\right)$.

Neste trabalho, três aspectos são levados em consideração:

a) os preços utilizados fazem referência às regiões ligadas efetivamente ao comércio da cidade de São Paulo;

b) os preços são corrigidos para que todos produtos se refiram à mesma unidade no varejo; e

c) considera-se a defasagem (d) de tempo entre os niveis de comercialização.

Para atender ao item (a) estabelece-se as principais regiões produtoras que abastecem o mercado paulistano, conforme descrito no ítem 2.1 .2 .

o procedimento utilizado no item (b), trata-se da metodologia apresentada por BARROS (1987), sendo, que os coeficientes de transformação da matēria-prima agrícola na forma consumida ao varejo, e a 
importância dos subprodutos foram obtidos em CANTO et alii (1985). o preço ao produtor $\vec{e}$ corrigido de forma a poder compatibiliza $\overrightarrow{-}$ lo com a unidade vendida ao varejo. Dada a inexistência de informações sobre as perdas durante o processo de comercialização, considera-se apenas os coeficientes tëcnicos de processamento.

Com relação ao ítem (c), observa-se inicialmente o sentido de causalidade, e atravēs do teste de exclusão detecta-se o nümero de defasagens (d) significativas que influenciam o preço endögeno no períodot. Dos produtos analisados nesta pesquisa, o arroz, o milho e a soja sofrem processamento durante a comercialização. No caso do arroz, dado que o preço ao produtor refere-se ao grão em casca, enquanto a unida de no varejo é do grão sem casca, longo, tipo 2, hä, portanto, necessidade de transformar-se o arroz em casca quantidade equivalente a um quilo do seu derivado ao varejo. Conforme indicam CANTO et alii (1985), para obter-se $1,0 \mathrm{~kg}$ de arroz sem casca é necessário $1,43 \mathrm{~kg}$ de arroz em casca, e, dado que a casca de arroz não apresenta valor comercial, o preço ao produtor è multiplicado por 1,43, para transformä-1o no produto sem casca, e assim utilizâa-lo no cālculo da margem.

No caso do milho e da soja, o processamento da matéria-pri ma gera alëm do derivado de interesse, outros subprodutos de valor econômico. Por exemplo, para obter-se $1,0 \mathrm{~kg}$ de fubä mimoso $\overrightarrow{\mathrm{e}}$ necessārio $1,5 \mathrm{~kg}$ de milho em grão. Em seguida observa-se, que ao se produzir $1,0 \mathrm{~kg}$ de fubä mimoso gera-se $0,45 \mathrm{~kg}$ de farelo. Essas quantidades dos dois derivados (fubá mimoso e farelo) são avaliadas a nível de varejo, obtendose, em média, que $75 \%$ do valor do milho ao varejo correspondem ao fubä 
mimoso e o restante ao farelo. Admite-se então, que $75 \%$ do valor de $1,5 \mathrm{~kg}$ de milho em grão ao produtor correspondem a $1,0 \mathrm{~kg}$ de fubä mimoso ao consumidor. Portanto, para efeito do cālculo de margem, o preço ao nível de produtor será multiplicado por $1,125(1,5 \times 0,75)$, para poder comparä-1o com o valor unitário do fubá mimoson'.

Para o caso do óleo de soja estabelece-se que para se obter 1 lata $(900 \mathrm{ml})$ de öleo refinado é necessārio $1,0 \mathrm{~kg}$ de ōleo bruto, que por sua vez necessita de $5,56 \mathrm{~kg}$ de soja em grão. Esta, todavia, gera além do óleo bruto, o farelo. No atacado, cerca de $56 \%$ do valor do complexo soja corresponde ao valor do óleo, confirmando observações de JUNQUEIRA \& CANTO (1971). Assim, do valor de $5,56 \mathrm{~kg}$ de soja em grão, $56 \%$ serão correspondentes ao valor do ōleo a nível de fazenda. Portanto," o preço do $\mathrm{kg}$ a nível de produtor será multiplicado por $3,114(5,56 \times 0,56)$, para poder ser comparado com o valor de uma lata de óleo refinado (900 ml) ao varejo.

Neste trabalho calcula-se, primeiramente, as margens correntes, ou seja, aquelas correspondentes à diferença entre os preços num mesmo instante de tempo (mês).

No entanto, a margem corrente pode não representar adequadamente os ajustamentos completos dos ịtermediārios às variações de preços. Suponha-se, por exemplo, que a anâlise de causalidade indique que, para certo produto, as variações de preços ao atacado antecedam as variações ao varejo. Além disso, admita-se que a equação de transmissão de

1/ A pressuposição feita para esses cālculos è que o derivado de interesse (fubā mimoso) represente, a nível de fazenda, a mesma proporção do seu valor no conjunto de derivados obtidos a nível de varejo. 
preço ajustada inclua defasagem de ordem "d" da variāvel preço exógena.

Caso haja então variação de $10 \%$ no preço ao atacado no mês t, a margem corrente desse mês capta apenas parcialmente o ajuste a ser verificado no preço ao varejo. Propõe-se então, que, alẻm da margem corrente, seja calculada a margem defasada, que no caso do exemplo considerado, envolveria o preço ao atacado no mês $t$ e o preço ao varejo no mês $(t+d)$, quando os efeitos da variação inicial teriam cessado.

Para operacionalizar essa proposta, procede-se da seguinte forma. Apōs a definição do sentido de causalidade, detecta-se o número de defasagens (d) significativas que inflienciam o preço endögeno. o preço exógeno serā então considerado com esta defasagem para o cálculo da margem defasada.

Supondo-se, como acima, que a anälise de causalidade indicou $\mathrm{Pa} \rightarrow \mathrm{Px}$, sendo "d" a defasagem, efetuou-se o seguinte cálculo para a margem defasada porcentual.

$$
M^{\prime} d=\frac{\left(\mathrm{Px}_{t}-\mathrm{Pa}_{t-\mathrm{d}}^{*}\right)}{P x_{t}} \cdot 100^{1 /}
$$

2.5. Anālise das Margens e Preços

Com o intuito de se associar o comportamento das margens correntes e defasadas (absoluta/porcentual), às variaçōes nos preços exögenos, desenvolve-se a seguir uma anālise que relaciona as elasticidades

If A margem absoluta defasada seră:

$$
\mathrm{Md}=\left(\mathrm{Px}_{t}-\mathrm{Pa}_{\mathrm{t}-\mathrm{d}}^{*}\right)
$$


de transmissão de preços às alterações esperadas das margens.

Seja a equação de transmissão de preços dado em (2.9), onde $\alpha_{0}, \alpha_{1}, \ldots, \alpha_{d}$ são as elasticidades de transmissão de preços:

$$
\ln \operatorname{Px}_{t}=\ln A+\sum_{i=0}^{d} \alpha_{i} \ln P a_{t-i}+u_{t}
$$

A margem defasada porcentual ( $\left.M^{\prime} d\right)$ é dada por:

$$
M^{\prime} d=\frac{P x_{t}-\theta P a_{t-d}}{P x_{t}}=1-\theta \frac{P a_{t-d}}{P x_{t}}
$$

onde $\theta \bar{e}$ o coeficiente de transformação, e, $\theta \mathrm{Pa}_{t-d}=\mathrm{Pâ̆}_{t-d}$.

A elasticidade de $M^{\prime} d$ em relação a $\left(\frac{\mathrm{Px}_{t}}{\mathrm{~Pa}_{t-d}}\right)$, $\vec{e}$ dada por:

$E\left(M^{\prime} d, \frac{P x_{t}}{P a_{t-d}}\right)=\frac{d\left(M^{\prime} d\right)}{d\left(\frac{P x_{t}}{P a_{t-d}}\right)} \cdot \frac{\left(\frac{P x_{t}}{P a_{t-d}}\right)}{M^{\prime} d}$

e, logo,

$$
E\left(M^{\prime} d, \frac{\mathrm{Px}_{t}}{\mathrm{~Pa}_{t-\mathrm{d}}}\right)=\frac{\theta}{\frac{\mathrm{Px}_{t}}{\mathrm{~Pa}_{t-\mathrm{d}}-\theta}>01 /}
$$

If Notar que $\left(\frac{\mathrm{Px}_{t}}{\mathrm{~Pa}_{\mathrm{t}-\mathrm{d}}}-\theta\right)=\frac{\mathrm{Px}_{t}-\theta \mathrm{Pa}_{\mathrm{t}-\mathrm{d}}}{\mathrm{Pa}{ }_{\mathrm{t}-\mathrm{d}}}>0$, que corresponde ao "markup". 
Portanto $M^{\prime} d$ e $\left(\frac{\mathrm{Px}_{t}}{\mathrm{~Pa}_{\mathrm{t}-\mathrm{d}}}\right)$ variam no mesmo sentido.

Examinando-se a relação entre $\left(\frac{\mathrm{Px}_{t}}{\mathrm{~Pa}_{t-\mathrm{d}}}\right)$ e $\mathrm{Pa}_{t-d}$, tem-se:

$$
\ln \left(\frac{\mathrm{Px}_{t}}{\mathrm{~Pa}_{t-\mathrm{d}}}\right)=\ln \mathrm{Px}_{t}-\ln \mathrm{Pa}_{t-\mathrm{d}}
$$

utilizando-se (2.9), tem-se:

$$
\begin{aligned}
\ln \left(\frac{\mathrm{Px}_{t}}{\mathrm{~Pa}_{t-d}}\right) & =\ln \mathrm{A}+\alpha_{0} \ln \mathrm{Pa}_{t}+\alpha_{1} \ln \mathrm{Pa}_{t-1}+\ldots+ \\
& +\alpha_{d} \ln \mathrm{Pa}_{t-d}-\ln \mathrm{Pa}_{t-d}
\end{aligned}
$$

Admitindo-se uma variação permanente em $\mathrm{Pa}_{t-\mathrm{d}}$ por $(\mathrm{d}+1)$ períodos, ou seja:

$$
\mathrm{d} \ln \mathrm{Pa}_{\mathrm{t}}=\mathrm{d} \ln \mathrm{Pa}_{t-1}=\ldots=\mathrm{d} \ln \mathrm{Pa}_{\mathrm{t}-\mathrm{d}}
$$

pode-se determinar que a elasticidade de $\left(\frac{\mathrm{Px}_{t}}{\mathrm{~Pa}_{t-\mathrm{d}}}\right)$ em relação a $\mathrm{Pa}{ }_{t-d}$ serä:

$$
E\left(\frac{P x_{t}}{P a_{t-d}}, P a_{t-d}\right)=\left(\begin{array}{c}
d \\
\sum_{i=0} \alpha_{i}
\end{array}\right)-1
$$

Então como:

$E\left(M^{\prime} d, P a_{t-d}\right)=\frac{d \ln M^{\prime} d}{d \ln \left(\frac{P x_{t}}{P a_{t-d}}\right)} \cdot \frac{d \ln \left(P x_{t} / P a_{t-d}\right)}{d \ln P a_{t-d}}$ 
tem-se que, usando-se (2.12) e (2.13),

$$
E\left(M^{\prime} d, P a_{t-d}\right)=\frac{\theta}{\frac{P x_{t}}{P a_{t-d}}-\theta} \cdot\left\{\sum_{i=0}^{d} \alpha_{i}-1\right\}
$$

que da a elasticidade de $M^{\prime} d$ em relação a $\mathrm{Pa}_{t-d}$.

Além disso, sabe-se que:

$$
\left(\begin{array}{c}
\mathrm{d} \\
\sum \alpha_{i=0} \alpha_{i}
\end{array}\right)-1 \stackrel{\gtrless}{\sum} 0, \text { se } \underset{i=0}{\mathrm{~d}} \alpha_{\mathbf{i}} \gtreqless 1
$$

Pode concluir-se usando-se (2.14) que M'd varia no mesmo d $\mathrm{d}$

sentido que Pat-d se $\sum_{i=0} \alpha_{i}>1$; varia em sentido oposto se $\sum_{i=0} \alpha_{i}<1 . M^{\prime} d$ serā constante se $\sum_{i=0}^{d} \alpha_{i}=1$.

Considerando-se, em particular, o nümero de defasagens $\mathrm{d}=0$, tem-se:

$$
M C^{\prime}=\frac{\mathrm{Px}_{t}-\theta \mathrm{Pa}_{t}}{\mathrm{Px}_{t}}=1-\theta \frac{\mathrm{Pa}_{t}}{\mathrm{Px}_{t}}
$$

onde, $\mathrm{MC}^{\prime}$ é a margem corrente porcentual de comercialização. A elasticidade de MC' em relação a Pa ${ }_{t}$ pode ser escrita:

$$
E\left(M C^{\prime}, P a_{t}\right)=\frac{\theta}{\left(\frac{P x_{t}}{P a_{t}}-\theta\right)}\left(\alpha_{0}-1\right)
$$


Pode-se concluir que MC' varia no mesmo sentido que $\mathrm{Pa}_{\mathrm{t}}$ se $\alpha_{0}>1$; varia em sentido oposto, se $\alpha_{0}<1$. $\mathrm{MC}^{\prime}$ serä constante se $\alpha_{0}=1$. No caso geral, envolvendo d defasagens, passa a importar a somatória de $\alpha_{i}$ em lugar de $\alpha_{0}$ somente, conforme (2.14).

Considerando-se a margem defasada absoluta, Md, como sendo:

$$
\mathrm{Md}=\mathrm{Px}_{t}-\theta P \mathrm{a}_{t-\mathrm{d}}
$$

ou seja:

$$
M d=M^{\prime} d \cdot P x_{t}
$$

e, portanto,

$$
\ln M d=\ln M^{\prime} d+\ln P_{t}
$$

então, utilizando-se (2.9), tem-se:

$$
\ln M d=\ln M^{\prime} d+\ln A+\alpha_{0} \ln P_{t}+\ldots+\alpha_{d} \ln P a_{t-d} e,
$$

admitindo-se uma variação permanente em $\mathrm{Pa}_{t-\mathrm{d}}$, por $(\mathrm{d}+1)$ períodos, podese escrever:

$\mathrm{d} \ln M d=\mathrm{d} \ln \mathrm{M}^{\prime} \mathrm{d}+\left(\begin{array}{c}\mathrm{d} \\ \sum_{\mathrm{i}=0} \alpha_{i}\end{array}\right) \mathrm{d} \ln \mathrm{Pa} \mathrm{t}_{-\mathrm{d}}$

A elasticidade de Md em relação a Pa ${ }_{t-d}$ será: 


$$
\begin{aligned}
& E\left(M d, P a_{t-d}\right)=E\left(M^{\prime} d, P a_{t-d}\right)+\left(\begin{array}{c}
d \\
\sum \alpha_{i} \\
i=0
\end{array}\right) \\
& =\left\{\frac{\theta}{\left(\frac{P x_{t}}{P a_{t-d}}-\theta\right)}\left[\left(\begin{array}{c}
d \\
\sum i=0
\end{array}\right)-1\right]+\left(\begin{array}{c}
d \\
\sum i=0
\end{array}\right)\right. \\
& =\frac{\left(\frac{P x_{t}}{P a_{t-d}} \sum_{i=0}^{d} \alpha_{i}\right)-\theta}{\left(\frac{P x_{t}}{P a_{t-d}}-\theta\right)}
\end{aligned}
$$

Assim, tem-se:

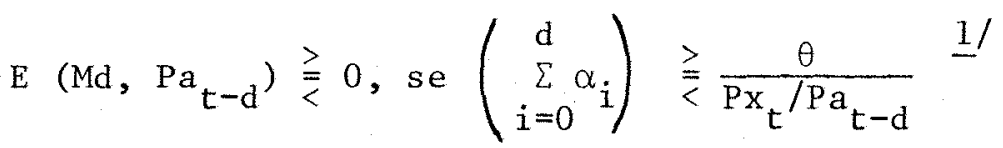

Alēm disso:

$E\left(M d, P a_{t-d}\right) \stackrel{\gtrless}{\gtrless}, \operatorname{se}\left(\begin{array}{c}d \\ \sum_{i=0} \alpha_{i}\end{array}\right) \gtreqless 1$

Considerando-se que o número de defasagens (d) seja nulo,

tem-se:

$$
M C=P x_{t}-\theta P a_{t}
$$

onde, MC è a margem corrente absoluta, e a elasticidade de MC em relação à Pa ${ }_{t}$ è dada por:

$1 /$ Notar que em (2.11) tem-se $M^{\prime} d>0$, se $\theta<\frac{P x_{t}}{P a_{t}-d}$ e $\theta \frac{P a_{t}-d}{P x_{t}}=1-M^{\prime} d$, ou, $\theta \frac{P a_{t}}{P x_{t}}=1-M C^{\prime}$ 
$E\left(M C, P a_{t}\right)=\frac{\alpha_{0}\left(\frac{P x_{t}}{P a_{t}}\right)-\theta}{\left(\frac{P x_{t}}{P a_{t}}\right)-\theta}$

Assim, tem-se:

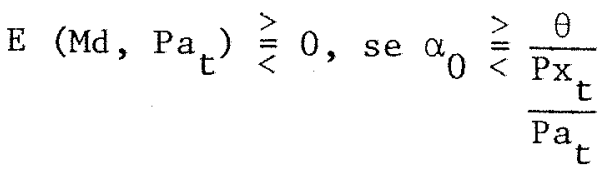

Alëm disso:

$\mathrm{E}\left(\mathrm{MC}, \mathrm{Pa} \mathrm{t}_{\mathrm{t}}\right) \stackrel{\gtrless}{\gtrless}$, se $\alpha_{0} \gtreqless 1$ 
3. RESULTADOS E DISCUSST̃O

3.1. Anālise de Causalidade

Nas Tabelas 2 a 5 são apresentados os resultados da anälise de causalidade para o arroz, milho, soja e laranja, considerando-se os respectivos níveis de mercado no processo de comercialização, visando o abastecimento dos equipamentos varejistas da cidade de São Paulo.

\subsubsection{Arroz}

Observando-se o teste $\mathrm{F}$ da Tabela 2, nota-se que o único efeito causal captado na anälise foi entre os preços recebidos pelos produtores do Estado de Goiás e o varejo, indicando exogeneidade do preço ao produtor de Goiās. Com relação às demais regiões (Estado de São Paulo e Rio Grande do Sul) e o preço do varejo, não se rejeitou a hipótese nula (coeficientes futuros nu1os), ao nível de significância de 5\%, indicando ausencia de causalidade entre os preços. 
Tabela 2. Testes para exclusão das variáveis futuras na análise de causalidade do arroz

\begin{tabular}{lcc}
\hline Variävel dependente & Periodo & $F^{(2)}$ \\
\hline & - Produtor-SP/Varejo & \\
APRS & $72-85$ & $0,68(4,129)$ \\
APV & $72-85$ & $1,71(4,129)$ \\
& - Produtor-Go/Varejo & \\
APRG & $74-80$ & $5,58 *(4,45)$ \\
APV & $74-80$ & $0,08(4,45)$ \\
& - Produtor-RS/Varejo & $0,21(4,22)$ \\
APRR & $80-84$ & $0,80(4,22)$ \\
\hline
\end{tabular}

(1) APRS, APRG, APRR, APV, referem-se ao preço do arroz aos produtores do Estado de São Paulo, Goiás, Rio Grande do Sul e do varejo, respectivamente.

(2) entre parênteses estão os graus de liberdade do teste.

(*) nível de significância: 5\%

\subsubsection{Mitho}

Na Tabela 3 apresentam-se os resultados da anälise de causalidade entre o preço ao varejo (fubá mimoso) e o preço do milho em grão nas regiões de produção (Estados de São Paulo, Paranā e Minas Gerais). 0 mercado atacadista não foi levado em consideração devido a indisponibilidade de dados e a sua pouca representatividade na cadeia de comercialização, pois as indústrias de fubä mimoso adquirem o milho em grão diretamente do produtor, e, na maioria das vezes, vendem o seu derivado diretamente ao supermercado. 
Todos os resultados apresentaram causalidade dos preços ao produtor para o varejo.

Tabela 3. Testes para exclusão das variāveis futuras na anālise de causalidade do mitho

\begin{tabular}{lcc}
\hline Variävel dependente & Periodo & $F^{(2)}$ \\
\hline & - Produtor-SP/Varejo & \\
MPRS & $75-85$ & $8,58 *(4,94)$ \\
MPV & $75-85$ & $0,49(4,94)$ \\
& - Produtor-PR/Varejo & \\
MPRP & $75-84$ & $5,93 *(4,82)$ \\
MPV & $75-84$ & $0,81(4,82)$ \\
& - Produtor-MG/Varejo & \\
MPRM & $75-84$ & $5,46 *(4,81)$ \\
MPV & $75-84$ & $0,19(4,81)$ \\
\hline
\end{tabular}

(1) MPRS, MPRP, MPRM, MPV, referem-se ao preço do milho em grão aos produtores do Estado de São Paulo, Paranā e Minas Gerais e do fubá mimoso no varejo, respectivamente.

(2) entre parênteses estão os graus de liberdade do teste.

(*) nível de significância: $5 \%$

\subsubsection{Soja}

Na Tabela 4 apresentam-se os resultados da anälise de causalidade entre preços nas regiões de produção (Estado de São Paulo, Mato Grosso/Mato Grosso do Sul e Minas Gerais) e mercado atacadista da cidade de São Paulo, e este, por sua vez, com o varejo. Da primeira anälise, de tectou-se causalidade do preço ao produtor (São Paulo e Mato Grosso/Mato Grosso do Sul) para o atacado. Os preços ao produtor de Minas Gerais e 
ao atacado apresentaram causalidade bidirecional. Da segunda, observouse causalidade do atacado para o varejo.

Tabela 4. Testes para exclusão das variáveis futuras na anālise de causalidade da soja

\begin{tabular}{|c|c|c|}
\hline Variävel dependente ${ }^{(1)}$ & Período & $\mathrm{F}^{(2)}$ \\
\hline & - Atacado/Varejo - & \\
\hline SPA & $72-85$ & $17,19 *(4,130)$ \\
\hline \multirow[t]{2}{*}{ SPV } & $72-85$ & $1,52(4,130)$ \\
\hline & - Produtor-SP/Atacado - & \\
\hline SPRS & $75-85$ & $2,81 *(4,94)$ \\
\hline \multirow[t]{2}{*}{ SPA } & $75-85$ & $0,88 \quad(4,94)$ \\
\hline & - Produtor-MT/Atacado - & \\
\hline SPRT & $74-84$ & $2,30 *(4,94)$ \\
\hline \multirow[t]{2}{*}{ SPA } & $74-84$ & $0,88 \quad(4,94)$ \\
\hline & - Produtor-MG/Atacado - & \\
\hline SPRM & $74-84$ & $2,23 *(4,94)$ \\
\hline SPA & $74-84$ & $3,25 *(4,94)$ \\
\hline
\end{tabular}

(1) SPRS, SPRT, SPRM, SPA, SPV, referem-se ao preço mëdio da soja em grão recebido pelos produtores do Estado de São Paulo, Mato Grosso / Mato Grosso do Sul e Minas Gerais, e do óleo de soja refinado enlatado no atacado e varejo, respectivamente.

(2) entre parênteses estão os graus de liberdade do teste.

(*) níve1 de significância: 5\% 


\subsubsection{Laranja de mesa}

A anālise de causalidade deste produto envolveu os preços ao produtor (Estado de São Paulo) e atacado, e este com o varejo. Observando-se a Tabela 5 conclui-se que o preço ao produtor causa o atacado, e o varejo causa o atacado, diagnosticando-se que o mercado atacadista re cebe influência do produtor e do varejo.

Tabela 5. Testes para exclusão das variäveis futuras na anälise de causalidade da laranja

\begin{tabular}{lcc}
\hline Variävel dependente & Periodo & $\mathrm{F}^{(2)}$ \\
\hline LPA & - Atacado/Varejo - & \\
LPV & $71-85$ & $0,89(4,142)$ \\
& - Produtor-SP/Atacado & $2,81 *(4,142)$ \\
LPRS & $71-85-85$ & \\
LPA & $78-85$ & $1,89 *(4,57)$ \\
\hline
\end{tabular}

(1) LPRS, LPA, LPV, referem-se ao preço médio da laranja recebido pelos produtores do Estado de São Paulo, no atacado e no varejo, respectivamente.

(2) entre parênteses estão os graus de liberdade do teste.

(*) nível de significância: $5 \%$

Em síntese, pode-se dizer quanto a anālise de causalidade, que:

(a) no caso do arroz, detectou-se fraca interrelação entre os níveis de mercado considerados, exceto para o caso da região de Goiás; 
aparentemente a produção goiana (de sequeiro), por ser mais instável, tem um efeito maior sobre os preços nos demais níveis de mercado;

(b) no caso do milho, a predominância de variações originárias do lado do produtor parece indicar que nesse mercado as oscilações de preços devem-se, principalmente, às variações de produção; tais variações não seriam antecipadas ao nível de varejo, devido talvez, ao grande nümero de regiões produtoras envolvidas;

(c) no caso da soja, o setor produtivo tendeu a anteciparse por ocasião das oscilações dos preços, exceção feita à região de Minas Gerais que apresentou causalidade bidirecional com o atacado; este comportamento deve estar associado, principalmente, à participação deste produto no mercado externo, pois oscilações no mercado internacional provocariam, inicialmente, alterações de preços ao produtor; e

(d) no caso da laranja, o atacado recebeu influência, tanto do produtor como do varejo; no primeiro caso aparentemente são as osci lações originadas no mercado externo que desencadeiam, inicialmente, alterações dos preços no lado do produtor; no segundo, as variações ocorridas na demanda (influenciada pela renda do consumidor, nível de emprego, preços dos produtos substitutos/complementares, etc.), ocasionariam, inicialmente, alterações dos preços ao varejo.

3.2. Anälise da Transmissão de Preços

Apōs a determinação do sentido de causalidade, inicia-se a aplicação do teste de exclusão de variäveis, para determinação do nümero de defasagens a ser considerado na anälise de transmissão de preços. 
Os resultados desta anālise são apresentados na Tabela 6 .

Tabela 6. Nümero de defasagens consideradas na anālise de transmissão de preços

\begin{tabular}{|c|c|c|c|}
\hline Produto & Reg & gressão & $\begin{array}{l}\text { Nümero de } \\
\text { defasagens }\end{array}$ \\
\hline Arroz & APV & $=\mathrm{f}(\mathrm{APRG})$ & 0 \\
\hline Milho & MPV & $=\mathrm{f}$ (MPRS) & 1 \\
\hline Mi tho & MPV & $=\mathrm{f}(\mathrm{MPRM})$ & 0 \\
\hline Milho & MPV & $=\mathrm{E}(\mathrm{MPRP})$ & 0 \\
\hline Soja & SPV & $=\mathrm{E}(\mathrm{SPA})$ & 6 \\
\hline Soja & SPA & $=\mathrm{f}(\mathrm{SPRS})$ & 0 \\
\hline Soja & SPA & $=\mathrm{E}(\mathrm{SPRT})$ & 0 \\
\hline Soja & SPA & $=f(S P R M)$ & 1 \\
\hline Soja & SPRM & $=\mathrm{f}(\mathrm{SPA})$ & 1 \\
\hline Laranja & LPA & $=\mathrm{f}(\mathrm{LPV})$ & 12 \\
\hline Laranja & LPA & $=f(L P R S)$ & 0 \\
\hline
\end{tabular}

Dado que a regressão foi realizada utilizando-se os logarítmos naturais dos preços, os coeficientes da função de transmissão correspondem aos valores estimados da elasticidade de transmissão de preços.

Nas Tabelas 7 a 16 são apresentadas as estimativas dos coeficientes das equações de transmissão de preços. Lembra-se que apenas entre o preço de soja ao produtor de Minas Gerais e ao atacado detectouse sentido bidirecional de causalidade. 


\subsubsection{Arroz}

Dentre as regiões de produção de arroz (Estado de São Pau1o, Goiās e Rio Grande do Sul), a ünica que apresentou efeito significativo na anālise de causalidade com o preço ao varejo foi o Estado de Goiās, no período 1974 a 1980. A anälise do período posterior indicou que não houve necessidade de defasagem.

Na Tabela 7 pode-se observar, que o coeficiente da regressão foi estimado em 0,4025 , que corresponde à elasticidade de transmissão de preços do produtor para o varejo, ou seja, um aumento de $10 \%$ nos preços recebidos pelos produtores de Goiás provoca um aumento imediato de 4,025\% no preço do arroz dos supermercados da cidade de São Paulo.

\subsubsection{Milho}

A anālise de causalidade do milho apresentou sentido unidirecional do preço recebido pelos produtores (Estados de São Paulo, Para ná e Minas Gerais) para o preço do fubà mimoso no supermercado da cidade de São Paulo. A ünica região que apresentou defasagem significativa $(\mathrm{d}=1)$ foi o Estado de São Paulo.

Na Tabela 8 observa-se a equação de transmissão de preços do produtor de São Paulo para o varejo, sendo que um acrëscimo de $10 \%$ no preço ao produtor provocarâ um aumento imediato de $1,54 \%$ no preço do fubā mimoso nos supermercados da cidade de São Paulo, e um efeito total, caso - aumento no preço ao produtor persistir até o final do primeiro mês, de $6,016 \%(1,54 \%+4,476 \%)$ 
Tabela 7. Equação de transmissão de preços do arroz $\frac{1 /}{}$, dos produtores de Goiās (APRG) para o varejo (APV), no período $01 / 74$ à $12 / 80^{2 /}$

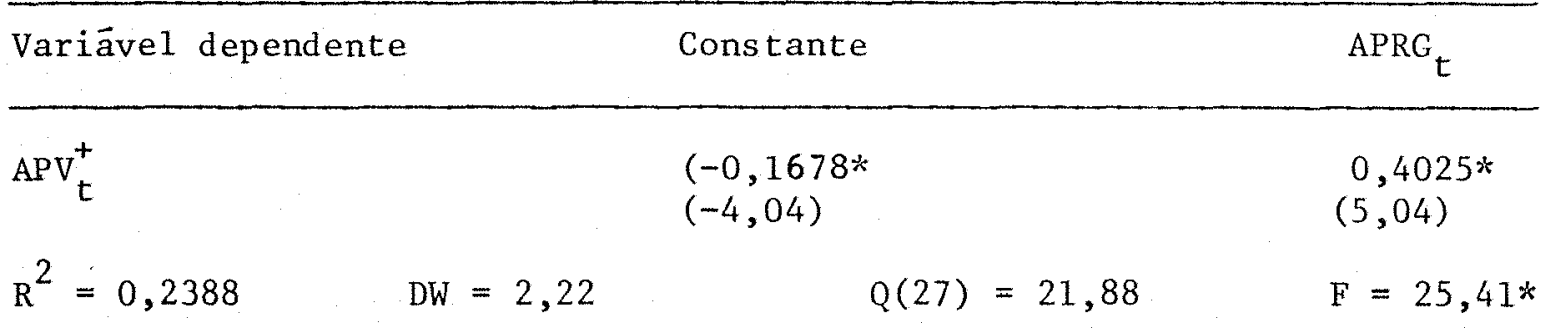

(1) com aplicação de uma filtragem de primeira ordem

(2) entre parênteses estão os valores do teste $t$

(*) níve1 de significância: $t$ - Student $=5 \%$ (bilateral), Durbin-Watson $=$ $=5 \%$ (bilateral), $Q=1 \%$ (graus de liberdade entre parêntes), $F=5 \%$.

(+) nível de significância: teste $t-$ Student $=5 \%$ (unilateral) para as hipöteses $\mathrm{H}_{0}: \sum_{i=0}^{\mathrm{d}} \alpha_{i}=1$ e $\mathrm{H}_{\mathrm{A}}: \sum_{i=0}^{\mathrm{d}} \alpha_{i}<1$, onde $\alpha_{i}$ são os parâmetros das variāveis independentes.

Tabela 8. Equação de transmissão de preços do milhô", dos produtores do Estado de São Paulo (MPRS) para o varejo (MPV), no período 01/75 a $12 / 85^{2} /$

\begin{tabular}{lccc}
\hline Variável dependente & Constante & MPRS $_{t}$ & MPRS $_{t-1}$ \\
\hline $\mathrm{MPV}_{t}^{+}$ & $-0,0365$ & 0,1541 & $0,4476 *$ \\
$\mathrm{R}^{2}=0,2019$ & $\mathrm{DW}=2,25$ & $(1,50)$ & $(4,35)$ \\
\end{tabular}

(1) com aplicação de uma filtragem de primeira ordem.

(2) entre parênteses estão os valores do teste $t$.

(*) nível de significância: $t$ - Student $=5 \%$ (bilateral), Durbin-Watson = $=5 \%$ (bilatera 1 ), $Q=5 \%$ (graus de liberdade entre parênteses), $F=5 \%$.

(+) nível de significância teste $t-$ Student $=5 \%$ (unilateral), para as hipóteses $H_{0}: \sum_{i=0}^{d} \alpha_{i}=1$ e $H_{A}: \sum_{i=0}^{d} \alpha_{i}<1$, onde $\alpha_{i}$ são parâmetros das variāveis independentes. 
Um aumento de $10 \%$ nos preços ao produtor dos Estados do Paranā e Minas Gerais provocam um aumento imediato no preço do fubā mimoso dos supermercados/SP de $7,32 \%$ e $6,94 \%$, respectivamente, conforme obser va-se nas Tabelas 9 e 10 .

Tabela 9. Equação de transmissão de preços do milhô", dos produtores do Estado do Paranä (MPRP) para o varejo (MPV), no período 01/74 à $12 / 85^{2 /}$

\begin{tabular}{|c|c|c|c|}
\hline Variāvel dependente & & Constante & $\mathrm{MPRP}_{\mathbf{t}}$ \\
\hline $\mathrm{MPV}_{\mathrm{t}}^{+}$ & & $\begin{array}{c}0,0424 \\
(0,70)\end{array}$ & $\begin{array}{l}0,7322 \% \\
(6,19)\end{array}$ \\
\hline $\mathrm{R}^{2}=0,2405$ & $D W=2,18$ & $Q(30)=46,43$ & $F=38,36 *$ \\
\hline
\end{tabular}

(1) com aplicação de uma filtragem de primeira ordem.

(2) entre parênteses estão os valores do teste $t$.

(*) nível de significância: $t-$ Student $=5 \%$ (bilatera1), Durbin-Watson $=$ $=5 \%$ (bilatera 1 ), $Q=1 \%$ (graus de liberdade entre parênteses), $F=5 \%$

(+) nível de significância teste $t-$ Student $=5 \%$ (unilateral) para as hipōteses $H_{0}: \sum_{i=0}^{d} \alpha_{i}=1$ e $H_{A}: \sum_{i=0}^{d} \alpha_{i}<1$, onde $\alpha_{i}$ são os parâmetros das variāveis independentes. 
Tabela 10. Equação de transmissão de preços do milhô/, dos produtores do Estado de Minas Gerais (MPRM) para o varejo (MPV), no período $10 / 75$ à $12 / 842 /$

\begin{tabular}{|c|c|c|c|}
\hline Variāvel dependente & & Constante & $\mathrm{MPRM}_{t}$ \\
\hline $\mathrm{MPV}_{t}^{+}$ & & $\begin{array}{c}-0,0052 \\
(0,09)\end{array}$ & $\begin{array}{l}0,6943^{*} \\
(6,35)\end{array}$ \\
\hline $\mathrm{R}^{2}=0,2582$ & $\mathrm{DW}=2,00$ & $Q(30)=30,28$ & $\mathrm{~F}=40,38 *$ \\
\hline
\end{tabular}

(1) com aplicação de duas filtragens de primeira ordem.

(2) entre parênteses estão os valores do teste $t$.

(*) nível de significância: $t$ - Student $=5 \%$ (bilateral), Durbin-Watson $=$ $=5 \%$ (bilateral), $Q=5 \%$ (graus de liberdade entre parênteses), $F=5 \%$

(+) nível de significancia teste $t-$ Student $=5 \%$ (unilatera1) para as hipóteses $\mathrm{H}_{0}: \sum_{i=0}^{\mathrm{d}} \alpha_{i}=1$ e $\mathrm{H}_{\mathrm{A}}: \sum_{i=0}^{\mathrm{d}} \alpha_{i}<1$, onde $\alpha_{i}$ são os parâmetros das variäveis independentes.

\subsubsection{Soja}

A equação estimada de transmissão de preços do óleo de soja do atacado para o varejo, que apresentou defasagem significativa atē $\mathrm{d}=6$, pode ser observada na Tabela 11 . Um aumento de $10 \%$ no preço do óleo de soja refinado enlatado ao atacado provoca um aumento imediato de 4,54\% no preço do óleo de soja refinado enlatado nos supermercados/SP, e caso este aumento persistir, estima-se que no final de seis meses ocorrerá um aumento de $10,72 \%$ nos preços ao varejo. 


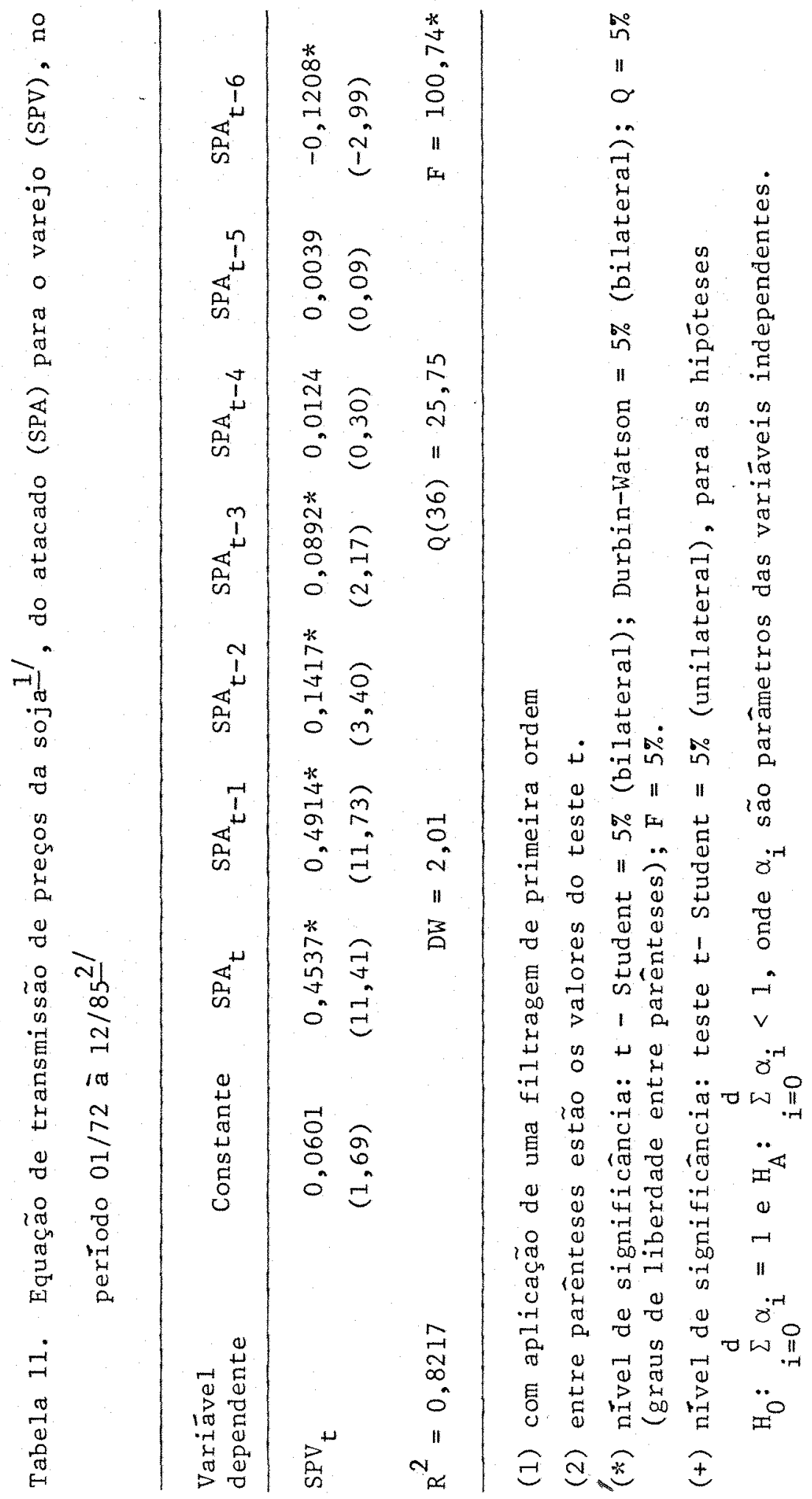


Nas Tabelas 12 e 13 são apresentadas' as equações de trans missão de preços dos produtores de soja dos Estados de São Paulo e Mato Grosso/Mato Grosso do Sul para o mercado atacadista/SP de óleo de soja refinado enlatado, respectivamente. Observa-se que um aumento de $10 \%$ nos preços aos produtores provocam um aumento imediato de $5,73 \%$ e 4,67\% nos preços ao atacado, quando as regiões de produção são são Paulo e Mato Grosso/Mato Grosso do Sul, respectivamente.

Os preços ao produtor do Estado de Minas Gerais e ao atacado/SP apresentaram causalidade bidirecional, que necessitou o ajustamento de um sistema de equações simultâneas (ver Tabela 14). Utilizando-se a forma estrutural, nota-se que um aumento de $10 \%$ nos preços ao atacado provoca, num mesmo momento, um aumento de $28,56 \%$ nos preços ao produtor de Minas Gerais, e um efeito total após a defasagem de um mês de $11,16 \%$. Quando o choque de preços se inicia no lado do produtor de Minas Gerais, um acréscimo de $10 \%$ no preço ao produtor reflete de imediato num acréscimo de $22,87 \%$ nos preços ao atacado, e um efeito total considerando uma defasagem de um mês, de 7,52\% nos preços ao atacado. 
Tabela 12. Equação de transmissão de preços da soja $1 /$, dos produtores do Estado de São Paulo (SPRS) para o atacado (SPA), no perío do $01 / 85$ à $12 / 85^{2 /}$

\begin{tabular}{|c|c|c|c|}
\hline Variävel dependente & & ante & $\operatorname{SPRS}_{t}$ \\
\hline $\mathrm{SPA}_{\mathrm{t}}^{+}$ & & & $\begin{array}{l}0,5725 * \\
(7,84)\end{array}$ \\
\hline $\mathrm{R}^{2}=0,3230$ & $\mathrm{DW}=1,98$ & $Q(33)=50,99$ & $\mathrm{~F}=61,53 \%$ \\
\hline
\end{tabular}

(1) com aplicação de uma filtragem de primeira ordem.

(2) entre parênteses estão os valores do teste $t$.

(*) nîvel de singificância: $t-$ Student $=5 \%$ (bilatera1), Durbin-Watson $=$ $=5 \%$ (bilateral), $Q=1 \%$ (graus de liberdade entre parênteses), $F=5 \%$

( + nível de significância: teste $t$ - Student $=5 \%$ (unilateral) para as hipöteses $\mathrm{H}_{0}: \sum_{i=0}^{\mathrm{d}} \alpha_{i}=1$ e $\mathrm{H}_{\mathrm{A}}: \sum_{i=0}^{\mathrm{d}} \alpha_{i}<1$, onde $\alpha_{i}$ são os parâmetros das variäveis independentes.

Tabela 13. Equação de transmissão de preços da soja $1 /$, dos produtores do Estado de Mato Grosso/Mato Grosso do Sul (SPRT) para o atacado (SPA), no período $01 / 74$ à $12 / 84$ ㄴ

Variável dependente

Constante

$\mathrm{SPRT}_{t}$

$\operatorname{SPA}_{t}^{+}$

$-0,0903$

$(-1,46)$

$0,4670 *$

$(5,90)$

$\mathrm{R}^{2}=0,2137 \quad \mathrm{DW}=2,01 \quad \mathrm{Q}(33)=52,34 \quad \mathrm{~F}=34,79 *$

(1) com aplicação de duas filtragens de primeira ordem.

(2) entre parênteses estão os valores do teste $t$.

(*) nive1 de significância: $t-$ Student $=5 \%$ (bilateral), Durbin-Watson $=$ $=5 \%$ (bilateral), $Q=1 \%$ (graus de 1 iberdade entre parêntes), $F=5 \%$.

(+) nível de significancia: teste $t-$ Student $=5 \%$ (unilateral) para as hipōteses $\mathrm{H}_{0}: \sum_{i=0}^{\mathrm{d}} \alpha_{i}=1$ e $\mathrm{H}_{\mathrm{A}}: \sum_{i=0}^{\mathrm{d}} \alpha_{i}<1$, onde $\alpha_{i}$ são os parâmetros das variāveis independentes. 
Tabela 14. Equação simultānea de transmissão de preços da soja, dos pro dutores do Estado de Minas Gerais (SPRM) para o atacado (SPA), no período de $01 / 74$ a $12 / 84$.

I - Forma Reduzida

Valor dos coeficientes

\begin{tabular}{|c|c|c|c|c|c|}
\hline $\begin{array}{l}\text { Variävel } \\
\text { dependente }\end{array}$ & Regressor & Estimativa & $t$ & $\mathrm{R}^{2}$ & $\mathrm{DW}$ \\
\hline \multirow{6}{*}{$\operatorname{SPRM}_{t}$} & constante & $-0,7851$ & $-2,8592 *$ & 0,8106 & 1,98 \\
\hline & $\operatorname{SPRM}_{t-1}$ & 0,7630 & $7,8407 *$ & & \\
\hline & SPRM $_{t-2}$ & 0,0484 & 0,5416 & & \\
\hline & $\mathrm{SPA}_{t-1}$ & 3,1646 & $3,0147 *$ & & \\
\hline & $\operatorname{SPA}_{t-2}$ & $-2,5138$ & $-2,6250 *$ & & \\
\hline & constante & $-2,2596$ & $-9,2384 *$ & 0,8623 & 1,93 \\
\hline \multirow{4}{*}{$\mathrm{SPA}_{t}$} & $\operatorname{SPRM}_{t-1}$ & 0,0496 & 0,5721 & & \\
\hline & $\operatorname{SPRM}_{t-2}$ & 0,1242 & 1,5595 & & \\
\hline & $\mathrm{SPA}_{t-1}$ & 8,1447 & $8,7110^{*}$ & & \\
\hline & $\operatorname{SPA}_{t-2}$ & $-1,4169$ & $-1,6611$ & & \\
\hline
\end{tabular}

II - Forma Estrutura1

\begin{tabular}{|c|c|c|c|c|c|}
\hline \multirow[b]{2}{*}{$\begin{array}{l}\text { Variāvel } \\
\text { dependente }\end{array}$} & \multicolumn{3}{|c|}{ Valor dos coeficientes } & \multirow[b]{2}{*}{$\mathrm{R}^{2}$} & \multirow[b]{2}{*}{$\mathrm{DW}$} \\
\hline & Regressor & Estimativa & $t$ & & \\
\hline \multirow{4}{*}{$\mathrm{SPRM}_{t}$} & constante & $-1,4170$ & $-4,9333^{*}$ & \multirow[t]{4}{*}{0,1073} & \multirow[t]{4}{*}{1,98} \\
\hline & $\mathrm{SPA}_{t}$ & 2,8561 & $4,3206 *$ & & \\
\hline & $S P A_{t-1}$ & $-1,7403$ & $-2,5894 *$ & & \\
\hline & $\mathrm{SPA}_{t-2}$ & 0,0317 & 0,1324 & & \\
\hline \multirow{4}{*}{$\mathrm{SPA}_{t}$} & constante & 1,4365 & $2,9413 *$ & \multirow[t]{4}{*}{0,1303} & \multirow[t]{4}{*}{1,94} \\
\hline & $\operatorname{SPRM}_{t}$ & 2,2866 & $3,1066 *$ & & \\
\hline & $\operatorname{SPRM}_{t-1}$ & $-1,5348$ & $-2,2540 *$ & & \\
\hline & $\operatorname{SPRM}_{t-2}$ & 0,1704 & 0,8995 & & \\
\hline
\end{tabular}

(*) nível de significância: t-Student $=5 \%$ (bilatera1)

Durbin-Watson $=5 \%$ (bilateral) 


\subsubsection{Laranja de mesa}

Na Tabela 15 apresenta-se a equação de transmissão de preços de laranja ao varejo para o atacado, que apresentou defasagem significativa para $\mathrm{d}=12$. Portanto, um aumento de $10 \%$ no preço da laranja do varejo, provoca no mesmo momento um acréscimo de $6,5 \%$ nos preços ao atacado/SP (CEAGESP), e um efeito total no final de doze meses de 9,07\%.

$\mathrm{Na}$ análise de transmissão de preços do produtor/SP para o atacado observa-se na Tabela 16, que um acréscimo de $10 \%$ nos preços ao pro dutor provoca um aumento imediato de $4,48 \%$ nos preços ao atacado.

\subsection{Anälise das Margens de Comercialização}

Na anälise das margens de comercialização foram considerados dois pontos importantes, que são:

a) o aspecto geográfico dos mercados, pois dado o equipamento varejista (supermercado ou feira-livre), definiu-se as principais regiões de procedência para abastecimento da cidade de São Paulo; e

b) o aspecto da defasagem do tempo, pois existe uma defasagem de tempo entre o aumento do preço exógeno e ajustamento do preço endōgeno.

Independentemente de ocorrer efeito causal entre os níveis de comercialização considerados neste trabalho, as margens correntes totais de comercialização do arroz sem casca, do fubá mimoso, do óleo de soja refinado enlatado e da laranja de mesa foram calculadas, além das mar-

gens correntes do atacado e varejo para o óleo de soja refinado enlatado e a laranja de mesa. 


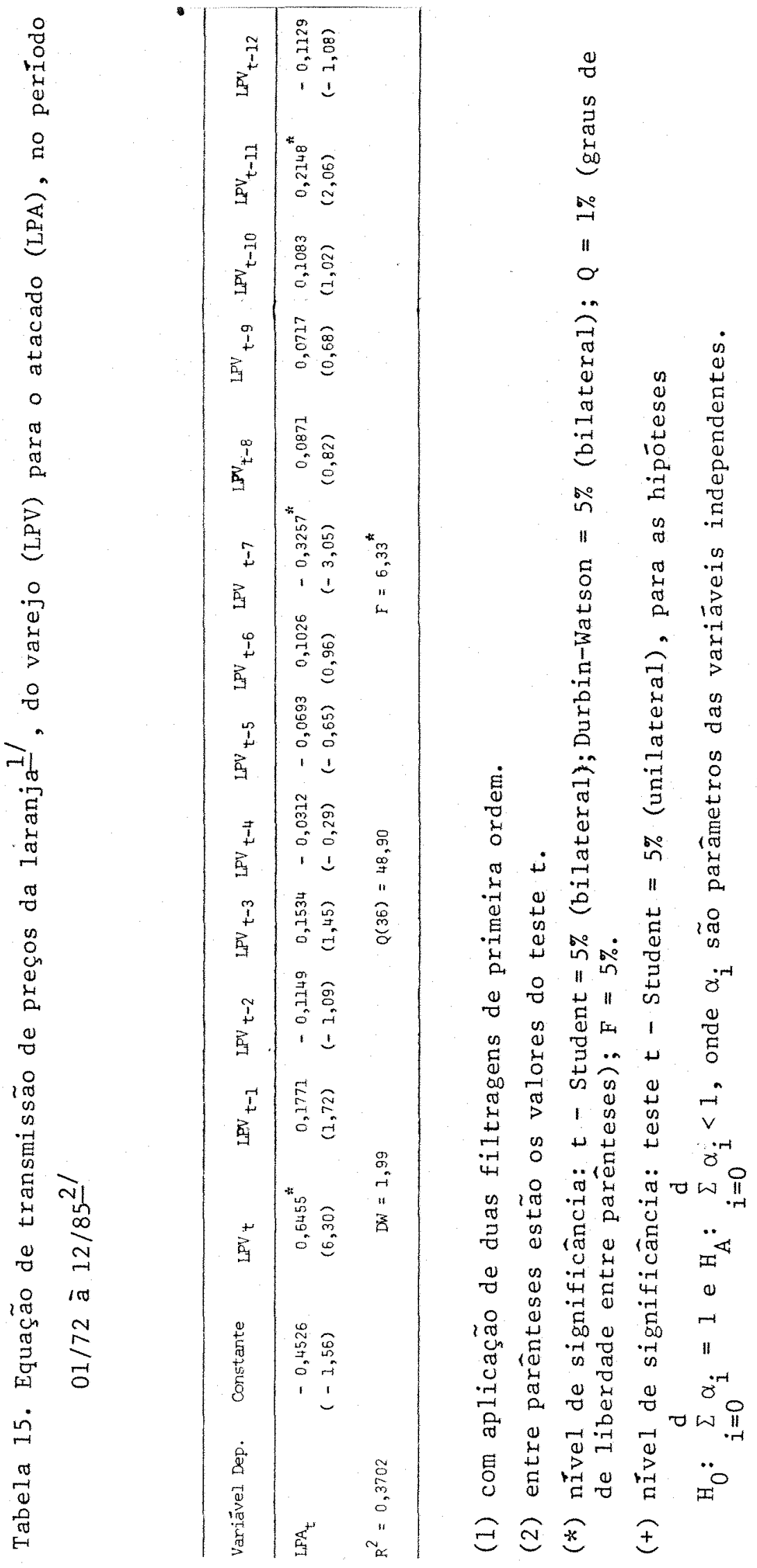


Tabẹla 16. Equação de transmissão de preços da laranja 1/, dos produtores do Estado de São Paulo (LPRS) para o atacado (LPA), no período $01 / 78$ à $12 / 85$ I/

Variāvel Dependente

Constante

LPRS $_{t}$

$\mathrm{LPA}_{t}^{+}$

$-1,0237 *$

$0,4479 *$

$(-6,08)$

$(6,73)$

$\mathrm{R}^{2}=0,3323$

$\mathrm{DW}=2,04$

$Q(27)=36,27$

$F=45,29 *$

(1) com aplicação de uma filtragem de terceira ordem.

(2) entre parênteses estão os valores do teste $t$.

(*) nível de significância: $t$ - Student $=5 \%$ (bilateral), Durbin-Watson = $=5 \%$ (bilateral), $Q=5 \%$ (graus de liberdade entre parênteses), $F=5 \%$.

$(t)$ nível de significância: teste $t-$ student $=5 \%$ (unilateral) para as hipöteses $H_{0}: \sum_{i=0}^{d} \alpha_{i}=1$ e $H_{A}: \sum_{i=0}^{d} \alpha_{i}<1$, onde $\alpha_{i}$ são os parâmetros das variāveis independentes.

Nas situações em que foi detectado sentido causal e houve coeficientes de variäveis defasadas significatios, as margens defasadas de comercialização foram também calculadas.

A margem corrente associa preços referentes ao mesmo mês. A margem defasada é calculada de acordo com a anälise de transmissão de preços, utilizando-se o critério de comparar o preço exógeno de maior defa sagem com o preço corrente num outro nível de mercado.

Para a interpretação dos resultados procedeu-se da seguinte forma: (a) a evolução média das margens ao longo de um ano, que analisa o comportamento mensal das margens; (b) evolução anual das margens, que mos tra a tendência das margens ao longo dos anos. 
As margens são calculadas tanto em termos absolutos ( $\mathrm{Cz} \$ / \mathrm{kg}$ ou Cz\$/lata), em valores de dezembro de 1987, como porcentualmente, como proporção do preço do varejo.

Ao se analisar as margens deve-se estar atento para dois aspectos. Primeiro, a sua evolução estacional provavelmente vai indicar um aumento das margens nos meses da safra com redução no período da entres safra. Isso se deve ao fato de que, em geral, os preços aos produtores so frem, na safra, queda proporcionalmente maior do que aos demais níveis de mercado, pois, nesse período, a maior demanda por serviços de comercialização tende a elevar os seus custos. Então, os preços aos produtores diminuirão porque os preços ao varejo cairão com o maior suprimento e tambẻm porque os custos de comercialização estão maiores nessa época. A medida em que os meses passam, tanto os preços ao produtor como ao atacado e varejo tendem a se elevar como decorrência dos custos acumulados de armazenamento. Essa tendência sofre corte abrupto com o advento da nova safra. E preciso reconhecer, no entanto, que o produtor que vende o seu pro duto na entressafra jā está realizando serviços típicos de comercialização como transporte e armazenamento - sendo por isso remunerado pelo acrēs cimo de preço. Como os custos desses serviços tendem a ser maiores nas re giões de produção - devido a problemas no armazenamento, por exemplo - espera-se que os preços ao produtor cresçam mais rapidamente do que aos demais niveis na entressafra. Com isso a margem tende a se reduzir nesse período. Colabora tambëm nesse sentido, o fato de que havendo maior suprimento na entressafra, os preços ao consumidor aumentam enquanto os custos de comercialização se reduzem, face à menor demanda. 
Em segundo lugar, è interessante observar o comportamento das margens ao longo dos anos analisados. Alëm dos possíveis efeitos do volume produzido anualmente e das políticas de preço adotadas, a evolução das margens pode refletir aumento ou diminuição da eficiência na comercialização.

A seguir $\vec{e}$ analisado o comportamento das margens de comercialização. Essa anälise baseia-se em figuras. No Apêndice 2 são apresentados os valores calculados das margens.

\subsubsection{Arroz sem casca}

Na Figura 7 apresenta-se o comportamento dos preços mensais e anuais recebidos pelos produtores de arroz em casca (Estados de São Pau1o, Goiás e Rio Grande do Sul) e o preço no varejo (supermercado/SP) do arroz sem casca. Tanto o preço mensal ao produtor como ao varejo apresentam um comportamento semelhante, com queda no período de safra (março a junho) e aumento no período de entressafra (setembro a janeiro). LOPES (1983) observou que a safra gaücha è colhida de um a dois meses após a safra dos Estados Centrais, permanecendo estāveis os preços daquela região no período de março a outubro, e a partir daí, sofrem uma ascensão até dezembro e janeiro. Os preços anuais, no período de 1973 a 1985, tanto ao produtor como ao varejo mostram uma tendência de queda.

As margens correntes totais de comercialização do arroz sem casca para os Estados de São Paulo, Goiās e Río Grande do Sul, respectivamente, são apresentadas nas Figuras 8 a 10 . Quando a região de produção è o Estado de São Paulo, a margem corrente absoluta mensal varia de 
$\mathrm{Cz} \$ 17,46 / \mathrm{kg}$ a $\mathrm{Cz} \$ 22,53 / \mathrm{kg}$, e a margem porcentual mensal indica que $37,03 \%$ a $46,56 \%$ do preço de varejo são absorvidos no processo de comercialização (Figura 8).

0 arroz oriundo do Estado de Goiàs e Rio Grande do Sul apre senta margens correntes totais de comercialização superiores, quando comparadas à região de produção de São Paulo. Tal diferença pode dever-se, principalmente, ao custo de transporte adicional envolvido no abastecimento do mercado varejista da cidade de São Paulo (Figuras 9 e 10).

As margens mensais de comercialização, quando a região de produção é o Estado de São Paulo ou Goiās, apresentam uma estacionalidade bem definida, com aumento no período de safra e diminuição na entressafra. Tal diferença safra/entressafra gira em torno de 20\%. Quando a região de produção é o Estado do Rio Grande do Sul, o comportamento das margens é diferente dos Estados Centrais, pois diminuem no período de safra e aumentam na entressafra.

$\mathrm{Na}$ anālise das margens anuais de comercialização, pode-se dizer que hã evidências de um comportamento bastante similar, quando são comparadas as três regiões de produção. Ocorre uma queda no final da dëcada de 70 , e a partir daí, inicia-se uma fase de ascensão. 


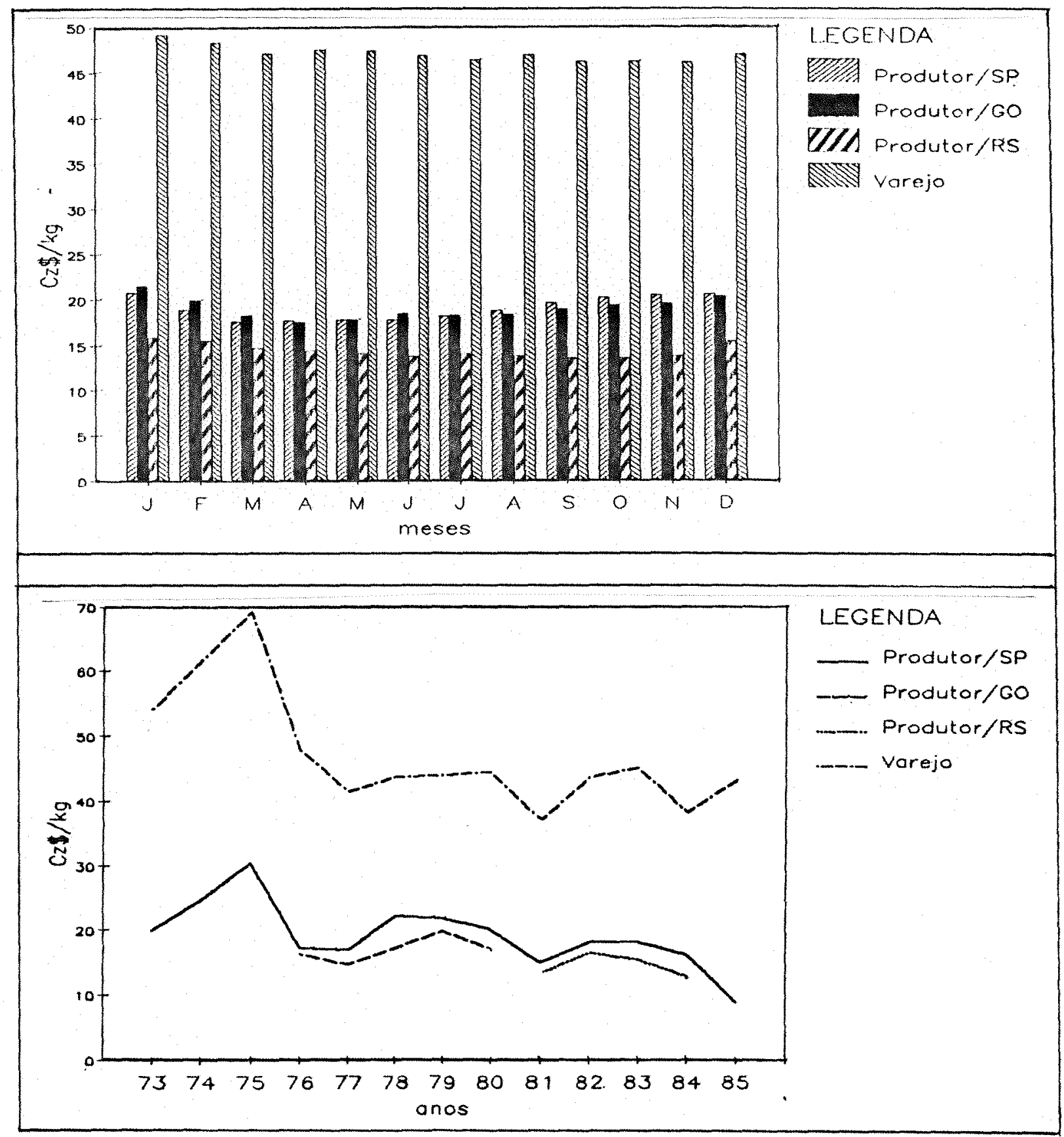

Figura 7 - Preço médio mensal e anual do arroz em casca ao produ tor e do arroz sem casca no varejo/SP, em Cz\$ de Dez/1987, no período 1973 a 1985 . 


\section{I - MARGEM MENSAL}

(a) absoluta*

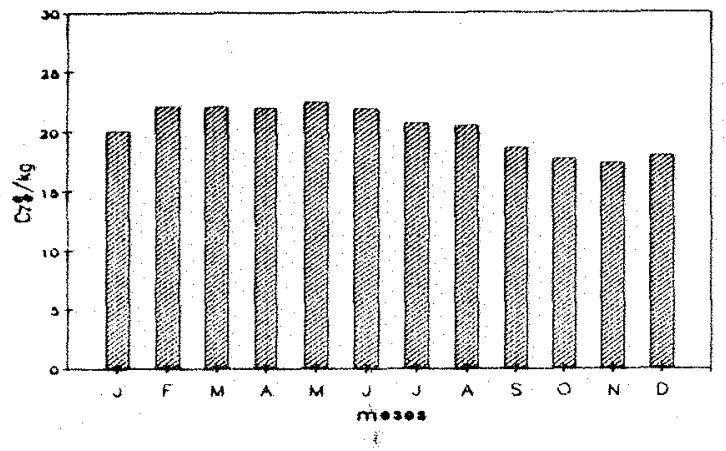

(1) porcentual

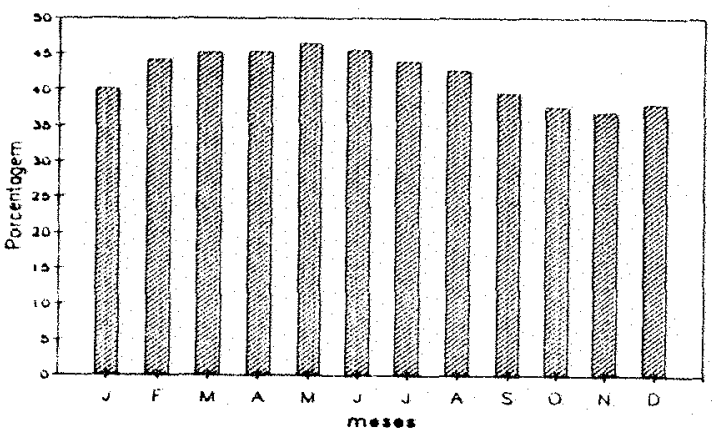

II- MARGEM ANUAL

(a) absoluta*

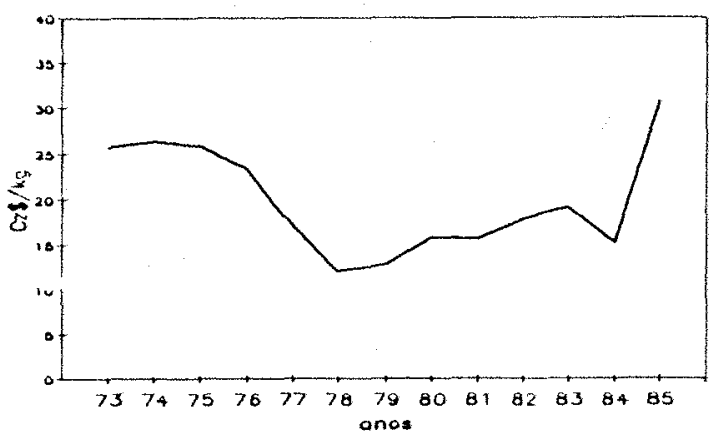

(b) porcentual

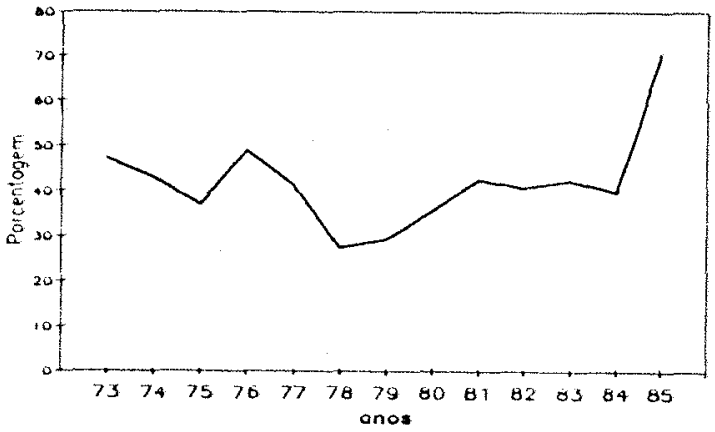

(*) valor real em $\mathrm{Cz} \$(\operatorname{Dez} / 87)$

Figura 8 - Margem corrente total de comercialização do arroz sem casca, tendo como região de produção o Estado de São Paulo (DIRAs de são José do Rio Preto e Ri beirão Preto), no periodo 1973 a 1985. 
I- MARGEM MENSAL

(a) absoluta*

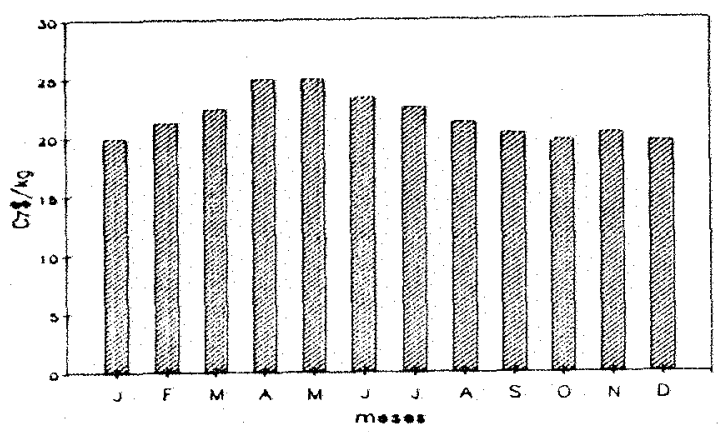

(1) juroentual

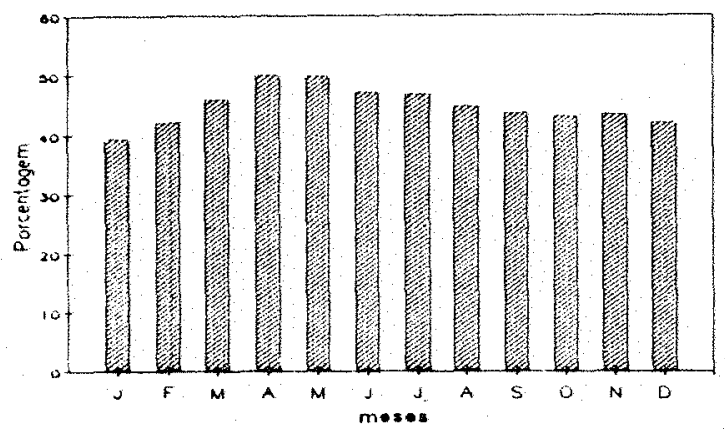

II- MARGEM ANUAL

(a) absoluta*

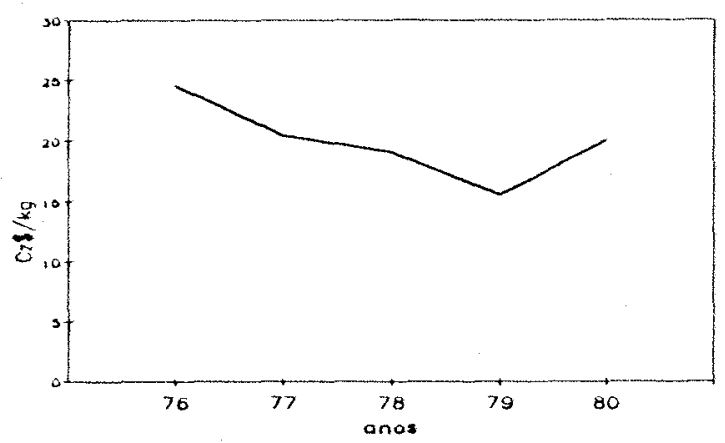

(b) porcentual

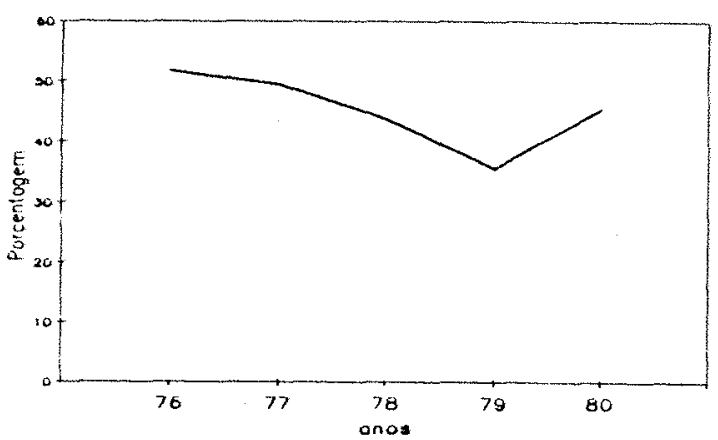

(*) valor real em Cz\$(Dez/87)

Figura 9 - Margem corrente total de comercialização do arroz sem casca, tendo como região de produção o Estado de Goiás, no período $1976 / 1980$. 


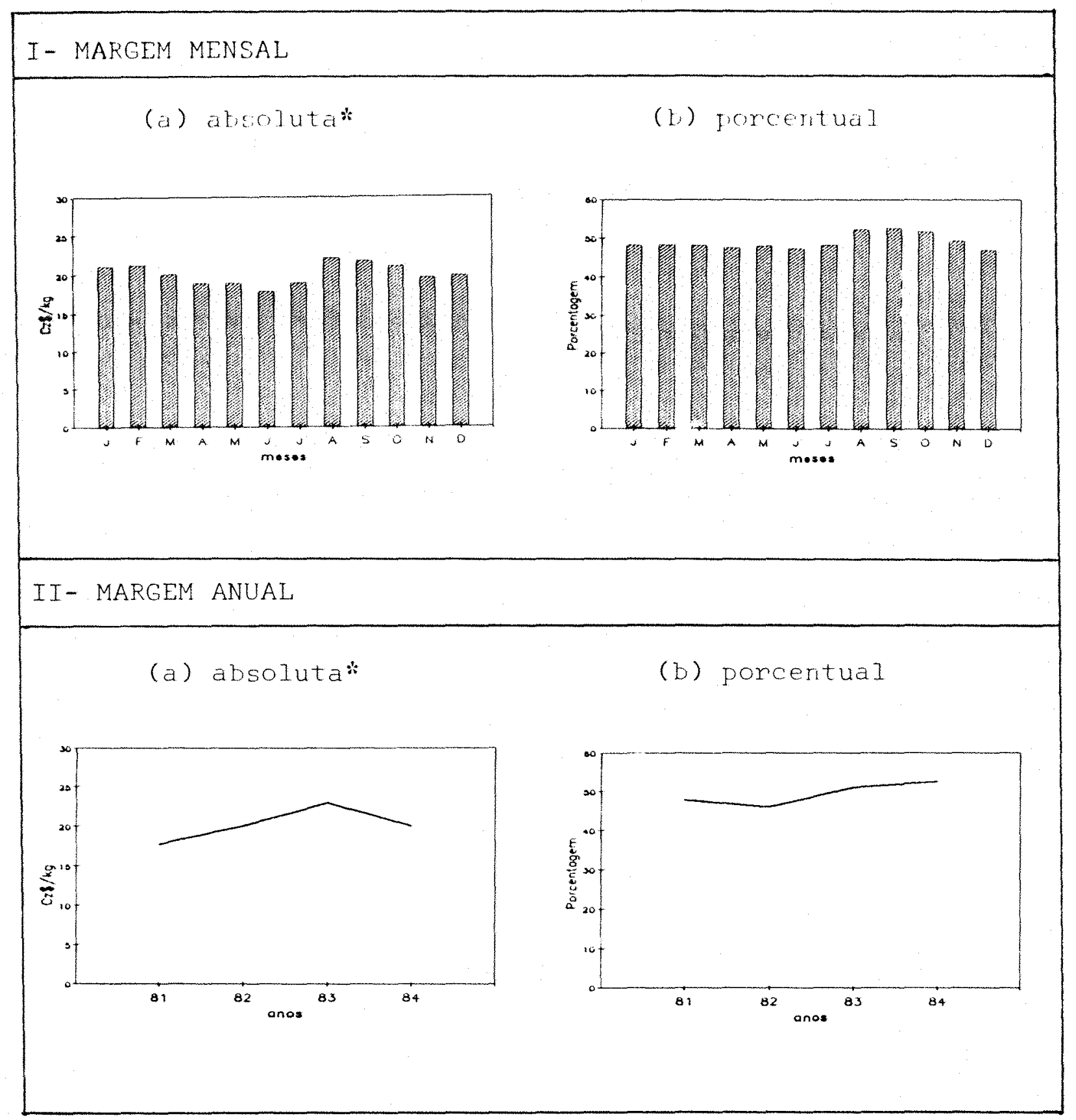

(*) valor real em Cz\$(Dez/87)

Figura 10 - Margem corrente total de comercialização do arroz sem casca, tendo como região de produção o Estado do Rio Grande do Sul, no período 1981 a 1984. 
Das regiões analisadas, apenas os preços do arroz goiano e ao varejo apresentaram significância no teste de causalidade. Utilizandose a Tabela 7, observa-se que o parâmetro da variāvel independente e menor do que 1 , a níve1 de significância de $5 \%$, indicando que a margem corrente porcentual total ( $\left.\mathrm{MC}^{\prime}\right)$ e os preços a nível de produtor $\left(\mathrm{Pa}_{t}\right)$ variam em sen tido conträrio. Tal fato pode ser evidenciado utilizando-se as Figuras 7 e 9 (b), pois na safra ocorre uma queda no preço ao produtor e a margem men sal aumenta, e em 1979 ocorre um aumento no preço ao produtor e a margem anual diminuiu. Com relação ao comportamento da margem corrente absoluta total (MC) e o preço ao produtor $\left(\mathrm{Pa}_{t}\right)$, observa-se que a diferença da margem porcentual com a unidade $\left(1-M C^{\prime}\right)$, considerando que a margem porcentual gira em torno de 0,45 , será 0,55 . Portanto, utilizando-se o teste $t$ de Student observa-se, a nível de significância de 5\%, que $\alpha_{0}<0,55$, ou seja, a margem absoluta (MC) e o preço ao produtor $\left(\mathrm{Pa}_{t}\right)$ variam em sentido conträrio. Utilizando-se as Figuras 7 e 9 (a) tem-se que na safra ocorre uma queda nos preços ao produtor e a margem absoluta mensal aumenta. Em 1979 o aumento do preço ao produtor é acompanhado pela diminuição da margem corrente absoluta anual.

\subsubsection{Fubä mimoso}

As regiões de abastecimento de milho em grão para o. fubá mimoso são os Estados de São Paulo (DIRAs de Ribeirão Preto e Sorocaba), Paraná e Minas Gerais. Na Figura 11 apresenta-se a evolução dos preços mensais e anuais recebidos pelos produtores de milho em grão e no varejo (supermercado/SP) do fụbā mimoso. 


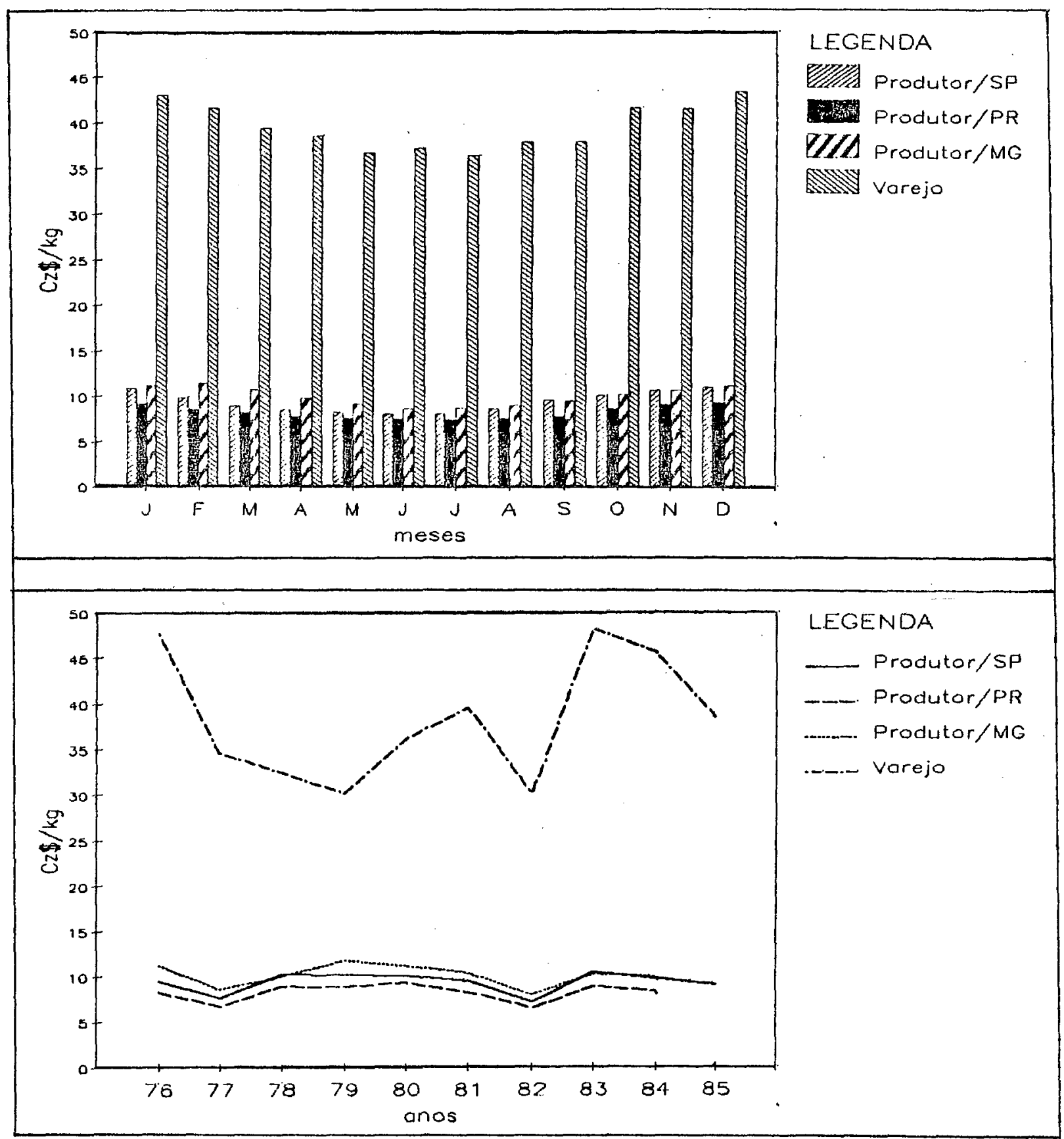

Figura 11 - Preço médio mensal e anual do milho em grão ao prodü tor, e do fubá mimoso no varejo/SP, em $\mathrm{Cz} \$$ de Dez/1987, no período 1976 a 1985 . 
Nas Figuras 12, 14 e 15 apresentam-se as margens correntes totais de comercialização do fubá mimoso. Considerando-se o Estado de São Paulo como região de produção, as margens correntes absolutas mensais variam de $\mathrm{Cz} \$ 25,86 / \mathrm{kg}$ a $\mathrm{Cz} \$ 30,46 / \mathrm{kg}$, e as margens correntes porcentuais mensais de $68,82 \%$ a $73,33 \%$. Quando as regiões de produção são os Estados do Paraná e Minas Gerais, tanto as margens correntes absolutas como as porcentuais apresentam-se superiores quando comparadas às margens de São Paulo. Esta diferença pode ser explicada, principalmente, pelo custo de transporte adicional envolvido para abastecer o mercado varejista.

A magnitude maior das margens do fubá mimoso estả relacionada ao nível de processamento na cadeia de comercialização.

A margem corrente absoluta mensa1, em todos os casos, apresenta um comportamento semelhante, ou seja, diminue no período de safra, e aumenta na entressafra. A diferença relativa entre as margens correntes da safra e entressafra encontra-se em torno de $17,0 \%$, quando a região de produção é São Paulo e $27,5 \%$, quando a região de produção é o Paranā ou Minas Gerais.

A margem corrente porcentual mensal apresenta um comportamento diferente da margem absoluta, uma certa estabilidade e ligeiro aumento no período de safra, e uma diminuição na entressafra.

As margens correntes absolutas anuais apresentam uma tendên cia semelhante, considerando-se as várias regiões de produção, diminuindo de 1976 a 1979, e a partir daí, aumentam até 1983. 


\section{I- MARGEM MENSAL}

(a) absoluta*

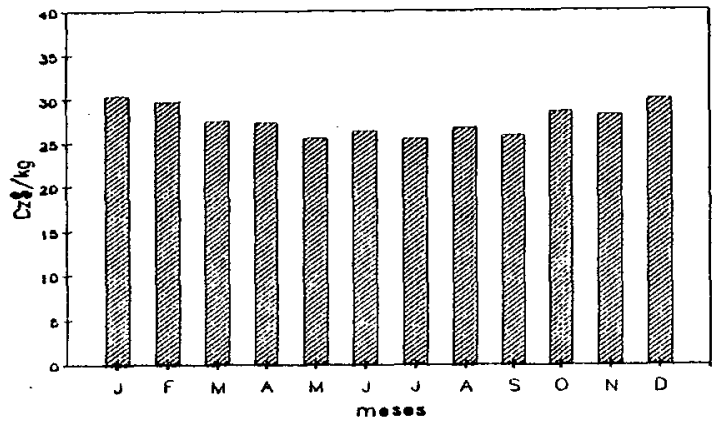

(L) porceritual

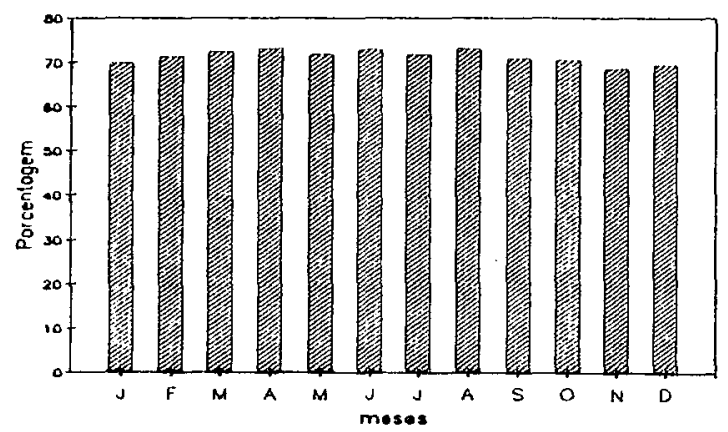

II- MARGEM ANUAL

(a) absoluta*

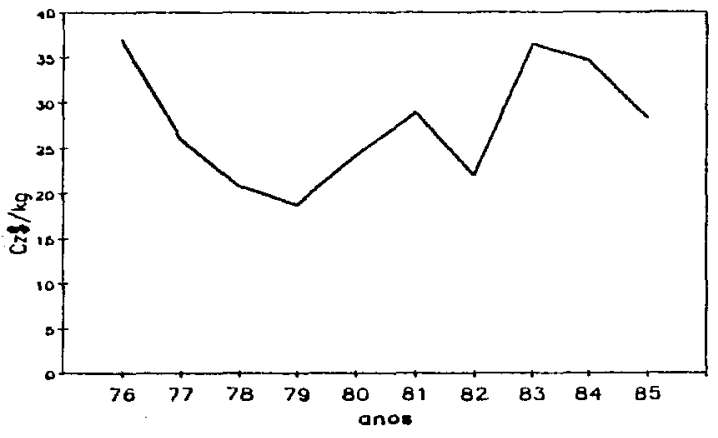

(b) porcentual

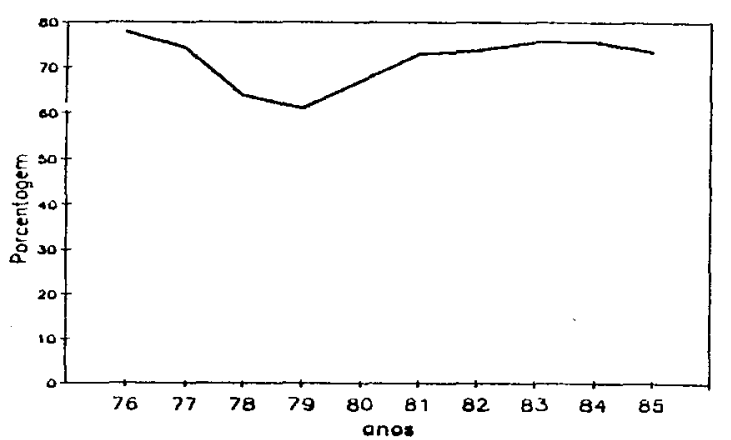

(*) valor real em Cz\$(Dez/87)

Figura 12 - Margem corrente total de comercialização do fubá mimoso, tendo como região de produção o Estado de São Paulo (DIRAs Ribeirão Preto e Sorocaba), no período 1976 a 1985 . 


\section{I- MARGEM MENSAL}

(a) absoluta*

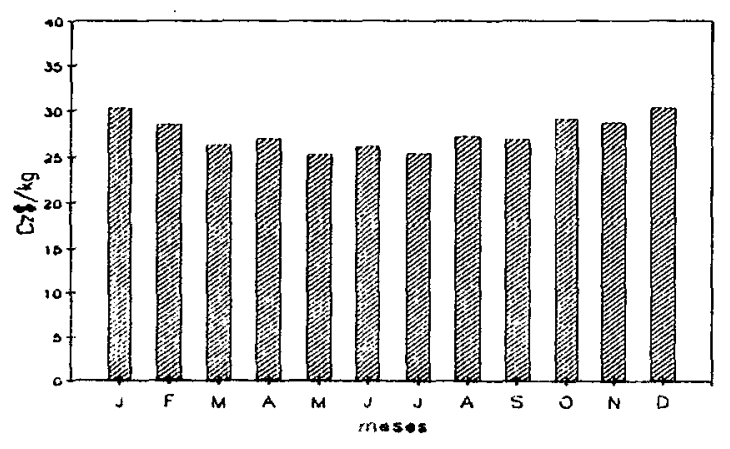

(b) poncestual

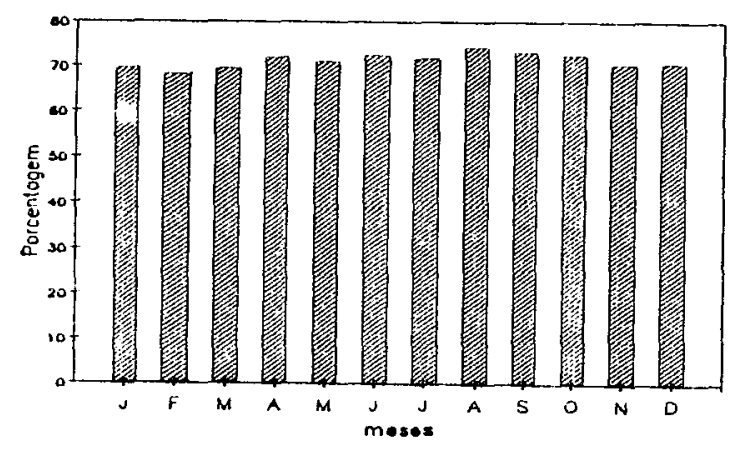

II- MARGEM ANUAL

(a) absoluta*

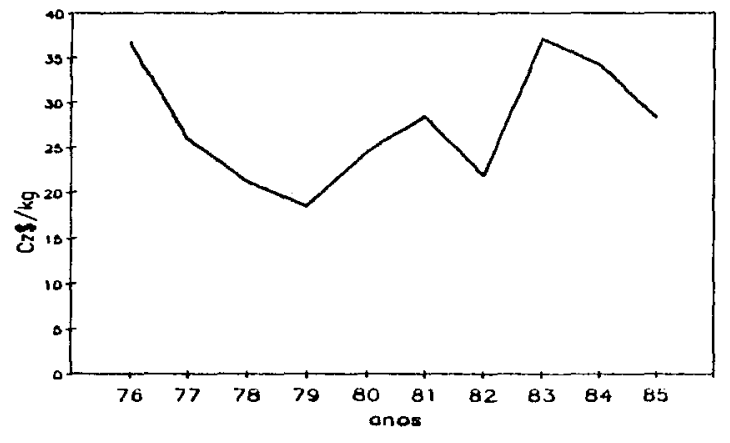

(b) porcentual

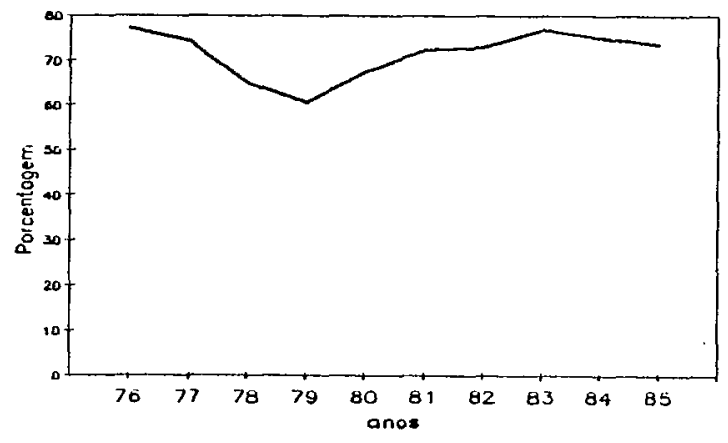

(*) valor real em Cz\$(Dez/87)

Figura 13 - Margem defasada (preço ao produtor defasado de 01 mês) total de comercialização do fubá mimoso, ten do como região de produção o Estado de São Paulo, no período 1976 a 1985 . 


\section{I- MARGEM MENSAL}

(a) absoluta*

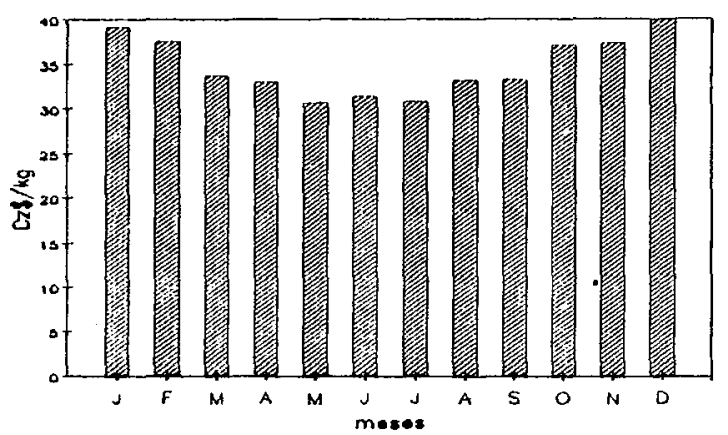

(L) porcestual

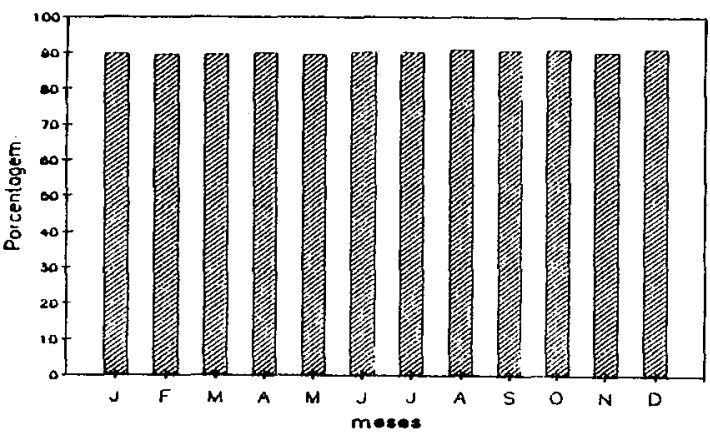

II- MARGEM ANUAL

(a) absoluta*

(b) porcentual
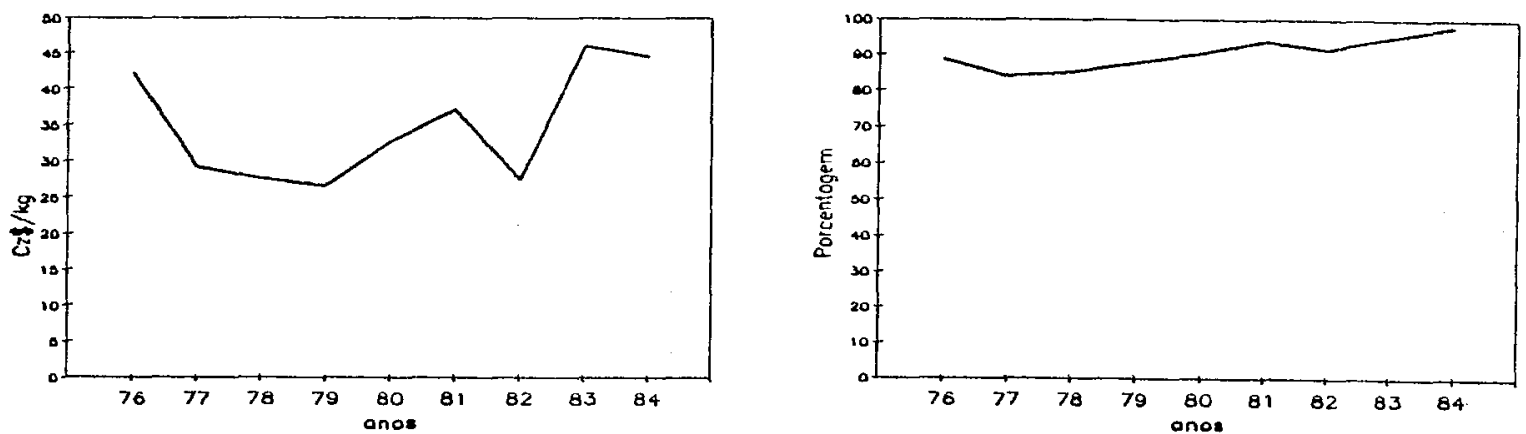

(*) valor real em Cz\$(Dez/87)

Figura 14 - Margem corrente total de comercialização do fubá mimoso, tendo como região de produção o Estado do Paraná, no período 1976 a 1984. 


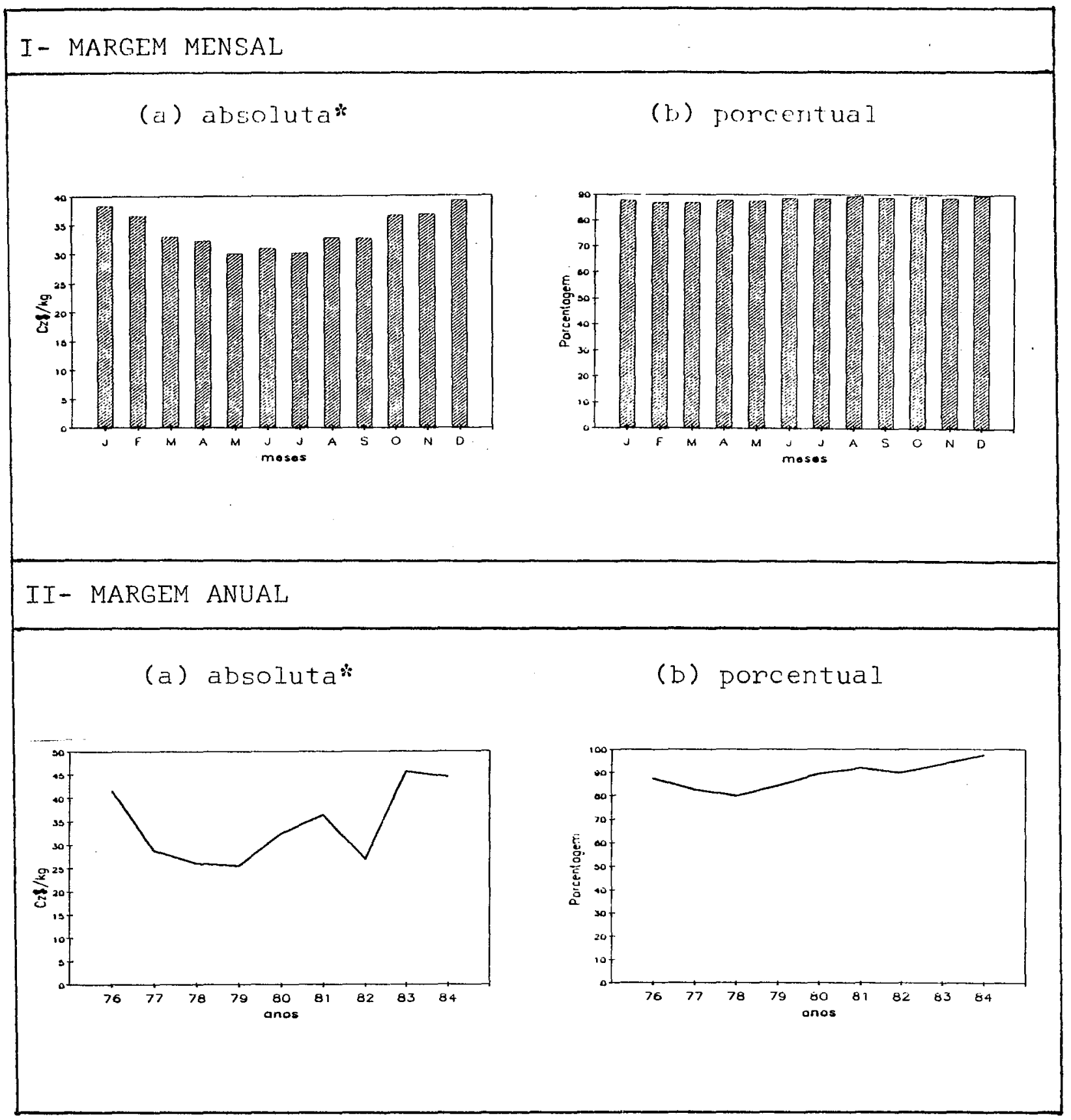

(*) valor real em Cz\$(Dez/87)

Figura 15 - Margem corrente total de comercialização do fubá mimoso, tendo como região de produção o Estado de Minas Gerais, no período 1976 a 1984. 
Nas anālises de causalidade, entre os preços ao produtor de milho em grão e ao varejo do fubā mimoso apresentaram-se, em todos os casos, unidirecional do produtor para o varejo. Das equações de transmissão analisadas, a ünica que apresenta defasagem significativa foi entre o milho em grão de São Paulo e o varejo $(\mathrm{d}=1)$. Assim sendo, ana1isa-se o comportamento da margem defasada (Figura 13), que mostra-se semeThante à respectiva margem corrente de comercialização.

$\mathrm{Na}$ tentativa de se observar o comportamento das margens por centuais ( $M C^{\prime}$ e $M^{\prime} d$ ) e eventuais oscilações nos preços ao produtor ( $\mathrm{Pa}_{t}$ ), constata-se inicialmente (Tabelas 8 e 10), que a somatōria dos parâmetros das variāveis independentes são, em todos os casos, menores que 1 , a nível de significância de $5 \%$, ou seja, a margem porcentual e o preço variam em sentido contrário, aumentando as margens porcentuais na safra e diminuindo na entressafra. Tal anālise pode ser evidenciada observando-se as Figuras $11,12(b), 13(b), 14(b)$ e $15(b)$.

Com relação às margens absolutas (MC e Md) e o preço ao produtor $\left(\mathrm{Pa}_{t}\right)$, analisou-se o comportamento da diferença da margem porcentual com a unidade $(1$ - MC'). Com exceção do parâmetro da variável independente $\left(\alpha_{0}\right)$ da Tabela 8 , todos ${ }^{-}$os outros casos apresentaram $\sum_{i=0}^{d} \alpha_{i}>\left(1-M^{\prime} d\right)$ e $\alpha_{o}>\left(1-M^{\prime}\right)$, levando a concluir que a margem absoluta $i=01$ e o preço ao produtor variam no mesmo sentido, ou seja, na safra a margem absoluta diminue, e na entressafra aumenta. Isto pode ser observado nas Figuras 11, 13(a), 14(a) e 15(a). No caso do parâmetro da variável independente não defasada $\left(\alpha_{0}\right)$ da Tabela 8 , observa-se, a nível de significância de 5\%, que $\alpha_{0}=\left(1-M C^{\prime}\right)$, ou seja a margem absoluta não varia com a 
variação no preço ao produtor. Entretanto, tal fato não foi evidenciado visualmente com a utilização das Figuras 11 e $12(a)$.

\subsection{3. óleo de soja}

Nas Figuras 16 e 17 apresentam-se os preços médios mensais e anuais recebidos pelos produtores de soja em grão, e do óleo de soja refinado enlatado no atacado e varejo (supermercado) da cidade de São Paulo. Os Estados de São Paulo, Mato Grosso/Mato Grosso do Sul e Minas Gerais foram considerados como regiões produtoras de soja em grão, que abastecem os mercados atacadistas e varejistas. $\overrightarrow{\mathrm{E}}$ importante salientar, que o mercado a nível de atacado utilizado neste trabalho, não $\bar{e}$ parte integrante indispensāvel na cadeia de comercialização do óleo de soja para o supermercado/SP, pois uma grande parte deste equipamento varejista adquire o seu pro duto, diretamente, do parque agroindustrial moageiro do Estado de São Pau1o. Entretanto, dada a disponibilidade de informações neste nível de mercado, os dados foram utilizados na tentativa de se estudar, indiretamente, o comportamento das margens no mercado atacadista e varejista.

A soja produzida no Brasil não é utilizada apenas para o abastecimento do mercado interno, mas também para o mercado externo, na forma de grão, óleo e farelo de soja. Desta forma, o preço a vigorar no mercado interno depende do comportamento da safra nacional (abril a junho) e da safra americana (setembro a novembro), que é o principal produtor e exportador mundial. Assim, poderão ocorrer periodos em que os preços reais praticados aos produtores brasileiros, durante o período de safra'são superiores aos da entressafra. 


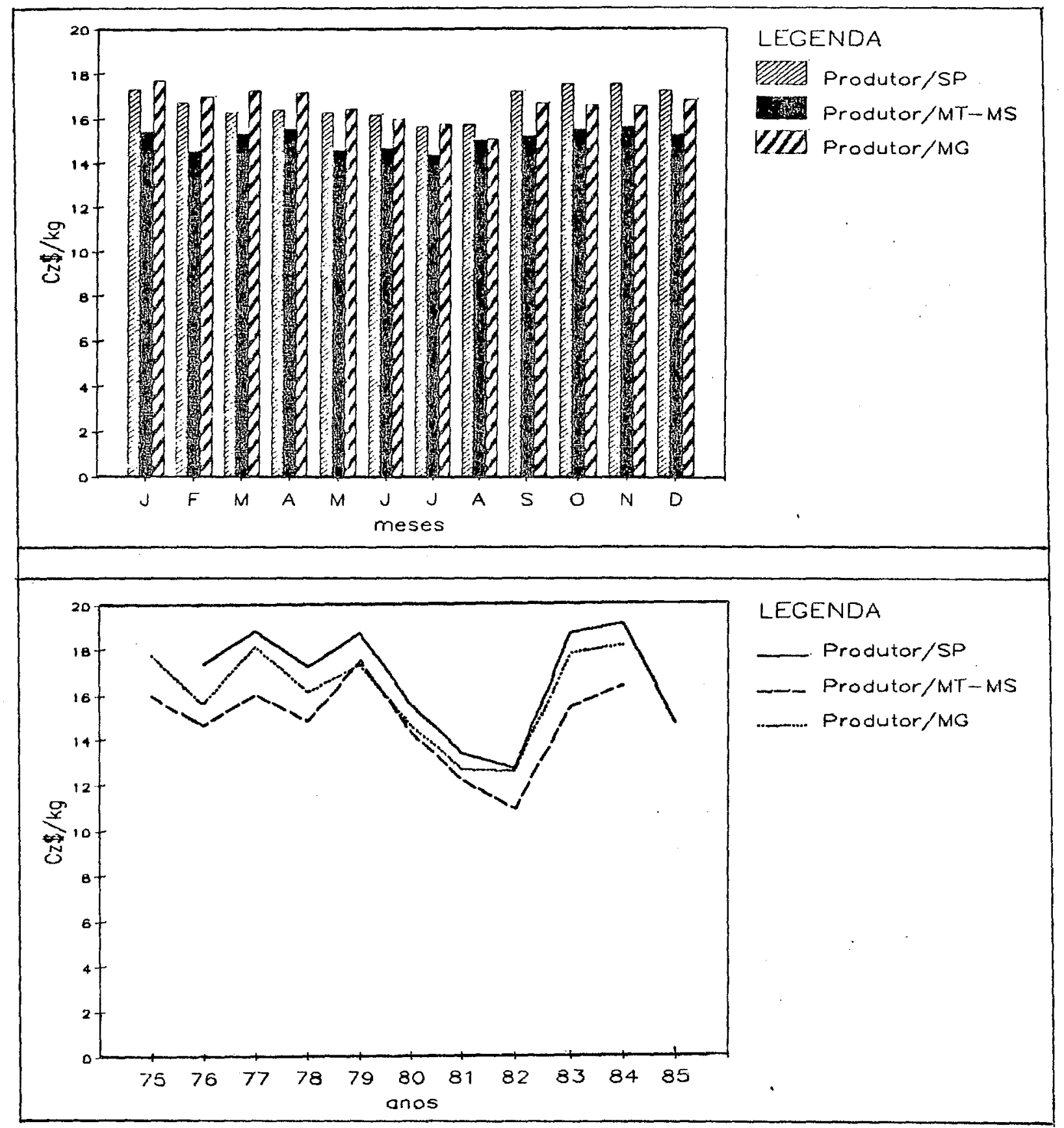

Figura 16 - Preço mëdio mensal e anual da soja em grão ao produ tor, em Cz\$ de Dez/1987, no período 1975 a 1985 . 


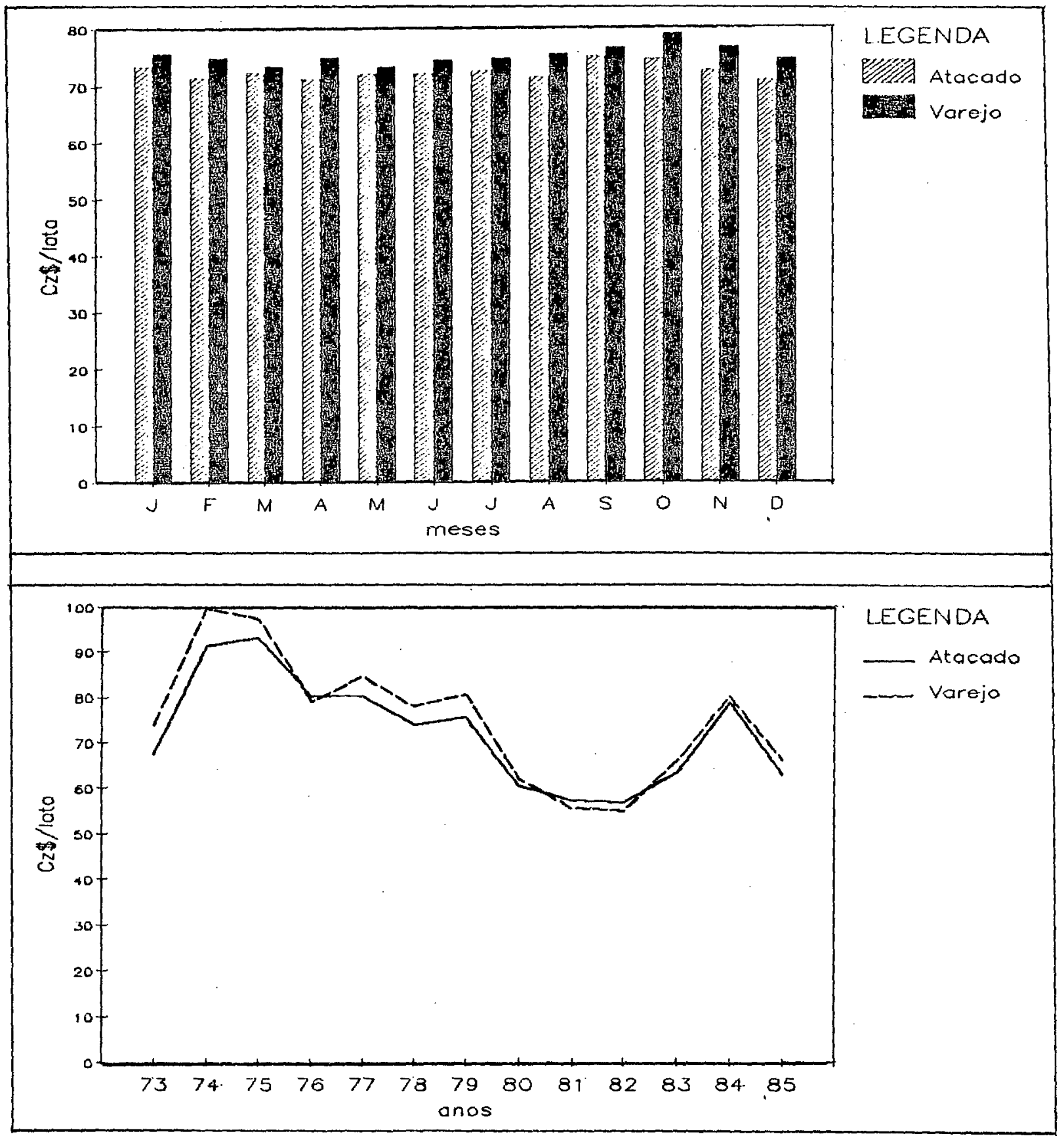

Figura 17 - Preço médio mensal e anual do öleo de soja refinado enliatado ( $900 \mathrm{ml}$ ) no atacado/SP e varejo/sP, em Cz\$ de Dez/1987, no período 1973 a 1985. 
As margens do varejo, atacado e total de comercialização do ōleo de soja são apresentadas nas Figuras 18 a 27.

As margens mensais apresentam de uma forma geral uma sazonalidade, sendo menores no período de safra e maiores na entressafra. A margem corrente absoluta mensal do varejo varia entre $\mathrm{Cz} \$ 0,73 /$ ata a $\mathrm{C} z \$ 4,93 /$ lata, ou seja, em torno de $3 \%$ do preço de varejo são absorvidos no mercado varejista (Figura 18). A margem corrente mensal do atacado varia conforme a região de produção. Quando o Estado de São Paulo abastece o mercado atacadista, a margem situa-se entre $\mathrm{Cz} \$ 12,47 /$ lata a Cz\$20,33/1ata, ou seja, ao redor de $24,46 \%$ do preço de varejo são absorvidos pelo atacado (Figura 20). Quando a região de produção é o Estado de Minas Gerais e Mato Grosso/Mato Grosso do Sul a margem corrente porcentual mensal do atacado situa-se em torno de $29,40 \%$ e 34,73\%, respectivamente (Figuras 21 e 22).

A margem corrente mensal total de comercialização do óleo de soja, quando a região de produção é o Estado de São Paulo situa-se ao redor de Cz\$20,90/lata e 27,71\%, conforme Figura 25. Nas Figuras 26 e 27 são apresentadas as margens correntes totais, considerando como regiões de produção os Estados de Mato Grosso/Mato Grosso do Sul e Minas Gerais, respectivamente.

A anālise de causalidade entre preços apresentou-se unidirecional do produtor (SP e MT/MS) para o atacado, e deste para o varejo: o preço recebido pelo produtor do Estado de Minas Gerais e ao atacado apre sentou causalidade bidirecional. Na anālise de transmissão de preços do atacado para o varejo, a defasagem d=6 é significativa. Então, analisa-se 
o comportamento da margem defasada do varejo, que varia em torno de Cz\$ $1,47 /$ lata e $0,15 \%$ do preço de varejo, apresentando-se negativa no período de safra e positiva na entressafra (ver Figura 19).

Tendo em vista a ocorrência de causalidade bidirecional entre os preços ao produtor de Minas Gerais e ao atacado e sendo significativa a defasagem $d=1$, calcula-se o comportamento da margem defasada do atacado de comercialização, tendo inicialmente o preço ao produtor defasado (Figura 23) e posteriormente o preço ao atacado defasado (Figura 24).

Utilizando-se a Tabela 11 e Figuras 17, 18 e 19, observase o comportamento das margens do varejo, quando ocorre uma variação no preço ao atacado. Tem-se, a nível de significância de $5 \%$, que $\sum_{i=0}^{6} \alpha_{i}=1$, ou seja, a margem defasada porcentual do varejo (MV'd) não se altera quando ocorre uma variação no preço defasado ao atacado $\left(\mathrm{Pc}_{\mathrm{t}-6}\right)$, e $\alpha_{0}<1$, significando que a margem corrente do varejo (MV') varia em sentido contrário ao do preço ao atacado $\left(\mathrm{Pc}_{\mathrm{t}}\right)$. Na análise da margem absoluta com o preço ao atacado, observa-se que $\sum_{i=0} \alpha_{i}=\left(1-\mathrm{MV}^{\prime} \mathrm{d}\right)$, evidenciando que a margem defasada absoluta (MVd) não varia quando o preço defasado ao atacado $\left(\mathrm{Pc}_{\mathrm{t}-6}\right)$ variar, e $\alpha_{\mathrm{o}}<\left(1-\mathrm{MV}^{\prime}\right)$, ou seja, a margem corrente absoluta (MV) varia em sentido contrário ao do preço ao atacado $\left(\mathrm{Pc}_{\mathrm{t}}\right)$.

Com base nas Tabelas 12 e 13 e Figuras 16,20 e 21, observa-se que $\alpha_{0}<1$ e $\alpha_{0}<\left(1-M A^{\prime}\right)$, ou seja, tanto a margem corrente porcentual do atacado (MA'), como a margem absoluta (MA) variam em sentido conträrio ao do preço ao produtor $\left(\mathrm{Pa}_{t}\right)$. 


\section{I- MARGEM MENSAL}

(a) absoluta*

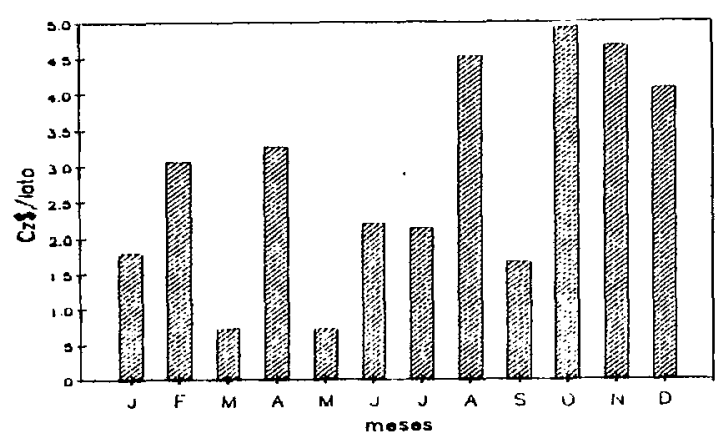

(1) porcestual

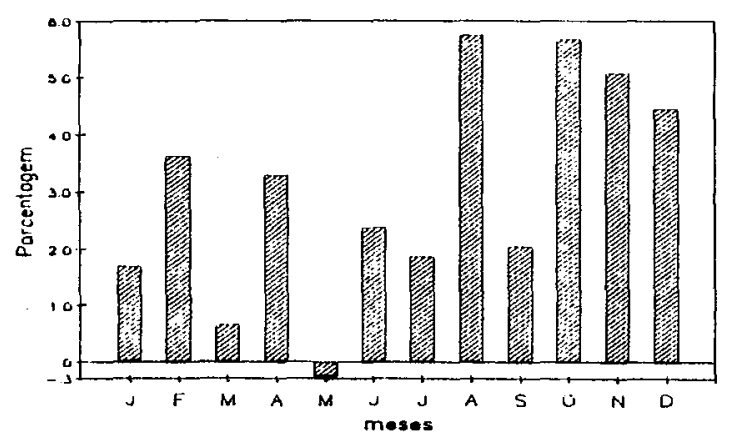

\section{II- MARGEM ANUAL}

(a) absoluta*

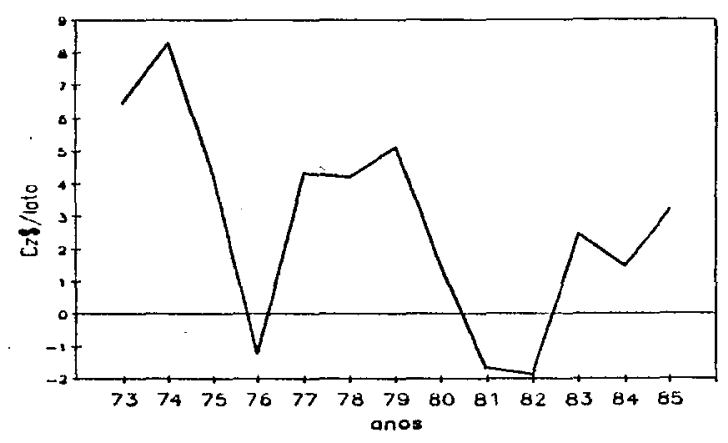

(b) porcentual

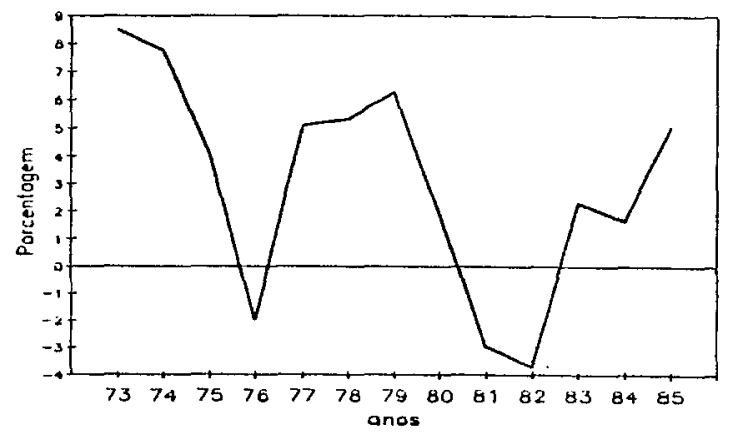

(*) valor real em Cz\$(Dez/87)

Figura 18 - Margem corrente do varejo de comercialização do óleo de soja, no período de 1972 a 1985. 


\section{I - MARGEM MENSAL}

(a) absoluta*

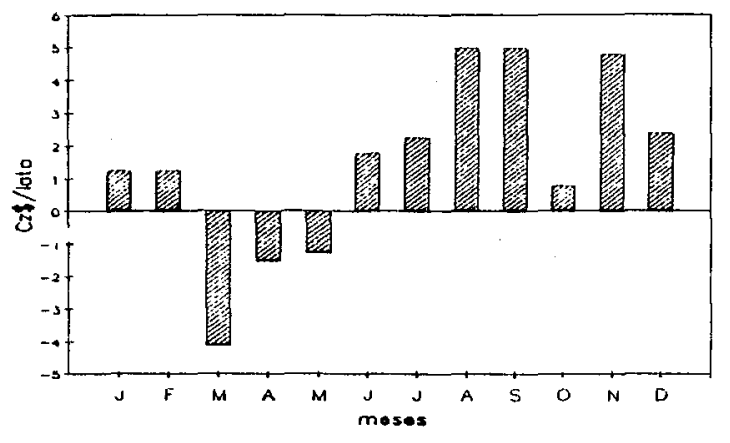

(b) porceritual

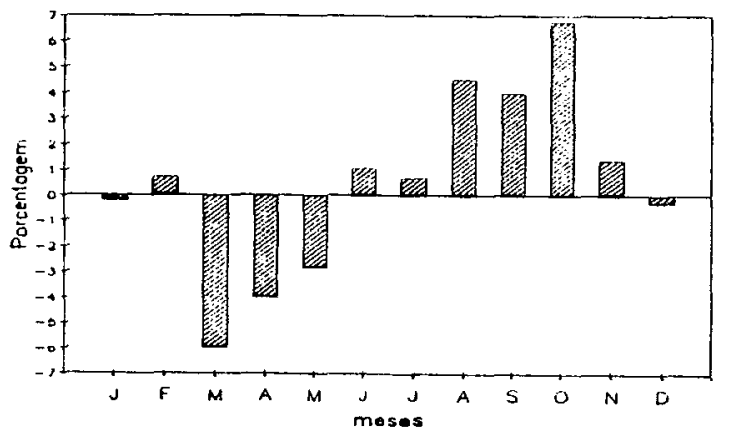

\section{II- MARGEM ANUAL}

(a) absoluta*

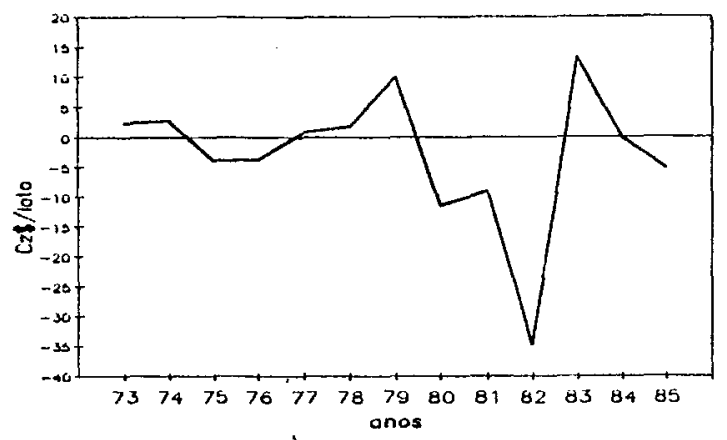

(b) porcentual

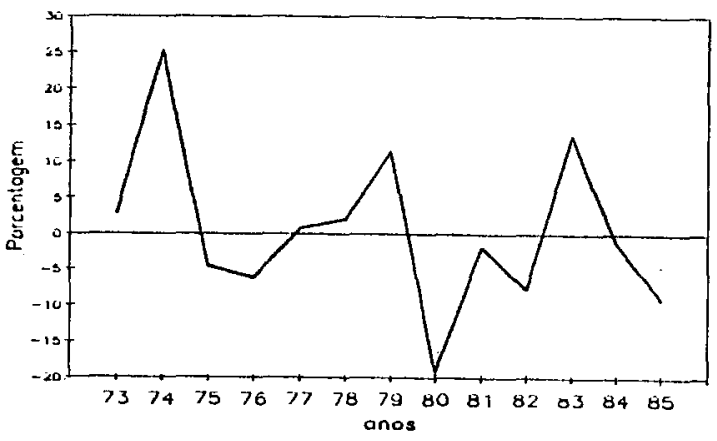

(*) valor real em Cz\$(Dez/87)

Figura 19 - Margem defasada (preço ao atacado defasado de 06 me ses) do varejo de comercialização do óleo de soja, no período 1973 a 1985 . 


\section{I - MARGEM MENSAL}

(a) absoluta*

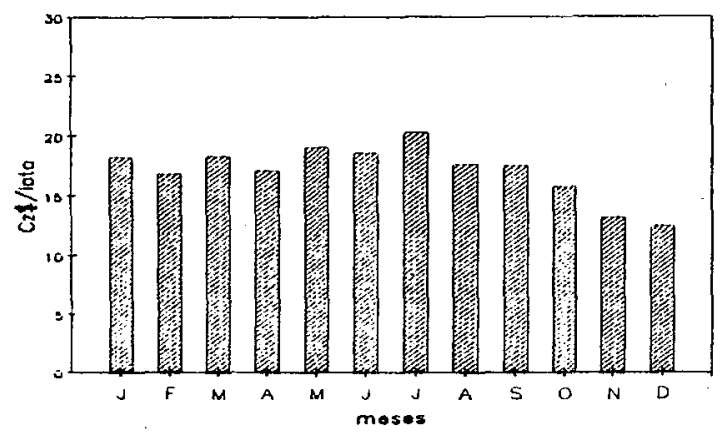

(b) porceritual

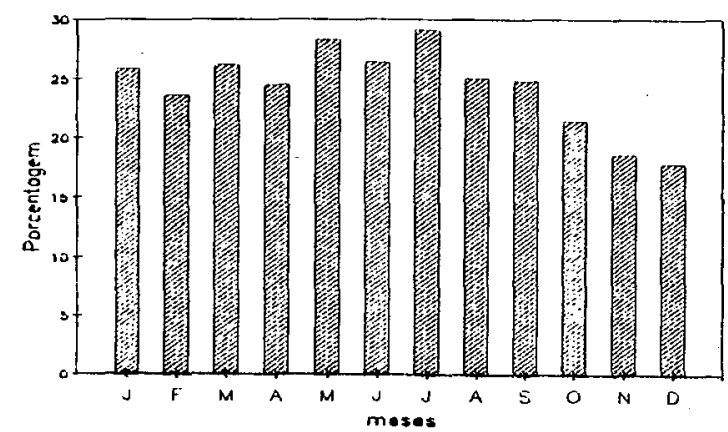

II- MARGEM ANUAL

(a) absoluta*

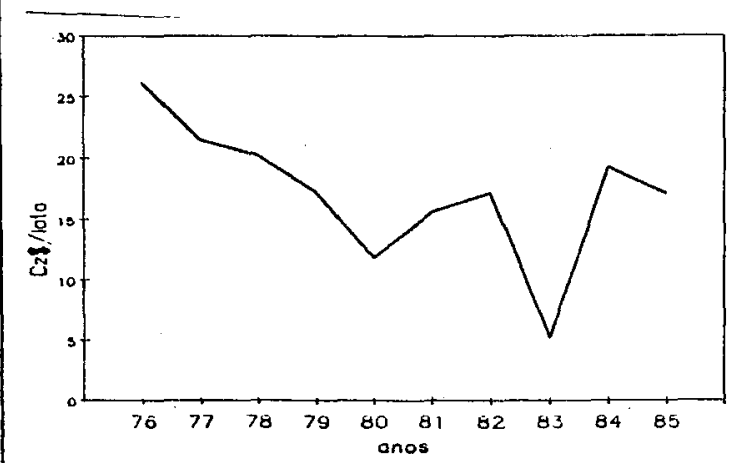

(b) porcentual

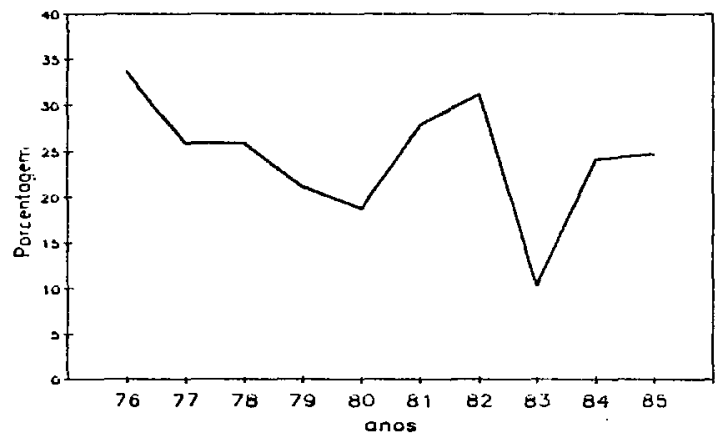

(*) valor real em Cz\$(Dez/87)

Figura 20 - Margem corrente do atacado de comercialização do óleo de soja, tendo como região de produção o Es tado de São Paulo (DIRAs de Marília e Ribeirão Preto), no período 1976 a 1985. 


\section{I- MARGEM MENSAL}

(a) absoluta*

(b) porcentual
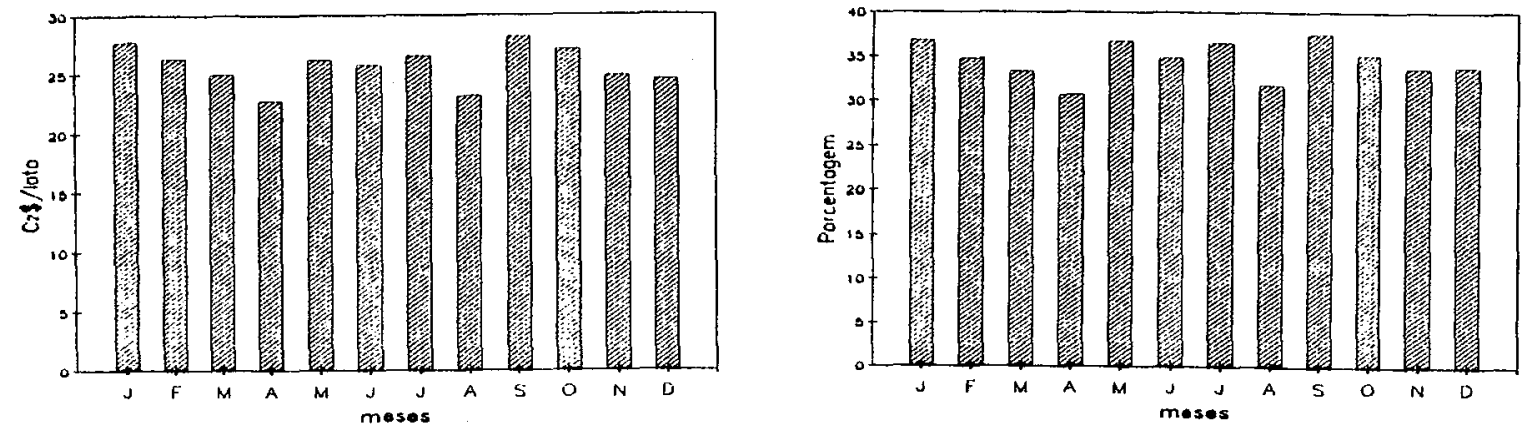

II- MARGEM ANUAL

(a) absoluta*

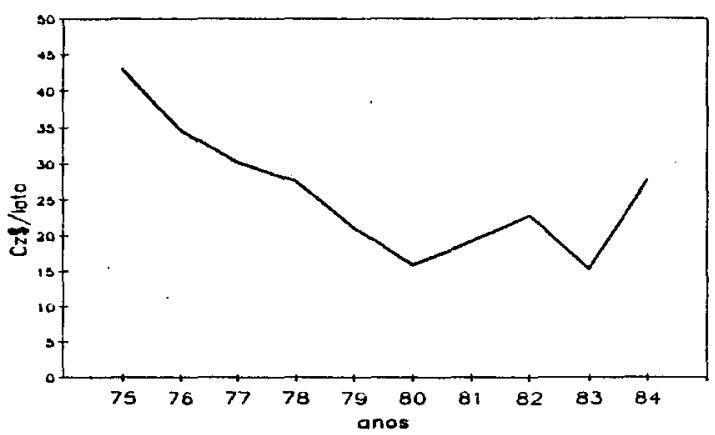

(b) porcentual

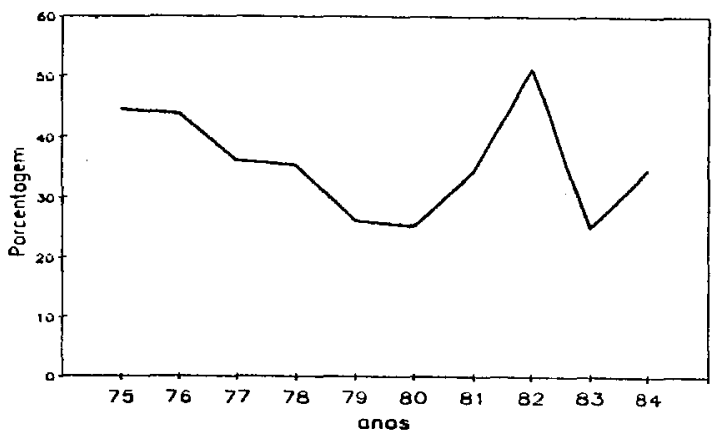

(*) valor real em Cz\$(Dez/87)

Figura 21 - Margem corrente do atacado de comercialização do óleo de soja, tendo como região de produção o Esta do de Mato Grosso/Mato Grosso do Sul, no período de 1975 a 1984. 


\section{I- MARGEM MENSAL}

(a) absoluta*

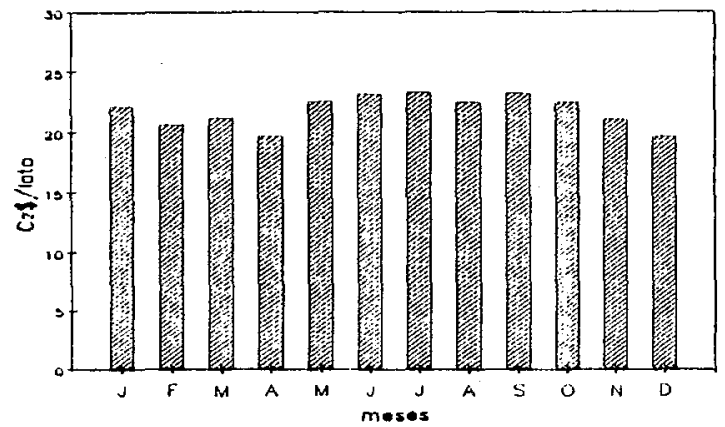

(1) porcentual

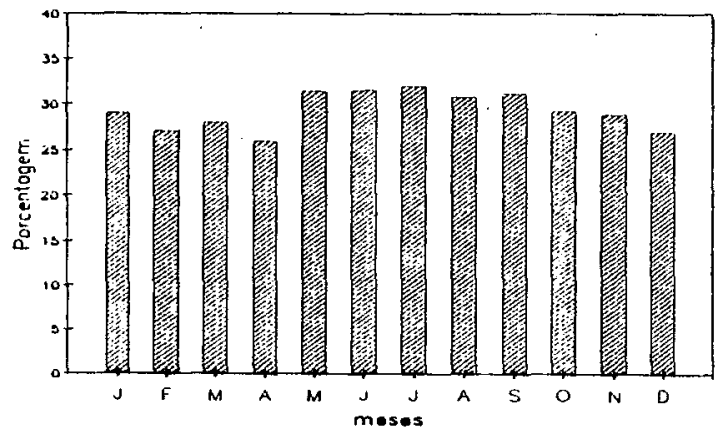

II- MARGEM ANUAL

(a) absoluta*

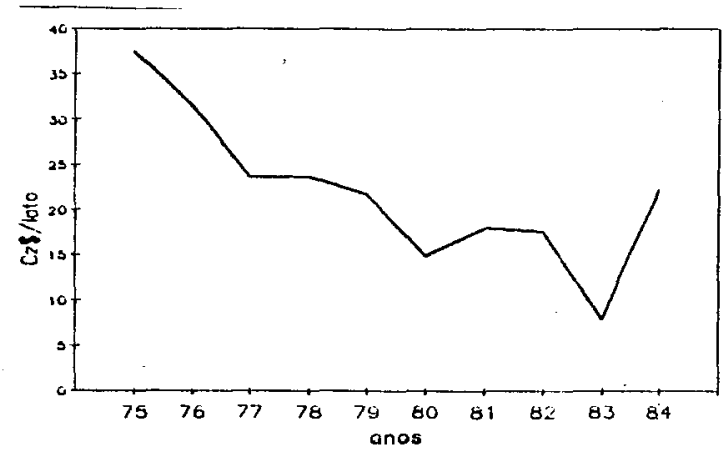

(b) porcentual

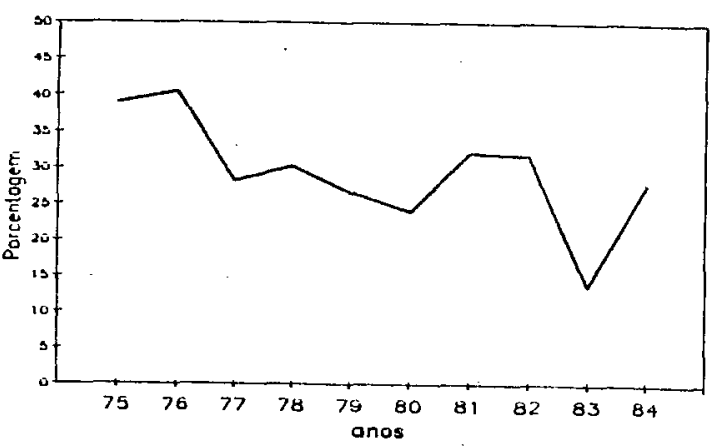

(*) valor real em Cz\$(Dez/87)

Figura 22 - Margem corrente do atacado de comercialização do óleo de soja, tendo como região de produção o Es tado de Minas Gerais, no período 1975 a 1984. 


\section{I- MARGEM MENSAL}

(a) absoluta*

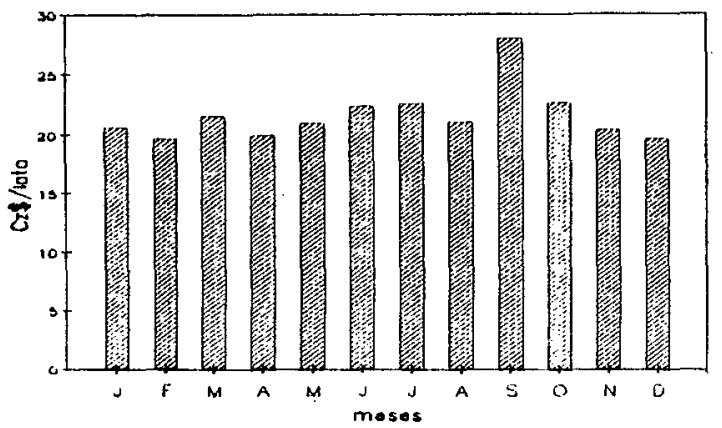

(b) jorceritual

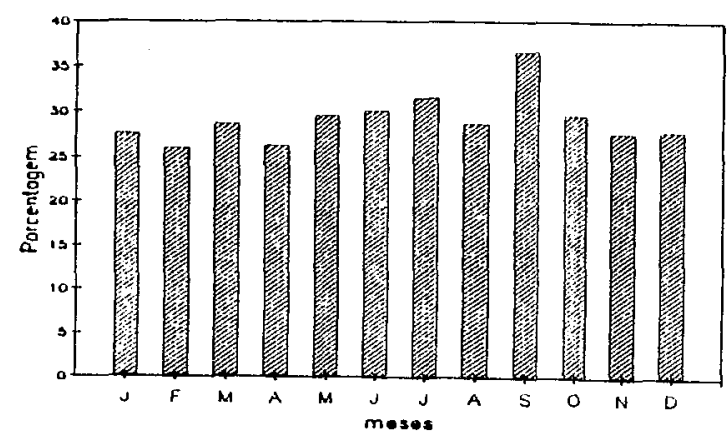

II- MARGEM ANUAL

(a) absoluta*

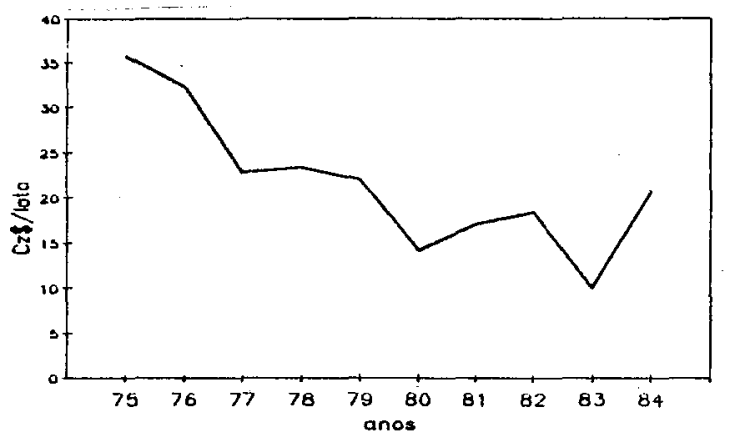

(b) porcentual

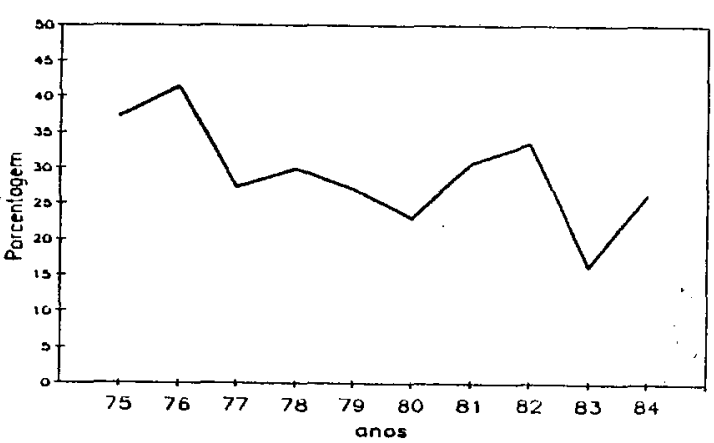

(*) valor real em Cz\$(Dez/87)

Figura 23 - Margem defasada (preço ao produtor defasado de 01 mês) do atacado de comercialização do óleo de so ja, tendo como região de produção o Estado de Mi. nas Gerais, no periodo 1975 a 1984. 


\section{I - MARGEM MENSAL}

(a) absoluta*

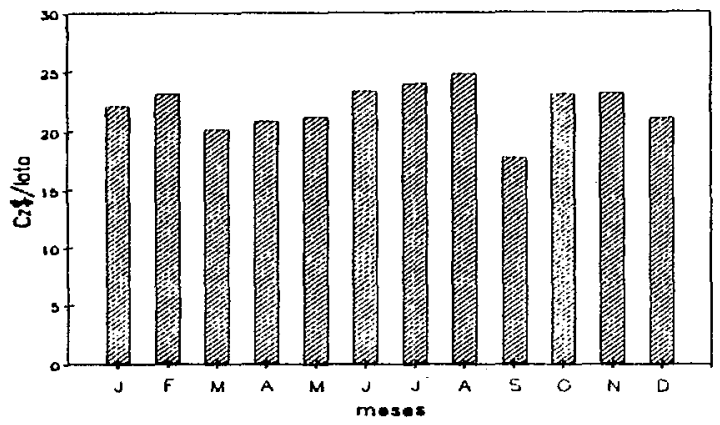

(1) porceritual

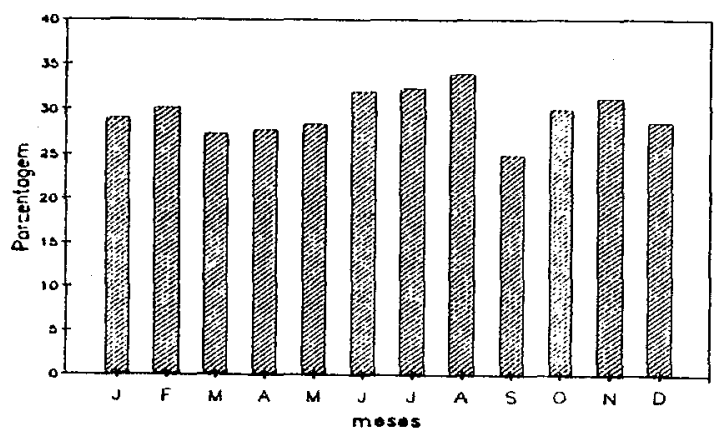

II- MARGEM ANUAL

(a) absoluta*

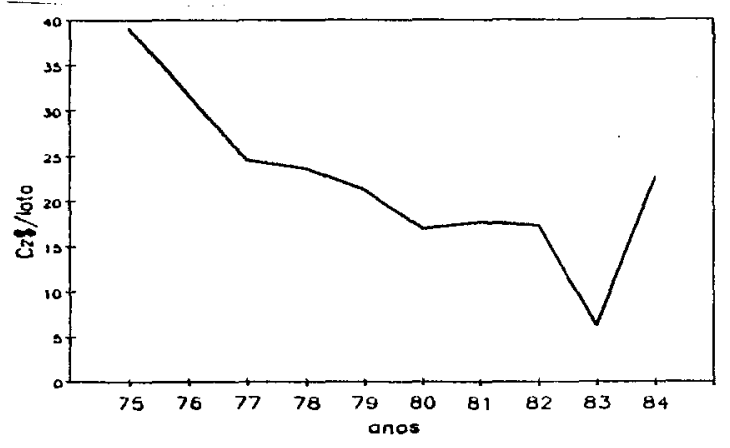

(b) porcentual

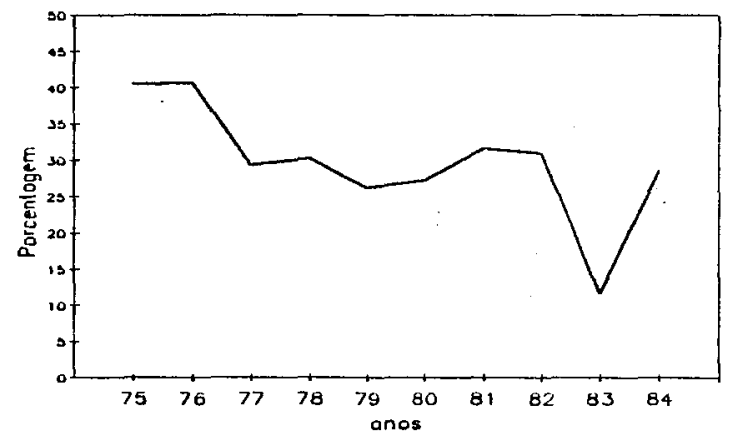

(*) valor real em Cz\$(Dez/87)

Figura 24 - Margem defasada (preço ao atacado defasado de 01 mês) do atacado de comercialização do óleo de so ja, tendo como região de produção o Estado de Mi nas Gerais, no periodo 1975 a 1984. 


\section{I - MARGEM MENSAL}

(a) absoluta*

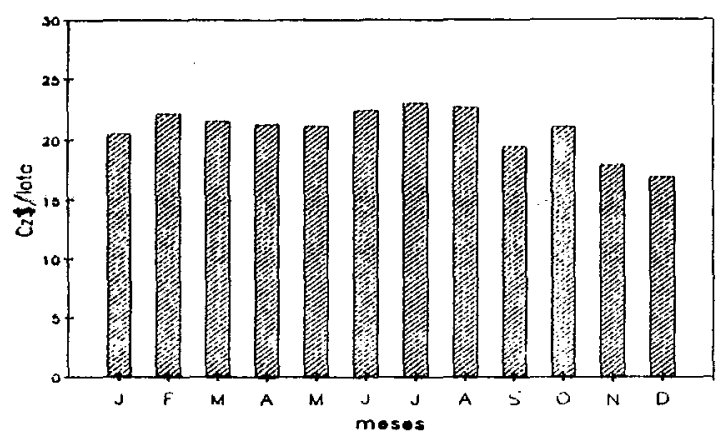

(b) porceritual

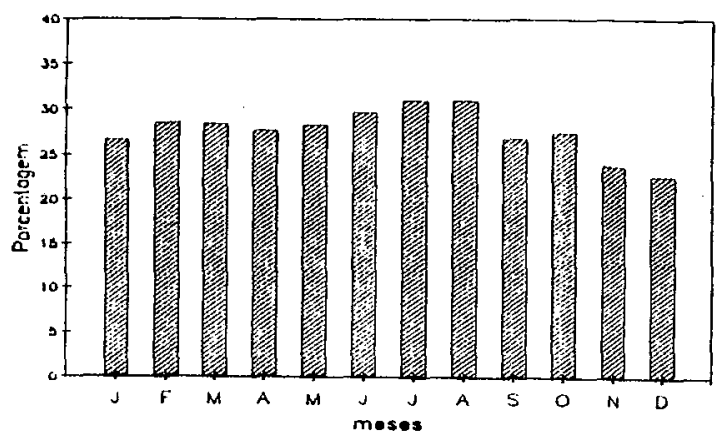

II- MARGEM ANUAL

(a) absoluta*

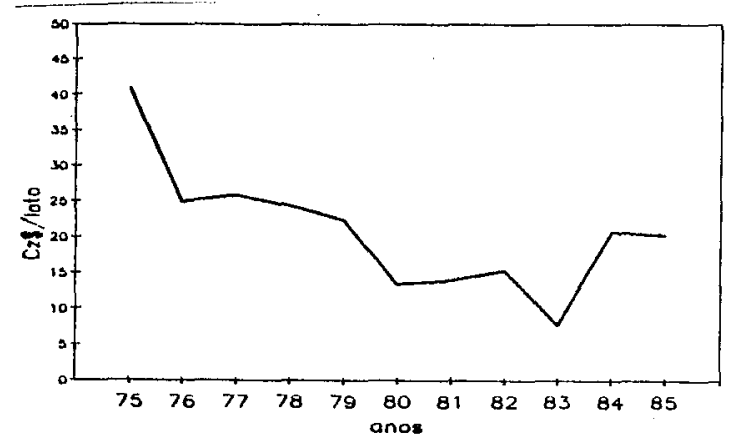

(b) porcentual

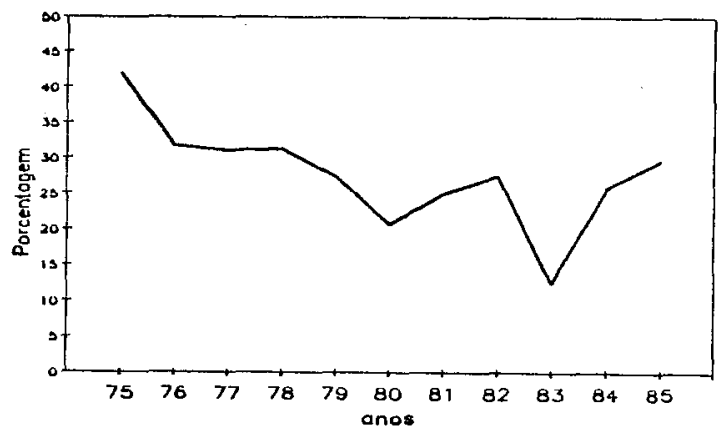

(*) valor real em Cz\$(Dez/87)

Figura 25 - Margem corrente total de comercialização do óleo de soja, tendo como região de produção o Estado de São Paulo (DIRAs Marïlia e Ribeirão Preto), no período 1975 a 1985 . 


\section{I- MARGEM MENSAL}

(a) absoluta*

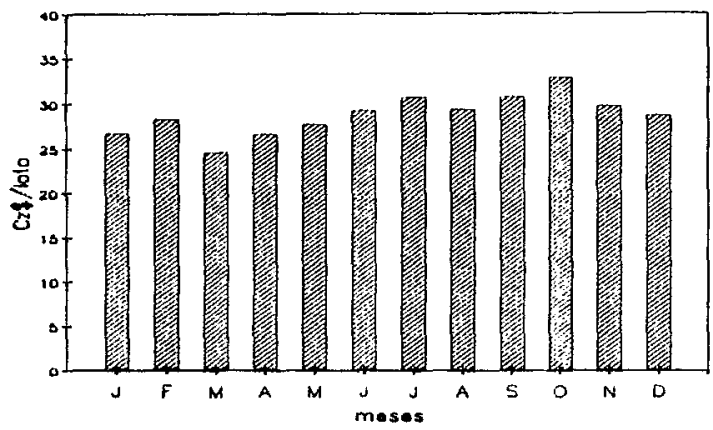

(L) jorcentual

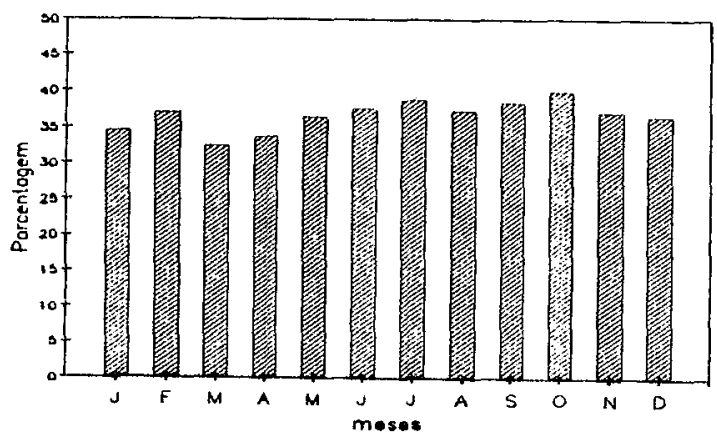

II- MARGEM ANUAL

(a) absoluta*

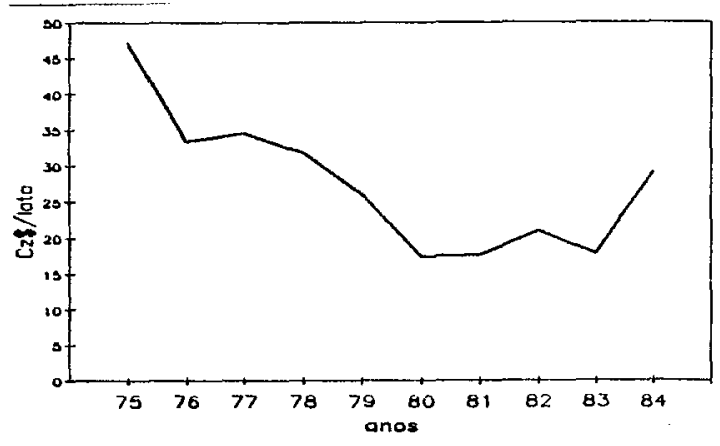

(b) porcentual

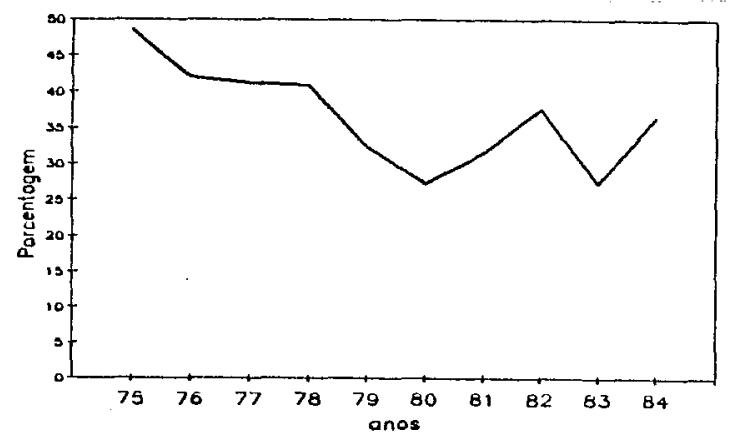

(*) valor real em Cz\$(Dez/87)

Figura 26 - Margem corrente total de comercialização do öleo de soja, tendo como região de produção o Estado de Mato GrossdMato Grosso do Sul, no periodo 1975 a 1984 . 


\section{I - MARGEM MENSAL}

(a) absoluta*

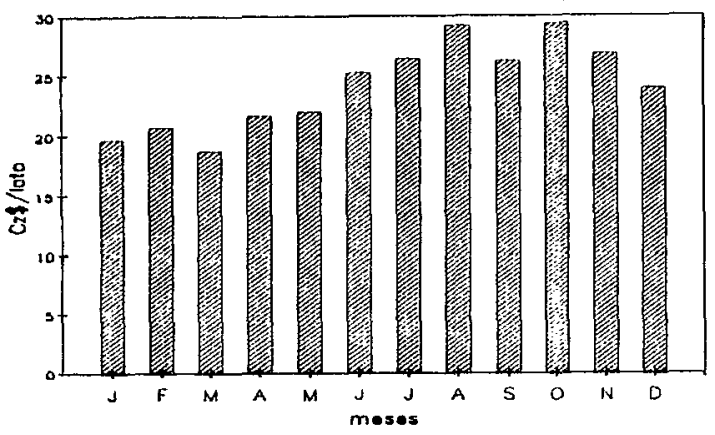

(1) forcentual

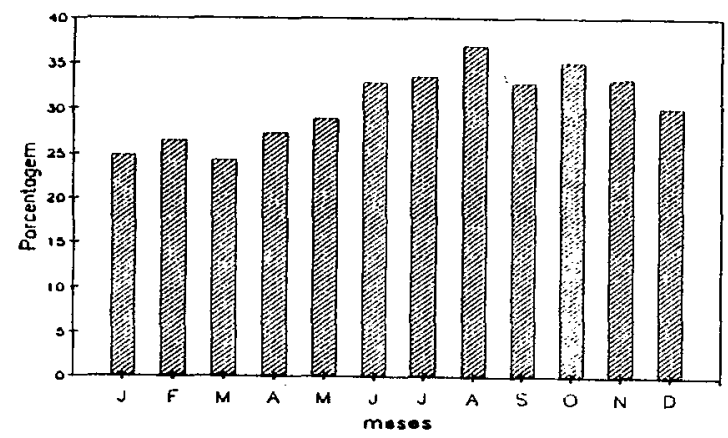

II- MARGEM ANUAL

(a) absoluta*

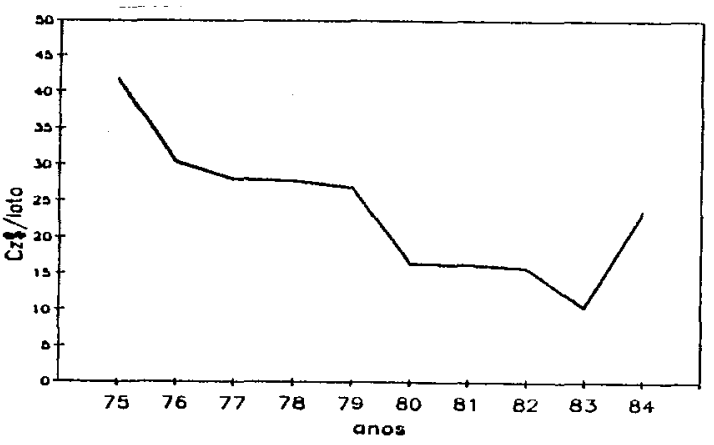

(b) porcentual

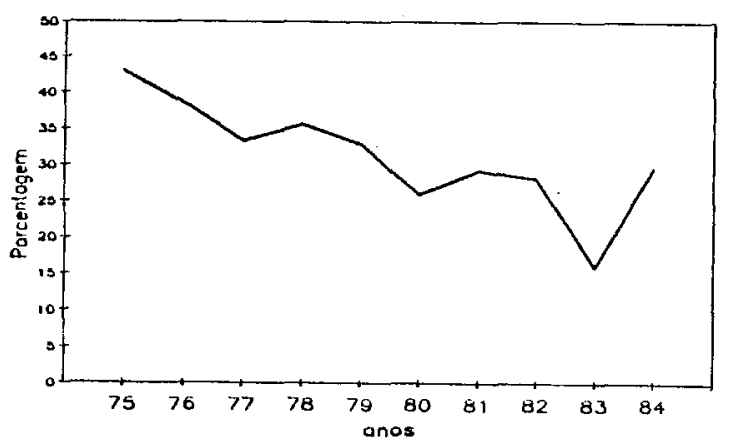

(*) valor real em Cz\$(Dez/87)

Figura 27 - Margem corrente total de comercialização do óleo de soja, tendo como região de produção o Estado de Minas Gerais, no período 197.5 a 1984. 
Observando-se a Tabela 14 e Figuras 16 e 20 têm-se que $\alpha_{0}>1$ e $\alpha_{0}>\left(1-\mathrm{MA}^{\prime}\right)$, ou seja, a margem corrente porcentual do atacado (MA') e a absoluta (MA) variam no mesmo sentido que o preço ao produtor de Minas Gerais $\left(\mathrm{Pa}_{t}\right)$. Analisando-se a Tabela 14 e Figuras 16 e 23 tem-se que $\sum_{i=0} \alpha_{i}<1$, ou seja, a margem defasada porcentual do atacado (MA'd) e o preço ao produtor de Minas Gerais $\left(\mathrm{Pa}_{t}\right)$ variam em sentido contrārio, e alēm disso, $\sum_{i=0}^{1} \alpha_{i}=\left(1-M A^{\prime} d\right)$, indicando que a margem defasada absoluta do atacado (MAd) não varia quando ocorre alteração no preço defasado ao produtor de Minas Gerais $\left(\mathrm{Pa}_{\mathrm{t}-1}\right)$. Com base na Tabela 14 e Figuras 17 e 24 observa-se que $\sum_{i=0} \alpha_{i}=1$, significando que a margem defasada porcentual do atacado (MA'd) não varia quando ocorre uma alteração no preço defasado ao atacado $\left(P c_{t-1}\right)$, e $\sum_{i=0}^{1} \alpha_{i}>\left(1-M A^{\prime} d\right)$, ou seja, a margem defasada absoluta do atacado (MAd) e o preço defasado ao atacado $\left(P c_{t-1}\right)$ variam no mesmo sentido.

\subsubsection{Laranja de mesa}

Na Figura 28 apresenta-se os preços mensais e anuais da laranja de mesa recebida pelos produtores do Estado de São Paulo, no atacado e varejo da cidade de São Paulo. Definiram-se como unidade atacadista representativa a CEAGESP/SP, e como equipamento varejista, a feira-livre. A safra paulista ocorre no período de julho a setembro, e a entressafra no período de fevereiro a março. A laranja, assim como a soja ē um produto que recebe grande influência do mercado externo, a qual é exportada na forma de suco de laranja. o principal país importador de suco do Brasil é os Estados Unidos, que colhe sua safra no período de janeiro a março. 
Desta forma, o comportamento do preço na entressafra brasileira depende, em grande parte, do desempenho da safra americana, podendo ocorrer fases em que os preços reais na entressafra são inferiores aos da safra.

As margens de comercialização da laranja de mesa são apresentadas nas Figuras 29 a 32 .

A margem corrente mensal total de comercialização da laranja situa-se em torno de Cz\$17,42/kg, e 77,46\% do preço de varejo (Figura 32). A margem correta absoluta mensal do varejo varia entre $\mathrm{C} z \$ 10,73 / \mathrm{kg}$ e $\mathrm{C} z \$ 13,60 / \mathrm{kg}$, que representa uma margem porcentual em torno de $53,25 \%$ (Figura 29). A margem corrente absoluta mensal do atacado varia entre $\mathrm{Cz} \$ 3,20 / \mathrm{kg}$ e $\mathrm{Cz} \$ 7,20 / \mathrm{kg}$, ou seja, uma margem porcentual ao redor de $23,31 \%$ (Figura 31).

A margem corrente anual de comercialização da laranja de mesa apresenta-se bastante estāvel durante o período 1978 a 1985.

A anālise de causalidade apresentou-se unidirecional dos preços ao produtor para o atacado, e dos preços ao varejo para o atacado. A anālise de transmissão de preços apresentou defasagem significativa $(d=12)$, apenas dos preços ao varejo para o atacado. Assim sendo, calcula-se a margem defasada do varejo de comercialização da laranja (Figura 30), que apresenta um comportamento mensal bastante semelhante à margem corrente do varejo, mas um comportamento anual diferente. 


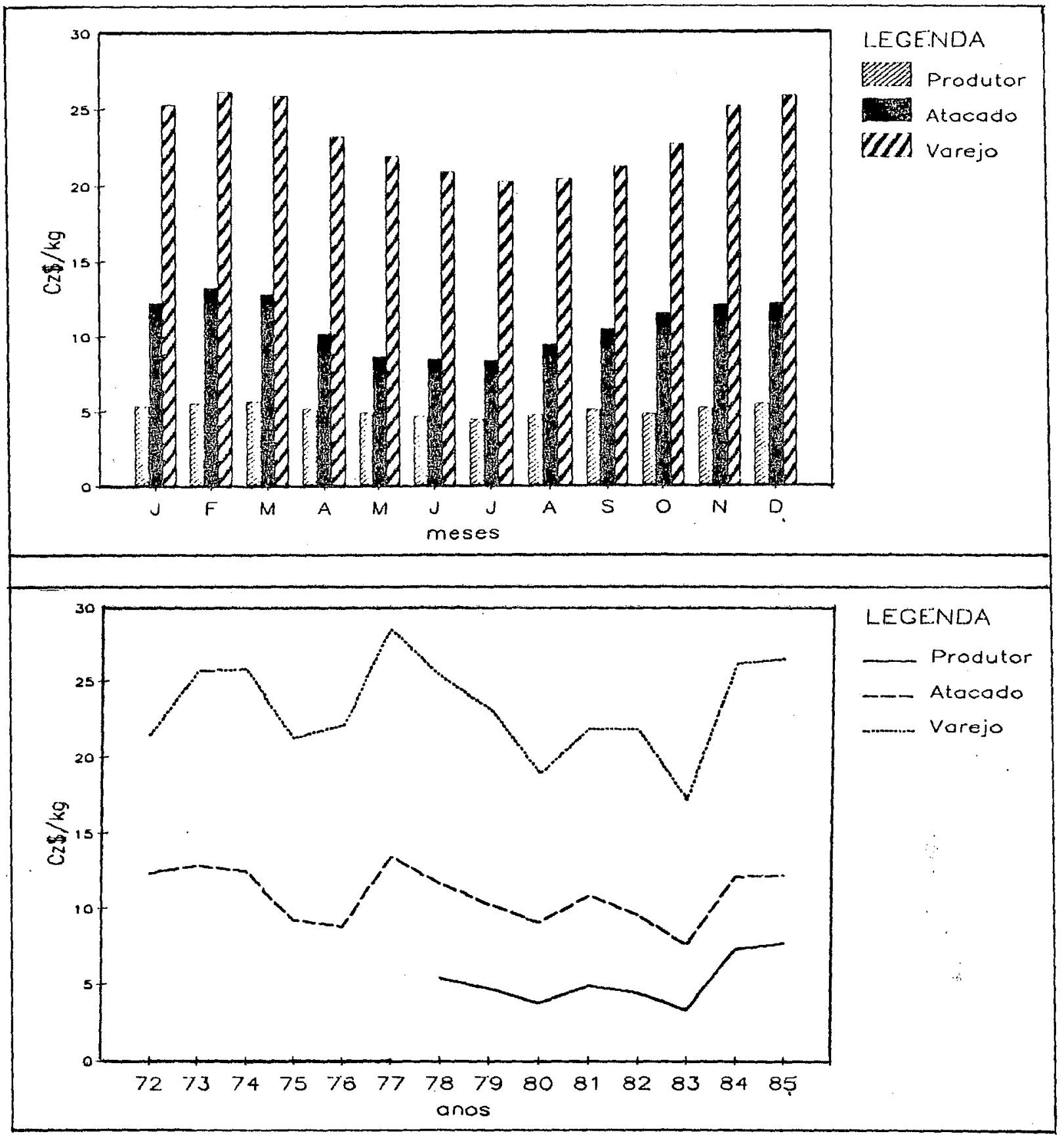

Figura 28 - Preço médio mensal e anual da laranja de mesa ao pro dutor, atacado/SP e varejo/SP, em Cz\$ de Dez/1987, no período 1972 a 1985 . 


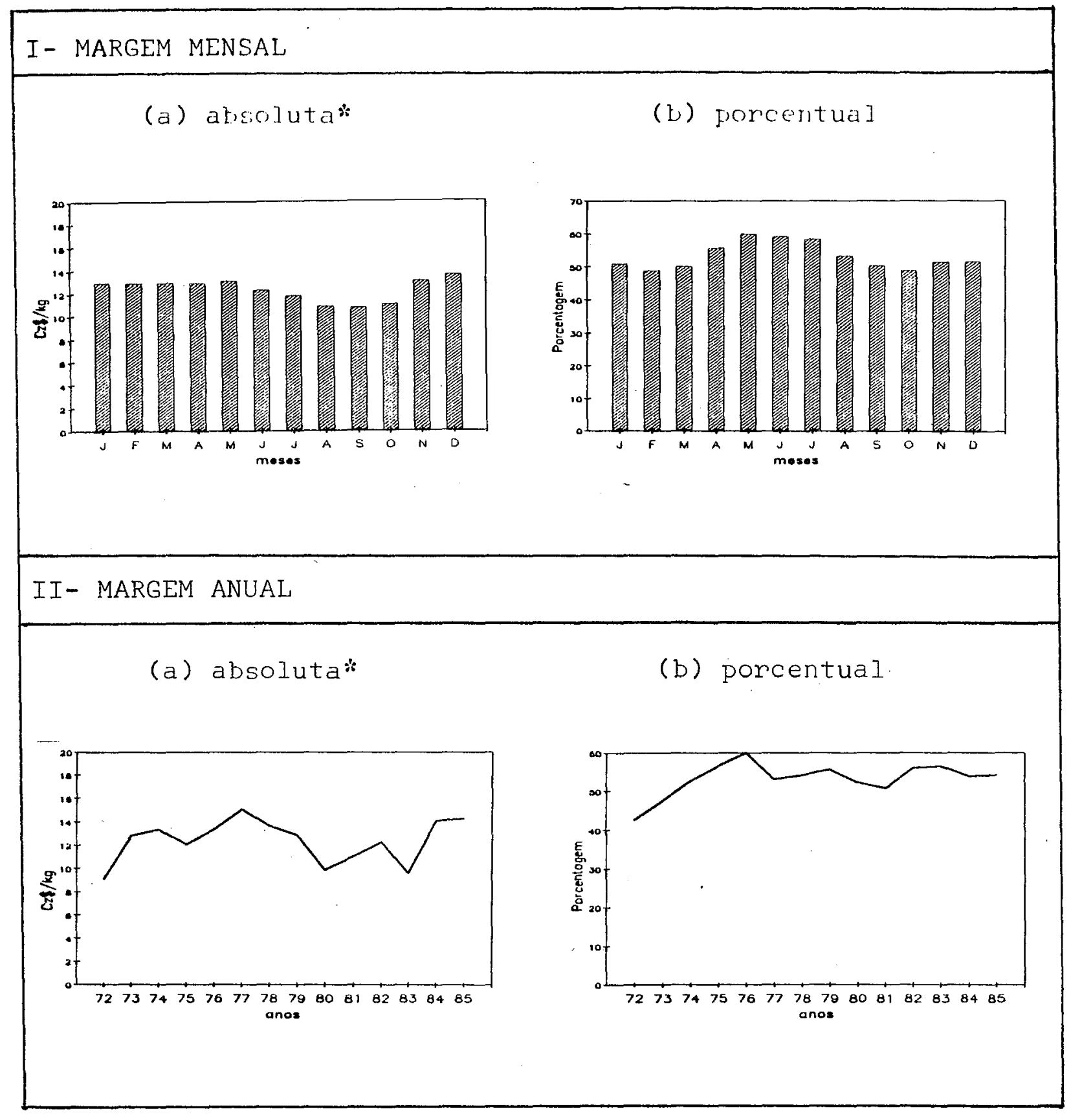

(*) valor real em Cz\$(Dez/87)

Figura 29 - Margem corrente do varejo de comercialização da lą ranja, no período 1972 a 1985. 


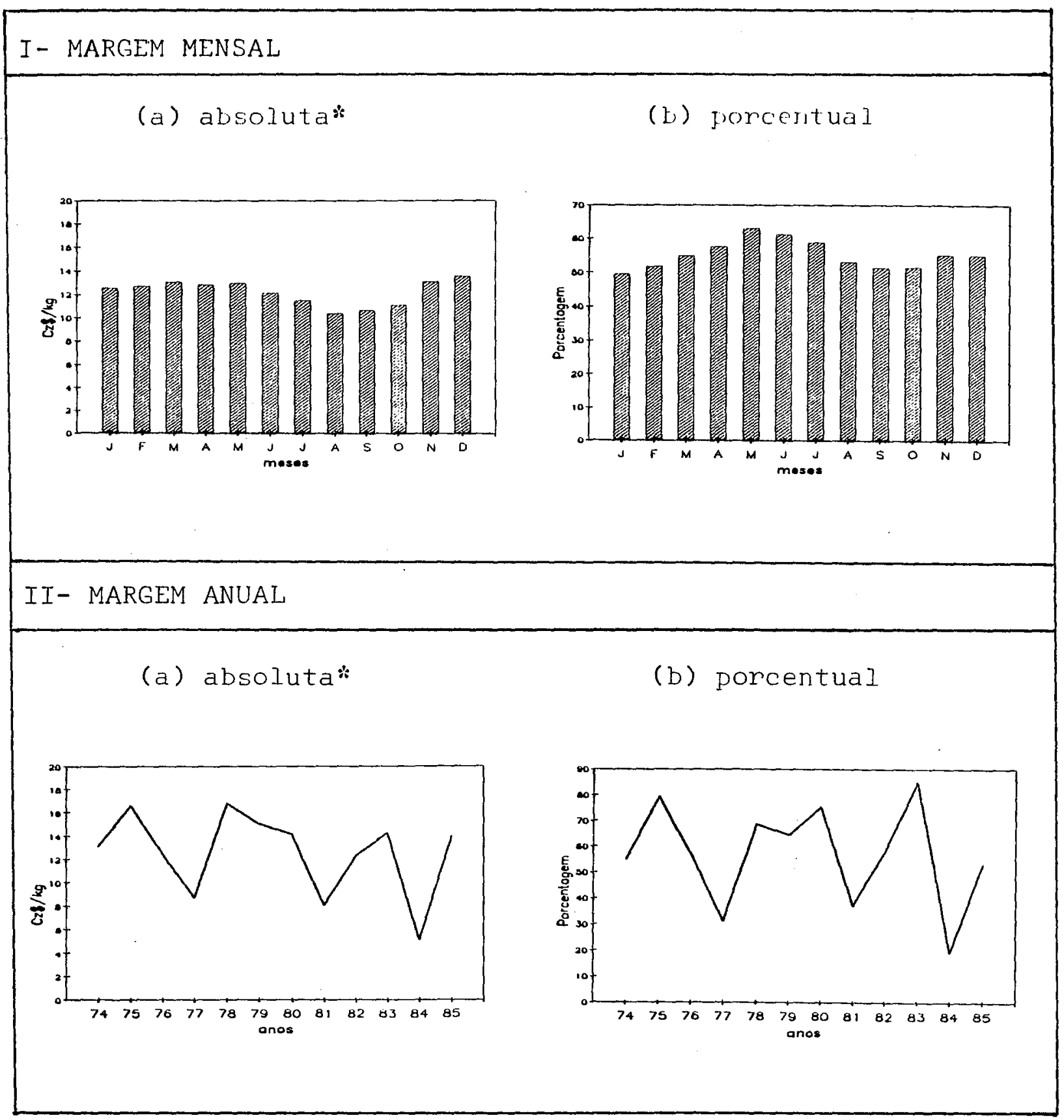

(*) valor real em Cz\$(Dez/87)

Figura 30 - Margem defasada (preço ao varejo defasado de 12 me ses) do varejo de comercialização da laranja, no período 1974 a 1985 . 


\section{I - MARGEM MENSAL}

(a) absoluta*

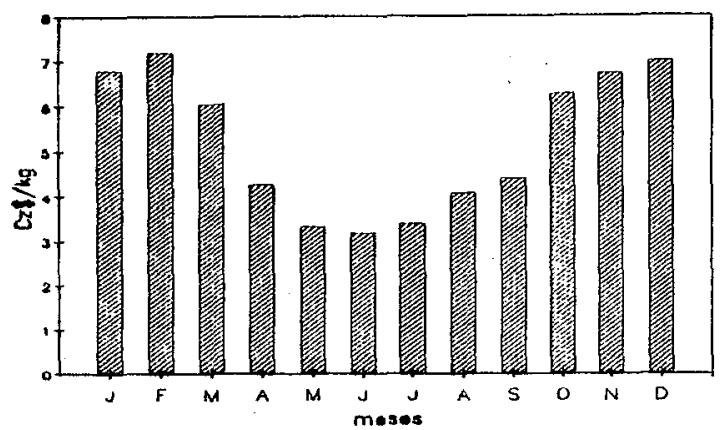

(b) yorcentual

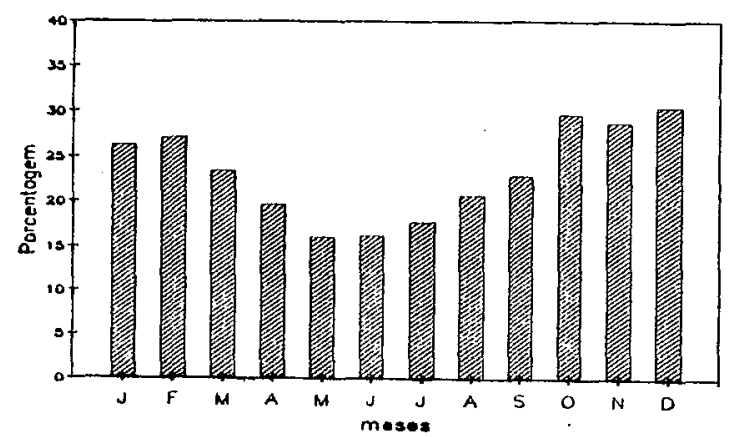

\section{II- MARGEM ANUAL}

(a) absoluta*

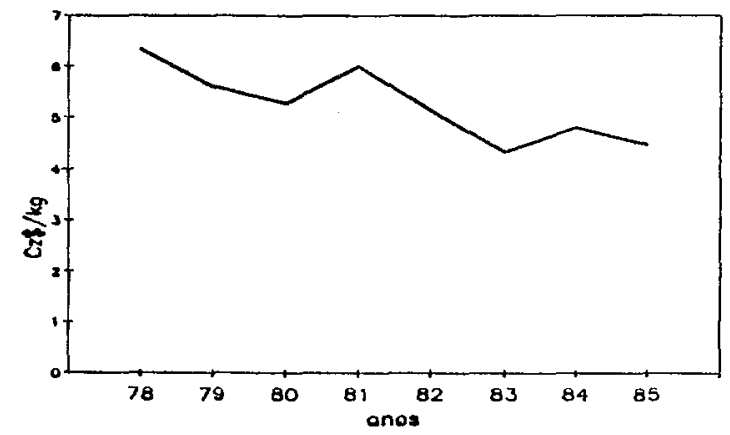

(b) porcentual

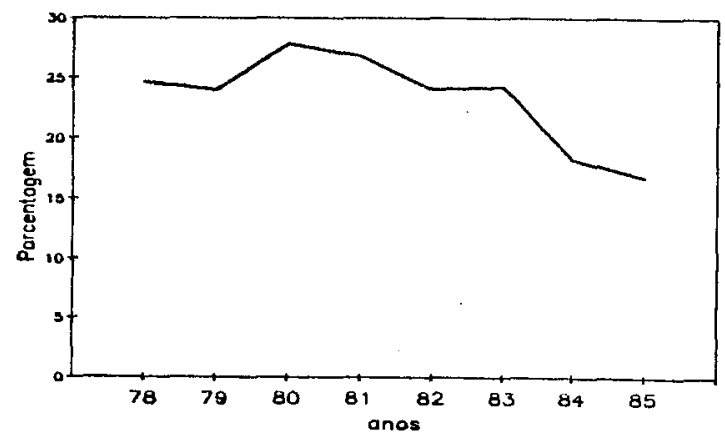

(*) valor real em $\mathrm{Cz} \$(\mathrm{Dez} / 87)$

Figura 31 - Margem corrente do atacado de comercialização da la ranja, tendo como região de produção o Estado de São Paulo, no período 1978 a 1985 . 
I- MARGEM MENSAL

(a) absoluta*

(b) Jorcestual
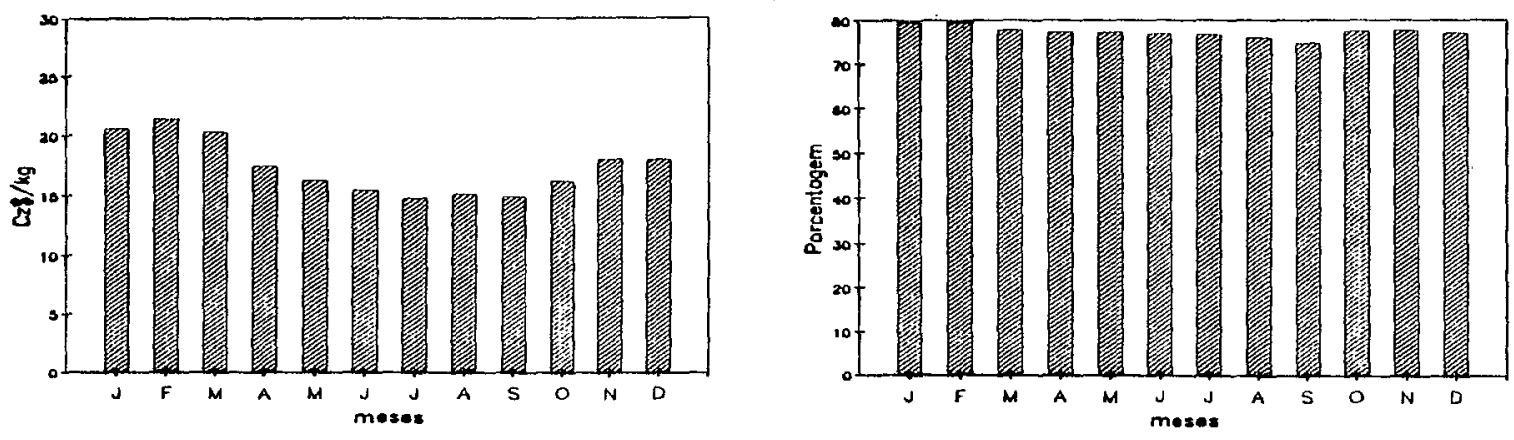

II- MARGEM ANUAL

(a) absoluta*

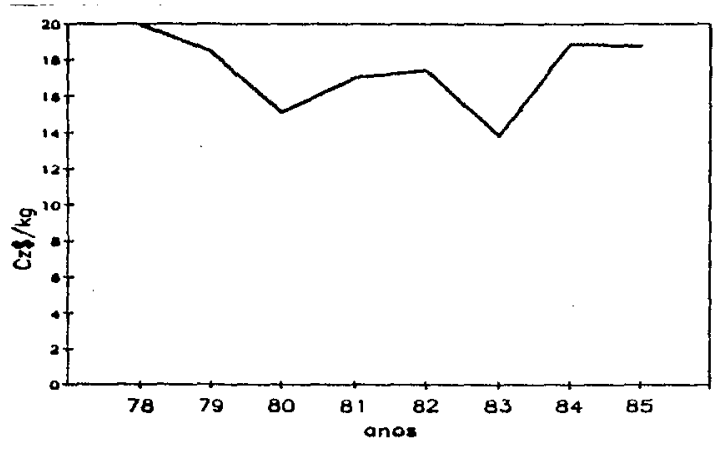

(b) porcentual

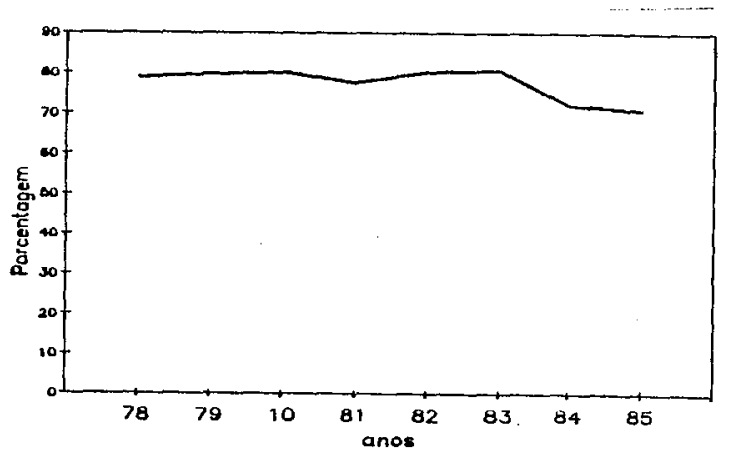

(*) valor real em $\mathrm{Cz} \$(\operatorname{Dez} / 87)$

Figura 32 - Margem corrente total de comercialização da laran ja, tendo como regĩão de produção o Estado de são Paulo, no período de 1978 a 1985 . 
12

Utilizando-se a Tabela 15 e Figuras 28 e 30 , observa-se que $\sum_{i=0} \alpha_{i}=1$, indicando que a margem defasada porcentual do varejo (MV'd) não se altera quando o preço defasado ao varejo $\left(\mathrm{Px}_{t-12}\right)$ varia. Ademais, tem12

se que $\sum_{i=0} \alpha_{i}>\left(1-M V^{\prime} d\right)$, significando que a margem defasada absoluta (MVd) varia no mesmo sentido que o preço defasado ao varejo $\left(\mathrm{Px}_{t-12}\right)$. Na tentativa de se observar o comportamento da margem corrente ao varejo, ana lisa-se o parâmetro da variāvel independente $\left(\alpha_{0}\right)$, que apresenta o seguinte comportamento, $\alpha_{0}<1$, e, $\alpha_{0}>\left(1-M V^{\prime}\right)$, significando que a margem corrente porcentual (MV') e o preço ao varejo $\left(\mathrm{Px}_{t}\right)$ variam em sentido conträrio, e a margem corrente absoluta (MV) e o preço ao varejo variam no mesmo sentido (Tabela 15 e Figuras 28 e 29).

Com base na Tabela 16 e Figuras 28 e 31 , observa-se que $\alpha_{0}<1$ e $\alpha_{0}<\left(1-M^{\prime}\right)$, ou seja, a margem absoluta (MA) e porcentual (MA') do atacado de comercialização da laranja de mesa deveriam variar em sentido conträrio da variação no preço ao produtor $\left(\mathrm{Pa}_{\mathrm{t}}\right)$. Entretanto, tal hi pōtese não se confirmou graficamente. Tal constatação aparentemente se deve a que a série original de preços ao atacado apresentou, alēm do efeito do preço ao produtor, um processo autorregressivo de terceira ordem. Dessa forma, apesar do efeito significativo do preço ao produtor, a série ao atacado apresenta um comportamento pröprio, levando aos resultados observados. 
4. CONCLUSÕES

0 presente trabalho preocupou-se em analisar o comportamento de preços agrícolas, tendo-se em conta os värios níveis de mercado, de forma a se detectar a origem e a intensidade das variações desses preços. Foram tambēm calculadas as margens de comercialização e suas relações com as variações de preços.

Para analisar essas questões foram utiliząas as sëries men sais de preços de arroz em casca, milho em grão, soja em grão e laranja de mesa, a nível de produtor; óleo de soja refinado enlatado e laranja de mesa, a nível de atacado; e arroz sem casca, fubá mimoso, óleo de soja refinado enlatado e laranja de mesa, a nível de varejo, no período de 1972 a 1985. Realizou-se, inicialmente, o teste de causalidade desenvolvido por GRANGER (1969) e implementado por SIMS (1972) e, posteriormente, nos casos que apresentaram causalidade unidirecional e bidirecional procedeu-se às análises de transmissäo de preços, do comportamento das margens de comercialização e suas relações com a elasticidade de transmissão de preços. 
A anālise de causalidade entre os preços nos vários nỉveis de comercialização agrícola foi efetuada, para o caso do arroz e milho, considerando-se, apenas, o preço ao produtor e varejo, e para a soja e laranja, os preços ao produtor, atacado e varejo. o mercado consumidor de finido foi a cidade de São Paulo, tendo como equipamento varejista o supermercado para arroz sem casca, fubá mimoso e óleo de soja refinado enlatado, e a feira-livre para a laranja de mesa. Para o arroz, detectou-se causalidade, apenas, entre o preço ao produtor do Estado de Goiās para o preço ao varejo, no período 1976 a 1980, sendo que o arroz oriundo de São Paulo e do Rio Grande do Sul apresentou ausência de causalidade. Para o milho, os preços ao produtor (Estados de São Paulo, Paranā e Minas Gerais) demonstraram exogeneidade com relação aos preços ao varejo. Para a soja, observou-se causalidade unidirecional dos preços ao atacado para o varejo, e dos produtores (Estados de São Paulo e Mato Grosso/Mato Grosso do Su1) para o atacado. o preço da soja provinda do Estado de Minas Gerais e o preço ao atacado apresentaram causalidade bidirecional. Para a laranja de mesa, os preços ao produtor (Estado de São Paulo) e ao varejo foram exógenos, quando analisados em relação ao atacado. De uma forma geral, para os casos analisados, pode-se dizer que os choques são originados a nível de produção, possivelmente, face às variações climáticas. Para os produtos relacionados ao mercado externo, como o óleo de soja e a laranja de mesa, acredita-se que as exportações (grão/farelo de soja e suco de laranja) podem desencadear, inicialmente, variações de preços diretamente ao produtor, por ser este, em geral, o elo de ligação entre os mercados externo e interno. Em outros casos, como no da laranja de mesa, a variação pode or $\underline{i}$ ginar-se a nível devarejo, pois é um produto que, aparentemente, apresenta 
a demanda fortemente influenciada por variações de renda e clima, por exem plo.

o fato do varejo desempenhar um papel relativamente passivo, para os produtos analisados, em termos de variação de preço, pode ser atribuido a duas causas básicas. Por um 1ado, a demanda dos produtos agrí colas pode ser mais estável do que a oferta, e, por outro lado, é possível que o comportamento do varejo, reflita o modelo teórico referente ao segmento mais concentrado da economia, em que os preços se moveriam única e tão somente, com as alterações de custo. 0 modelo competitivo de HEIEN (1980), tambēm racionaliza tal comportamento.

Na anālise de transmissão de preços do arroz, observou-se que um aumento de $10 \%$ nos preços ao produtor de Goiäs ocasionaria um aumento instantâneo, em torno, de 4,03\% nos preços ao varejo (supermercado/SP). No caso do milho, um aumento de $10 \%$ nos preços ao produtor, independente da região de produção (Estados de São Paulo, Paranã e Minas Gerais), acarretaria um aumento total no preço do fubä mimoso entre $6,02 \%$ a 7,32\%. Para a soja, um aumento de $10 \%$ nos preços ao atacado, levaria a um aumento imediato nos preços ao varejo de $4,54 \%$, e, no final de seis meses, caso este aumento persistir, um aumento total de 10,72\%; para a soja oriunda do Estado de São Paulo e Mato Grosso/Mato Grosso do Sul, um aumento de $10 \%$ nos preços ao produtor, ocasionaria um aumento imediato entre 4,67\% a 5,73\% nos preços do óleo de soja refinado enlatado a nível de atacado; jä para a soja do Estado de Minas Gerais que apresentou causalidade bidirecional em relação ao atacado, observou-se que um aumento de $10 \%$ nos preços ao atacado levaria, num mesmo momento, a um aumento de $28,56 \%$ nos 
preços ao produtor, e a um aumento total, apös um mês, de $11,16 \%$; se o choque dos preços iniciar-se no lado do produtor de Minas Gerais, um acrés cimo de $10 \%$, refletiria de imediato num acréscimo de $22,87 \%$ nos preços ao atacado, e, no final de um mês, um aumento total de 7,52\%. Para a laranja, um aumento de $10 \%$ no preço ao varejo, seria associado a um aumento imediato de $6,5 \%$ no preço ao atacado, e um aumento total, no final de doze meses, de 9,07\%; um aumento de 10\% nos preços da laranja oriunda do Estado de São Paulo acarretaria um aumento imediato de $4,48 \%$ nos preços ao atacado.

Assim sendo, na aná1ise de transmissão de preços observouse dois aspectos importantes:

a) não houve evidências, de uma forma geral, de que o setor de intermediação amplie os choques de preços ocorridos, quer a nível de demanda, quer a nível de produção; e

b) na maioria dos casos, os efeitos de choque de preços se fizeram sentir de imediato, havendo para alguns produtos, um certo espaço de tempo, entre o choque no preço exógeno e o ajustamento total no preço endōgeno.

As margens correntes mensais totais de comercialização foram calculadas em valores absolutos (em valores de Déz/1987) e porcentualmente (em relação ao preço de varejo). No caso do arroz sem casca, as mar gens variaram em torno de $\operatorname{Cz} \$ 20,38 / \mathrm{kg}(42,26 \%), \operatorname{Cz} \$ 21,78 / \mathrm{kg}(45,05 \%)$ e $\mathrm{C} z \$ 20,18 / \mathrm{kg}(49,73 \%)$, quando as regiões de produção foram os Estados de São Paulo, Goiās e Rio Grande do Sul, respectivamente. Para o fubá mimoso 
giraram em torno de $\mathrm{Cz} \$ 27,69 / \mathrm{kg} \quad(71,48 \%), \quad \mathrm{Cz} \$ 34,85 / \mathrm{kg} \quad(90,44 \%)$ e Cz\$ $34,16 / \mathrm{kg}(88,44 \%)$, quando as regiões de produção foram os Estados de São Paulo, Paranā e Minas Gerais, respectivamente. Para o óleo de soja re finado enlatado oscilaram em torno de Cz\$20,90/1ata $(27,71 \%), \mathrm{Cz} \$ 28,83 / 1$ a ta $(36,76 \%)$ e $\mathrm{Cz} \$ 24,22 / 1$ ata $(30,57 \%)$, quando as regiões de produção foram os Estados de São Paulo, Mato Grosso/Mato Grosso do Sul e Minas Gerais, res pectivamente. Para a laranja de mesa variaram em torno de Cz\$17,42/kg $(77,46 \%)$, considerando-se o Estado de São Paulo como região de produção. A margem do varejo de comercialização do óleo de soja girou em torno de Cz\$ 2,82/1ata $(3,03 \%)$ e da laranja de mesa $\mathrm{Cz} \$ 12,37 / \mathrm{kg}(53,25 \%)$. As margens do atacado de comercialização da soja oscilaram em torno de Cz\$ $17,15 /$ lata $(24,46 \%), C z \$ 25,73 /$ lata $(34,75 \%)$ e Cz\$ $21,85 /$ lata $(29,40 \%)$, considerando os Estados de São Paulo, Mato Grosso/Mato Grosso do Sul e Minas Gerais como as respectivas regiões de produção. Para a laranja esta margem situou-se em torno de $\mathrm{C} z \$ 5,23 / \mathrm{kg}(23,31 \%)$.

A anālise das margens mensais de comercialização dos produtos analisados revelou, que as mesmas, apresentam um forte componente es taciona1. o aumento das margens, geralmente observado no período da safra, pode estar associado a dois importantes aspectos:

a) um aumento dos custos de comercialização, proveniente do aumento da demanda pelos serviços de comercialização, e em decorrência do qual,

b) a queda de preços a nível de produtor, resultante do des locamento da oferta, não é transmitida integralmente a nível de consumidor. 
As margens correntes anuais de comercialização não apresentaram nenhuma tendência definida durante o período analisado, com exceção do óleo de soja, que mostrou uma tendência de queda.

Para os produtos que apresentaram defasagem significativa no processo de transmissão de preços, procedeu-se à análise da margem defasada, considerando-se o preço exógeno defasado. Tal anālise foi realizada para o fubá mimoso, óleo de soja e laranja de mesa, que, no entanto, apresentaram um comportamento semelhante às margens correntes.

0 comportamento das margens face a variações nos preços exō genos, foram analisados tendo em conta os valores estimados das elasticidades de transmissão de preços. No caso do arroz oriundo de Goiās, o aumento de preço a nível de produtor diminue as margens correntes porcentual e absoluta totais de comercialização do arroz sem casca. Para o milho, o aumento de preço a nível de produtor (Estados de São Paulo, Paranā e Minas Gerais) diminue as margens correntes e defasadas porcentuais totais de comercialização do fubá mimoso, e aumentam as margens correntes e defasadas absolutas totais (com exceção do milho oriundo de São Paulo, em que o aumento de preços a nível de produtor não provoca alteração na margem corren te absoluta de comercialização). Para a soja, o aumento de preço a nível de atacado, diminue as margens correntes porcentual e absoluta do varejo do óleo de soja refinado enlatado, e, um aumento no preço defasado de 6 períodos do atacado não provoca alterações na margem defasada porcentual e absoluta do varejo; o aumento do preço da soja ao produtor (Estados de São Paulo e Mato Grosso/Mato Grosso do Sul) provoca uma diminuição nas margens correntes absoluta e porcentual do atacado, e um aumento no preço a nível 
de produtor de Minas Gerais aumenta a margem corrente porcentual e defasada do atacado de comercialização. Para a laranja de mesa, o aumento de preço a nível de varejo não altera a margem defasada porcentual do varejo de comercialização da laranja de mesa, diminue a margem corrente porcentual do varejo e aumenta a margem corrente e defasada absoluta do varejo de comercialização; o aumento de preço a nível de produtor (Estado de São Pau1o) diminue a margem corrente porcentual e absoluta do atacado de comercialização da laranja de mesa.

Das anālises do comportamento das margens de comercialização, face à variação nos preços exōgenos, observou-se atravēs das Figuras, que, apenas, as margens correntes do atacado de comercialização da laranja de mesa não confirmaram a hipótese de que o aumento de preços a nível de produtor diminuem a margem corrente porcentual e absoluta de comercialização. Tal constatação, aparentemente, pode se dever à existência de um pró cesso autorregressivo de terceira ordem na série de preços ao atacado.

De um modo geral, pode-se dizer, que a margem porcentual e - preço exógeno movịmentaram-se em sentido contrārio e que a margem absoluta e o preço exögeno apresentaram um comportamento bastante variável entre os produtos. 


\section{REFEREิNCIAS BIBLIOGRĀFICAS}

ADABO, J.H. Tendência das margens de comercializą̧ão da carne bovina em São Paulo. Rio de Janeiro, ESAP/FGV, 1978. 64p. (mimeografado).

BARBOSA, F.E.P. Comercialização de bovinos no Piaui e tendências nas suas margens, no tempo - 1967/72. Teresina, FCRP, 1974. 33p.

BARROS, G.S.C. Economia da comercialização agricola. Piracicaba, FEALQ, 1987. 306p.

BARROS, G.S.C. \& MARTINES Fọ, J.G. Transmissão de preços agrícolas entre níveis de mercado. In: XV Encontro Nacional de Economia, 2., Salvador, 1987. Anais. ANPEC. p.53-68.

BARROS, G.S.C. \& XAVIER, L.E. Aspectos da comercialização e seus efeitos sobre os preços e rendas agrícolas. Revista de Economia Rural, Brasilia, $17(3): 25-50,1979$. 
BESSLER, D.A. Relative price and money: a vector autoregression on brazilian data. American Journal of Agricultural Economics, New York, $66(1): 25-30,1984$.

BISHOP, R.V. The construction and use of causality tests. Agricultural Economics Research, 31(4):1-6, 1979.

BOLSA DE CEREAIS DE SÃo PAULO. Informativo Mensal. São Paulo, Departamento de Estatística. (vārios).

BRANDT, S.A. Anālise econométrica das margens de comercialização. Revista de Economia Rural, Brasilia, 3(3):70-97, 1971.

BURNQUIST, H.L. A questão da causalidade entre preços a diferentes níveis de mercados agrícolas. Piracicaba, 1986. 83p. (Mestrado - Escola Superior de Agricultura "Luiz de Queiroz"/USP).

CANTO, W.L.; OLIVEIRA, O.G.; CORTE, O.O.; VITTI, P.; VALLE, J.L.E.; SILVEIRA, E.T.F.; SCHMUTZLER, R. Sistema ponderal de conversões e determinação de margens de comercialização. Campinas, Instituto de Tecnologia de Alimentos, 1985. 55p.

CHAMBERS, R.G. Agricultural and financial market interdependence in the short run. American Journal of Agricultural Economics, New York, 66 (1) :12-24, 1984 . 
CIBANTOS, J.S. A demanda de tecnologia biológica; o caso de sementes certificadas de algodão. Botucatu, 1983. 83p. (Livre-docência - Faculdade de Ciências Agrärias/UNESP).

COMPANHIA DE ENTREPOSTOS E ARMAZENS GERAIS DE SÃO PAULO. BoZetim Informativo Mensal. São Paulo, Departamento de Anālises Estatísticas. (vārios).

CONSTDERA, C.M. Preços, markup e distribuição funcional de renda na indústria de transformação: dinâmica de longo e de curto prazo - 19591980. Pesquisa e Planejamento Econômico, São Paulo, 11(3) : 617-636, 1981.

DOAN, T.A. \& LITTERMAN, R.B. User's manual; rats. Minneapolis, MN: VAR Econometrics, 1981. 525p.

FIALLOS, L.E.W. Anälise da demanda e preços de tomate no Estado de São Paulo. Piracicaba, 1981. 116p. (Mestrado - Escola Superior de Agricultura "Luiz de Queiroz"/USP).

FUNDAÇÃo GETÜLIO VARGAS. Conjuntura Econômica. Rio de Janeiro. (värios)

FUNDAÇÃo GETÚLIO VARGAS. Preços Recebidos pelos AgricuZtores. Rio de Janeiro, Centro de Estudos Agrícolas. (vārios).

FUNDAÇÃO INSTITUTO BRASILEIRO DE GEOGRAFIA E ESTATÍSTICA. Estudo Nacional da Despesa Familiar; despesa da família. Rio de Janeiro, FIBGE, 1978. 85p. 
GARDNER, B.L. The farm; retail price spread in competitive food industry. American Joumal of Agricultural Economics, New York, 57(3): $399-409$, 1975.

GRANGER, C.W.J. Investigating causal relations by Econometric models and cross spectral methods. Econométrica, 37(3):424-38, 1969.

HEIEN, D.M. Markup pricing in a dynamic Model of the food industry. American Joumal of Agricultural Economics, New York, 62(1):10-18, 1980.

HOFFMANN, R. Anälises econométmicas das margens de comercialização de ovos no Estado de São PauZo. Piracicaba, ESALQ/DESR, 1969. 18p. (Sërie pesquisa, 10) .

INSTITUTO DE EOCNOMIA AGRICILA. Informações Econômicas, São Paulo, Secretaria da Agricultura do Estado de São Paulo. (vārios).

JUNQUEIRA, P.C.; LINS, E.R.de; AMARO, A.A. Comercialização de produtos agrícolas no Estado de São Paulo. Agricultura em São Paulo, São Paulo, $15(1 / 2): 5-60,1968$.

JUNQUEIRA, P.C. \& CANTO, W.L. Cesta de mercado; margens totais de comercialização. Agricultura em São Paulo, São Paulo, 18(9-10):1-46, set/ out. 1971.

LOPES, M.R. Formação e estabilização de preços agrícolas; a especulação nos mercados agrícolas e formação da renda do produtor. Brasília, CFP, 1983. 180p. (Coleção anälise e pesquisas 28). 
KMENTA, J. Elementos de econometria. São Paulo, Atlas, 1978. 670p.

RUAS, D.G.G. Anālise da margem e dos preços de milho no Estado de São Pau 1o. Piracicaba, 1978. 112p. (Mestrado - Escola Superior de Agricultura "Luiz de Queiroz"/USP).

SAYAD, J. Abastecimento urbano e inflação. In: Encontro Nacional de Economia, 8., Nova Friburgo, 1980. Anais. Brasília, ANPEC, 1980. p.591630 .

SOARES, M.F.V. Anālise do mercado de laranja e banana, a nível de atacado no Estado do Rio de Janeiro. Viçosa, 1981. 90p. (Mestrado - Univer sidade Federal de Viçosa).

SIMS, C.A. Money, income and causality. American Economic Review, 62(4): 540-552. 1972.

TEIXEIRA, H.H.L. Modelo de desequilíbrio de margens de comercialização agrícola. Viçosa, 1972. 69p. (Mestrado - Universidade Federal de Viçosa).

WARD, R.W. Asymmetric in retail. wholesale, and shipping point pricing for fresh vegetables. American Journal of Agricultural Economics, New York, 64(2):205-212, 1982. 
AP $\widehat{E} N D I C E \quad 1$ 

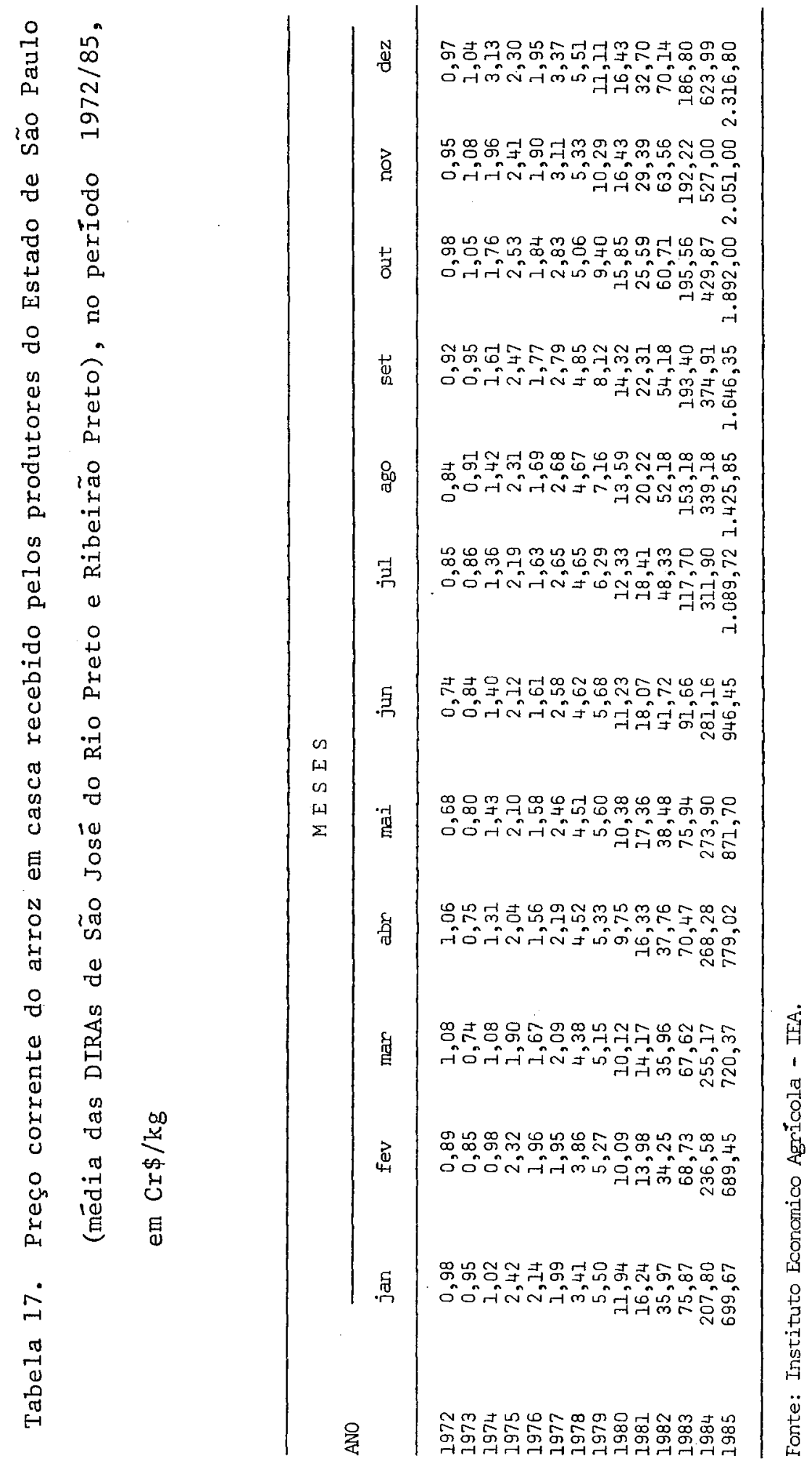


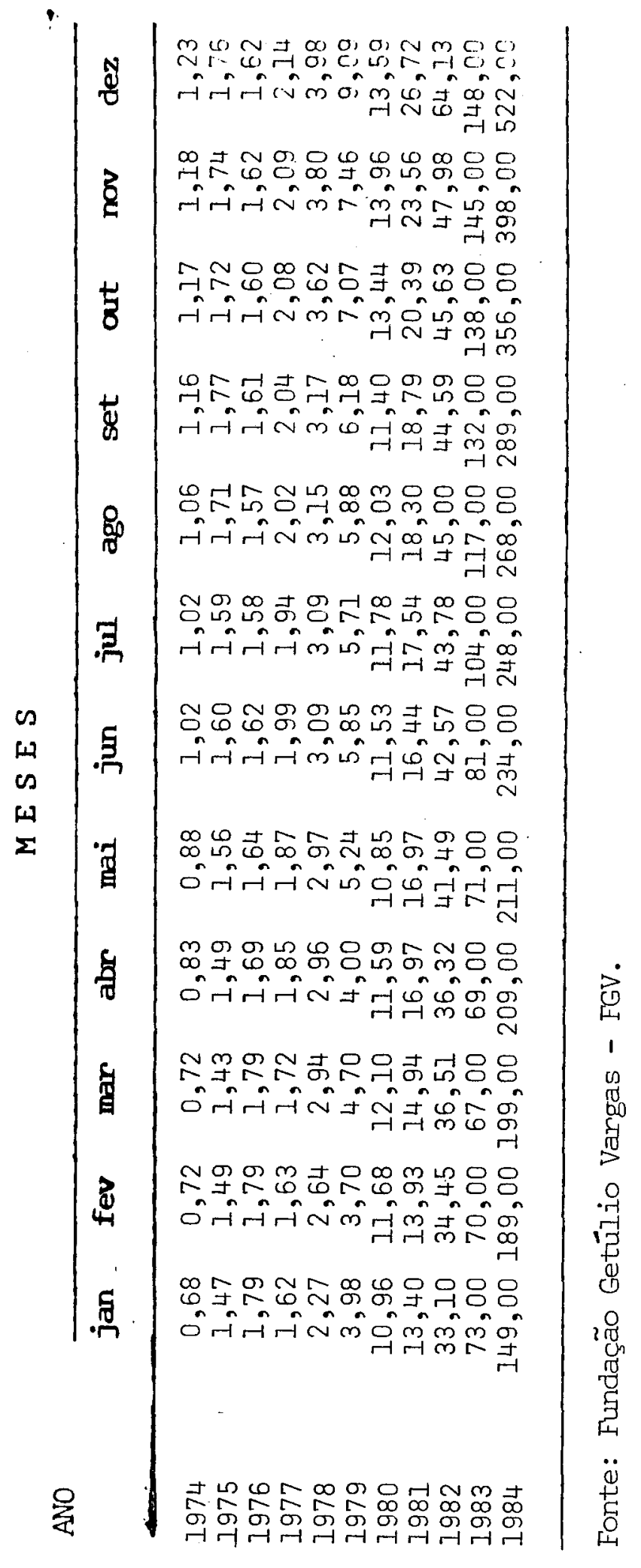




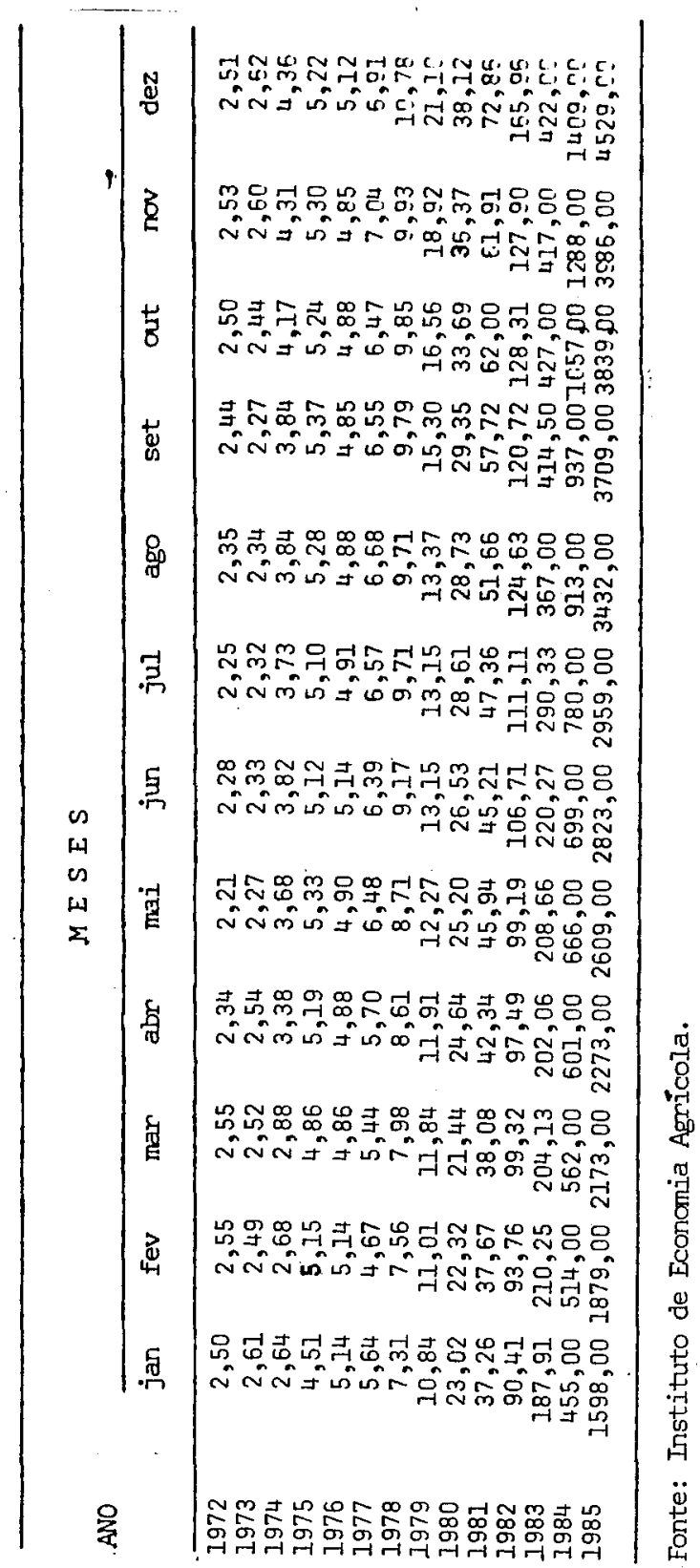




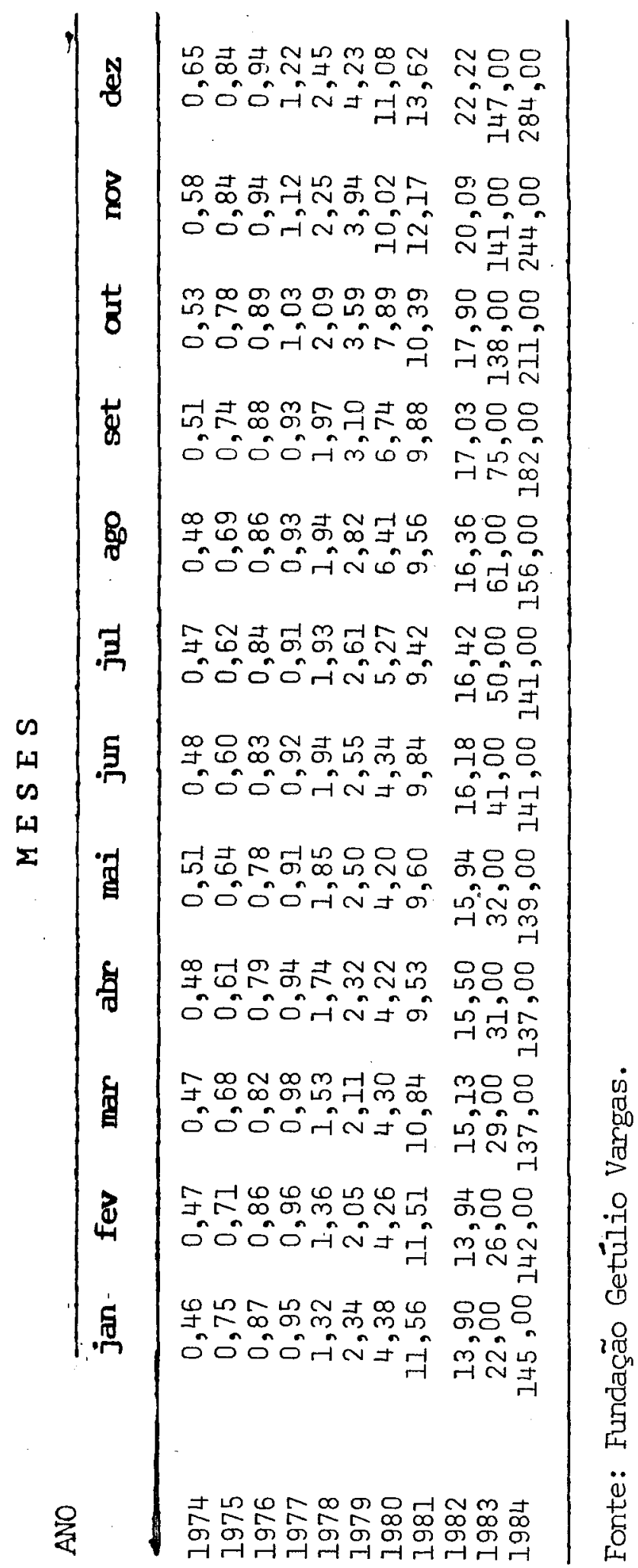




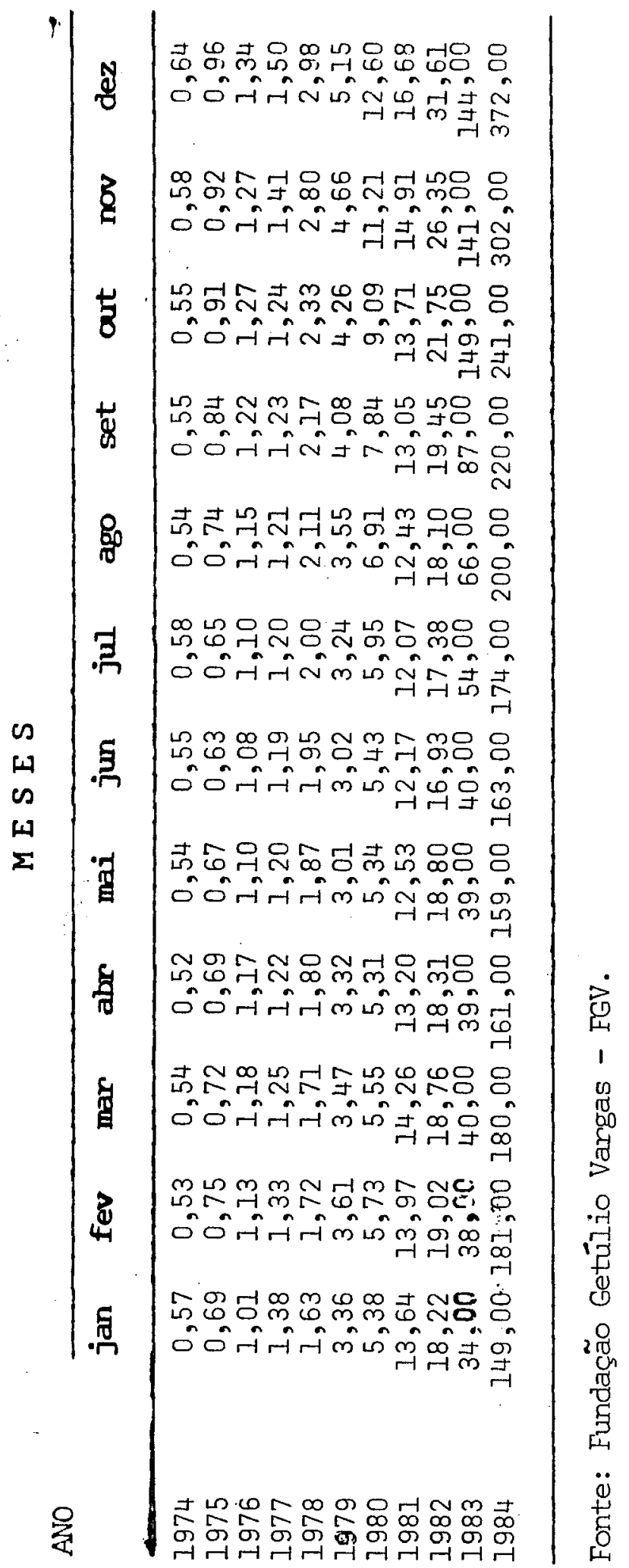




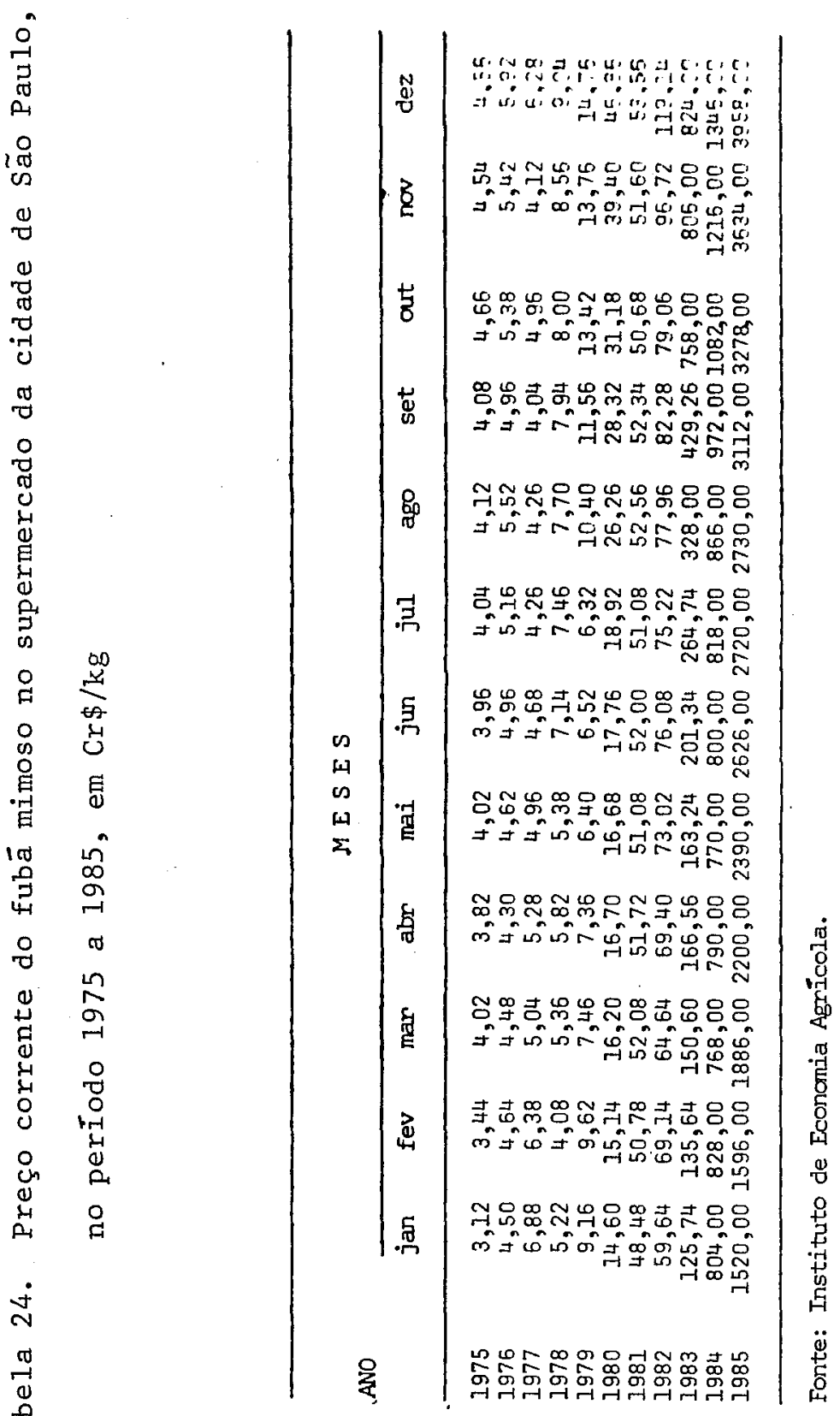




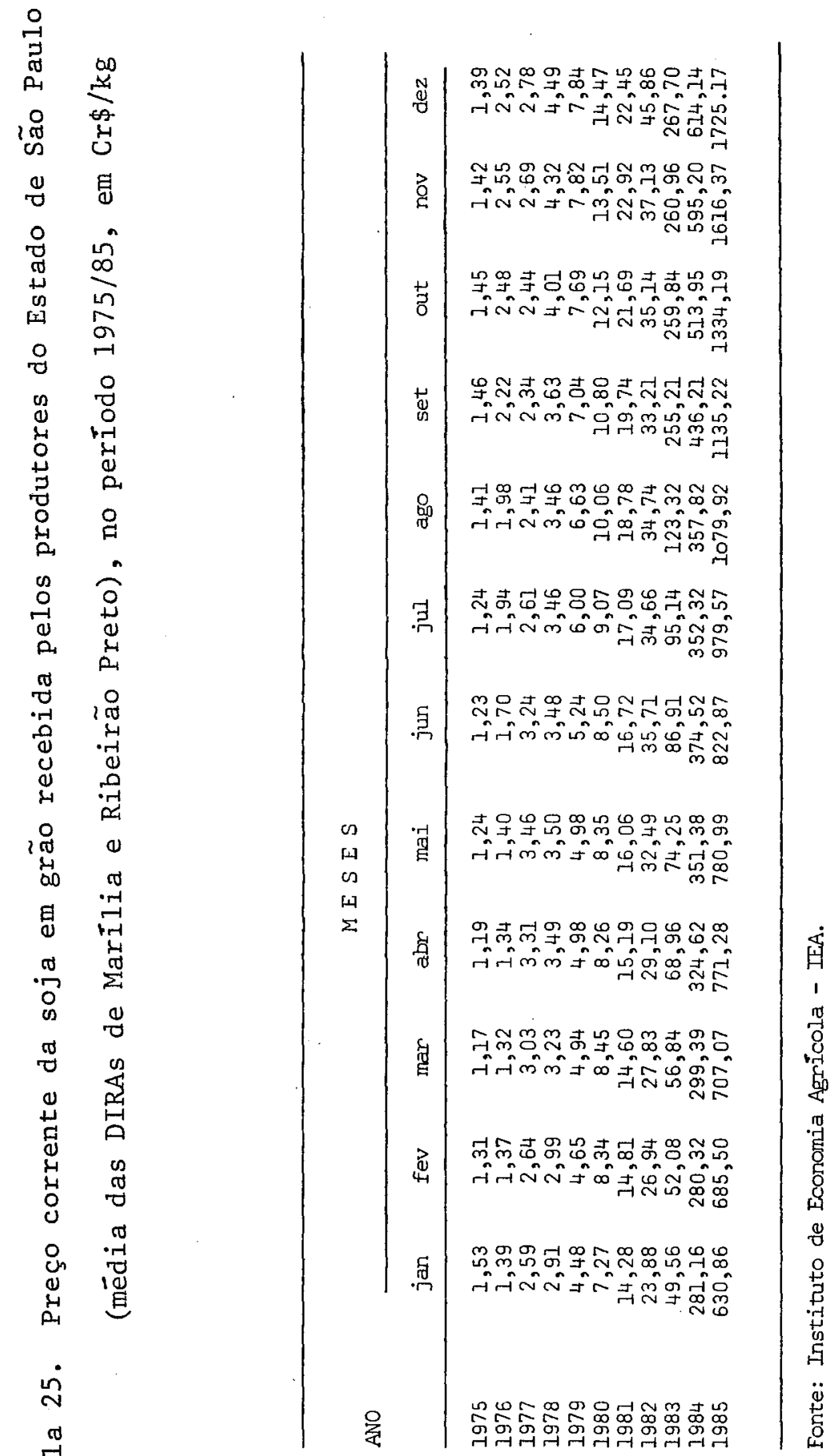




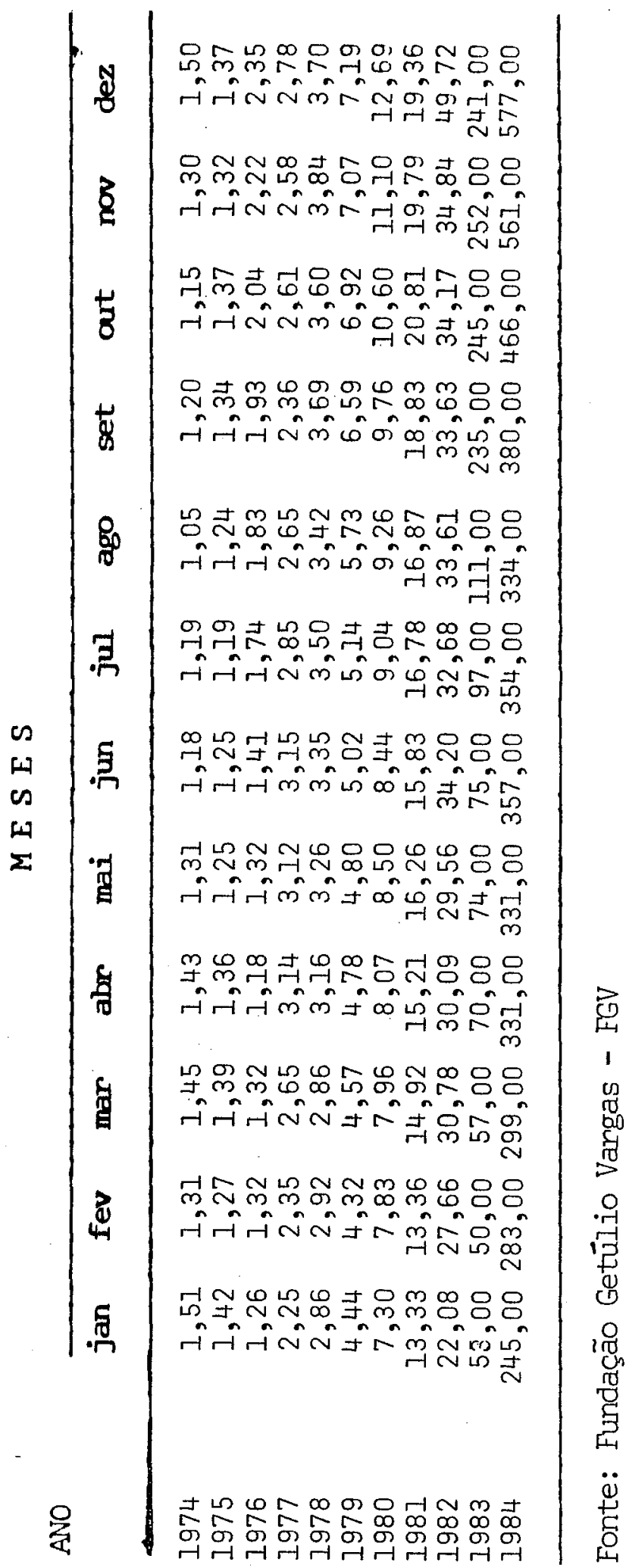




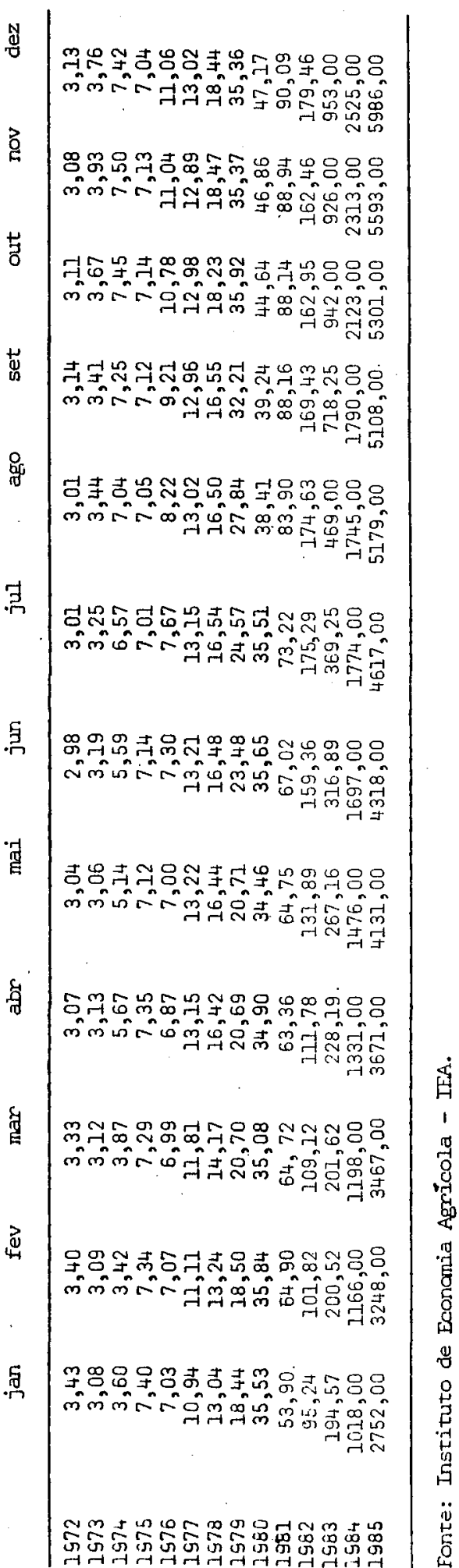




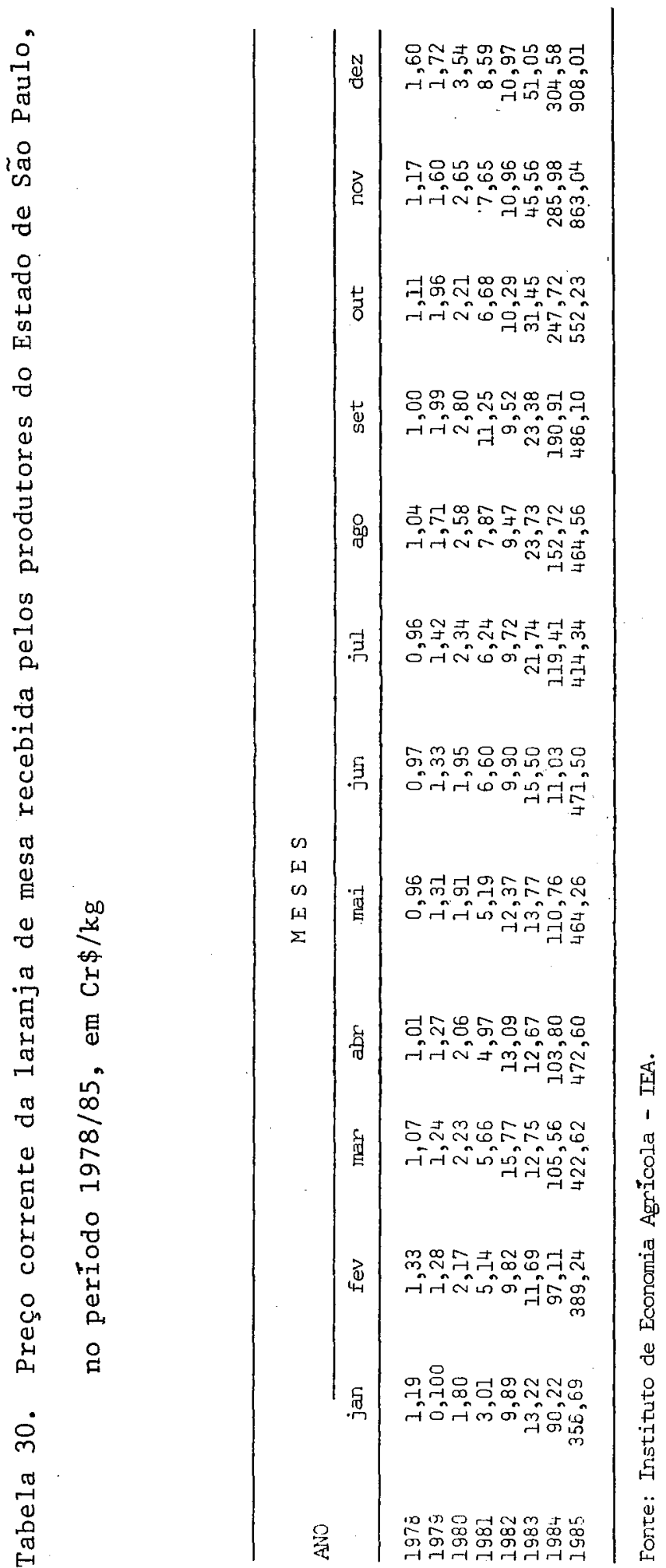




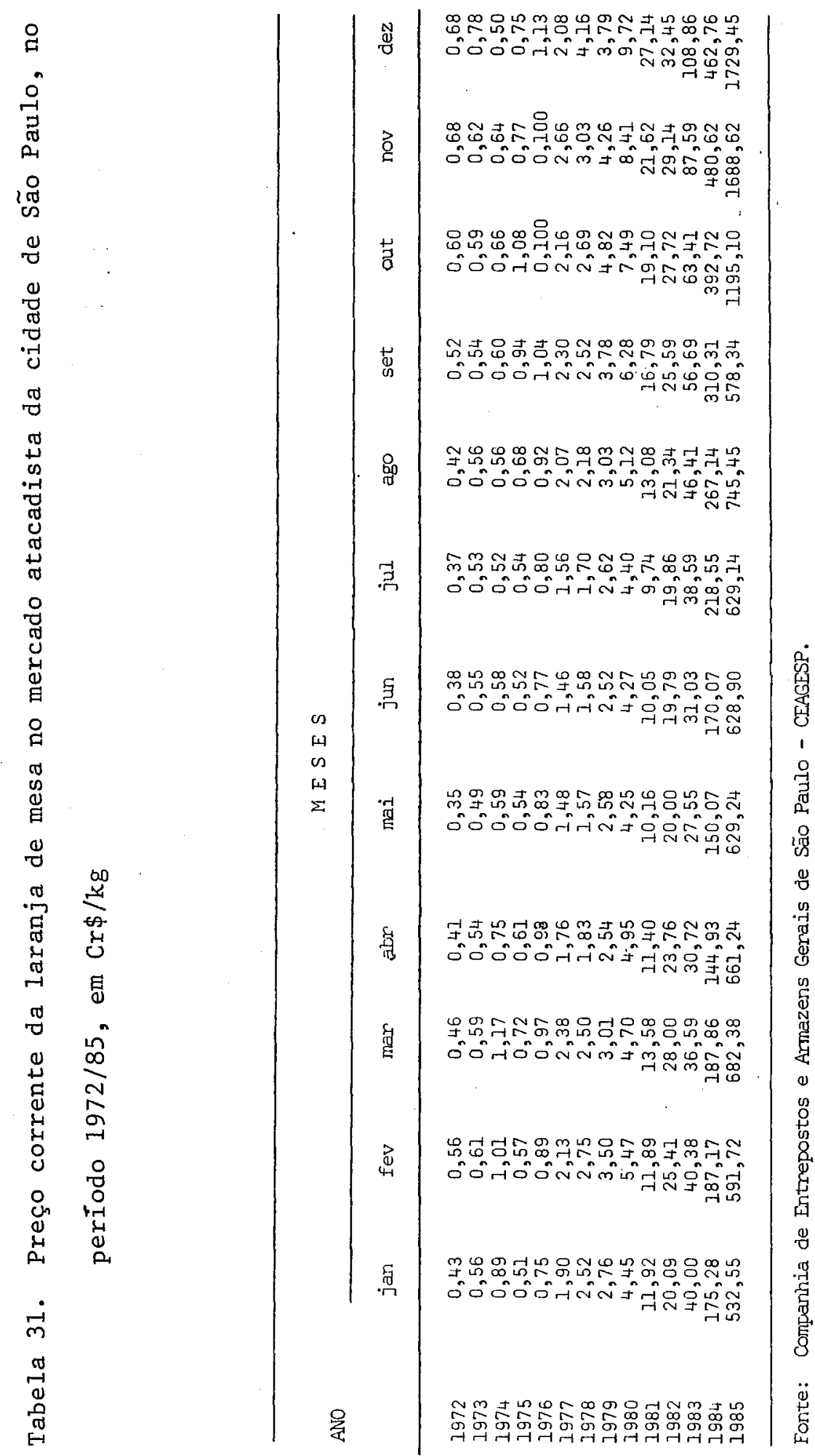




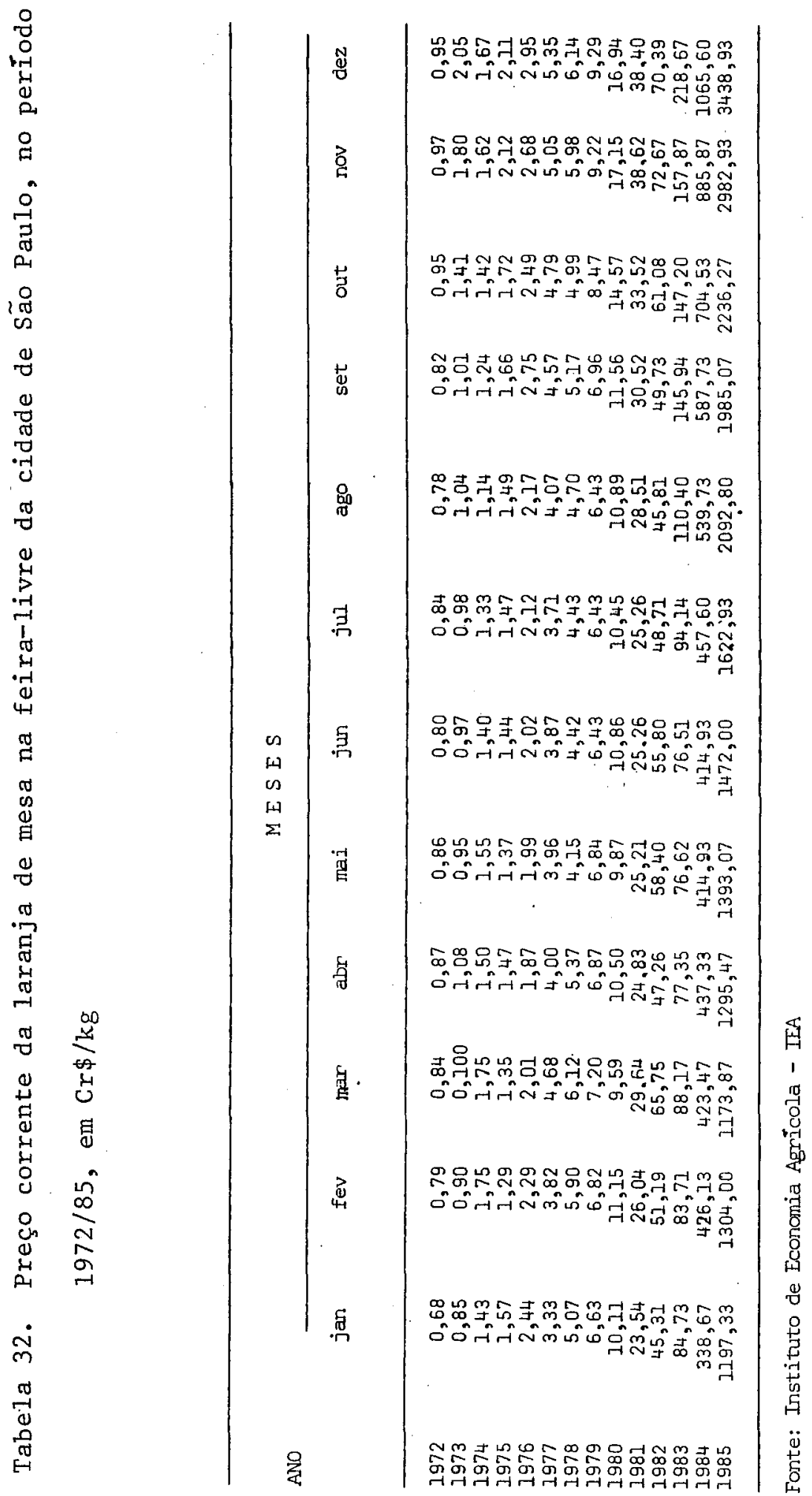


APÊNDICE 2 
Tabela 33. Margem corrente total de comercialização do arroz sem casca, tendo como região de produção o Estado de São Paulo (DIRAs de São Josē do Rio Preto e Ribeirão Preto), no período 1973 a 1985

\begin{tabular}{|c|c|c|}
\hline I - Margen Mensal & & \\
\hline Mês & $\begin{array}{l}\text { Margem absoluta } \\
\left.(\text { Cruzados } / \mathrm{Kg})^{I}\right)\end{array}$ & $\begin{array}{l}\text { Margem porcentual } \\
\text { (8) }\end{array}$ \\
\hline $\begin{array}{l}\text { Janeiro } \\
\text { Fevereiro } \\
\text { Março } \\
\text { Abril } \\
\text { Maio } \\
\text { Junho } \\
\text { Julho } \\
\text { Agosto } \\
\text { Setembro } \\
\text { Outubro } \\
\text { Novembro } \\
\text { Dezembro }\end{array}$ & $\begin{array}{l}20,13 \\
22,20 \\
22,20 \\
22,06 \\
22,53 \\
22,00 \\
20,80 \\
20,60 \\
18,73 \\
17,80 \\
17,46 \\
18,06\end{array}$ & $\begin{array}{l}40,22 \\
44,35 \\
45,35 \\
45,42 \\
46,56 \\
45,70 \\
44,05 \\
42,83 \\
39,71 \\
37,83 \\
37,03 \\
38,07\end{array}$ \\
\hline \multicolumn{3}{|l|}{ II - Margem Anual } \\
\hline Ano & $\begin{array}{c}\text { Margen absoluta } \\
(\text { Cruzados } / \mathrm{Kg})\end{array}$ & $\begin{array}{c}\text { Margem porcentual } \\
\left(\frac{\%}{\%}\right)\end{array}$ \\
\hline $\begin{array}{l}1973 \\
1974 \\
1975 \\
1976 \\
1977 \\
1978 \\
1979 \\
1980 \\
1981 \\
1982 \\
1983 \\
1984 \\
1985\end{array}$ & $\begin{array}{l}25,73 \\
26,33 \\
25,80 \\
23,40 \\
17,13 \\
12,00 \\
12,73 \\
15,73 \\
15,60 \\
17,80 \\
19,00 \\
15,13 \\
30,66\end{array}$ & $\begin{array}{l}47,30 \\
43,00 \\
37,06 \\
48,88 \\
41,37 \\
27,44 \\
29,22 \\
35,46 \\
42,32 \\
40,56 \\
42,30 \\
39,69 \\
70,83\end{array}$ \\
\hline
\end{tabular}

(1) Valor real en Cz\$ (Dez/1987.) 
Tabela 34. Margem corrente total de comercialização do arroz sem casca, tendo como região de produção o Estado de Goiās, no período $1976 / 1980$

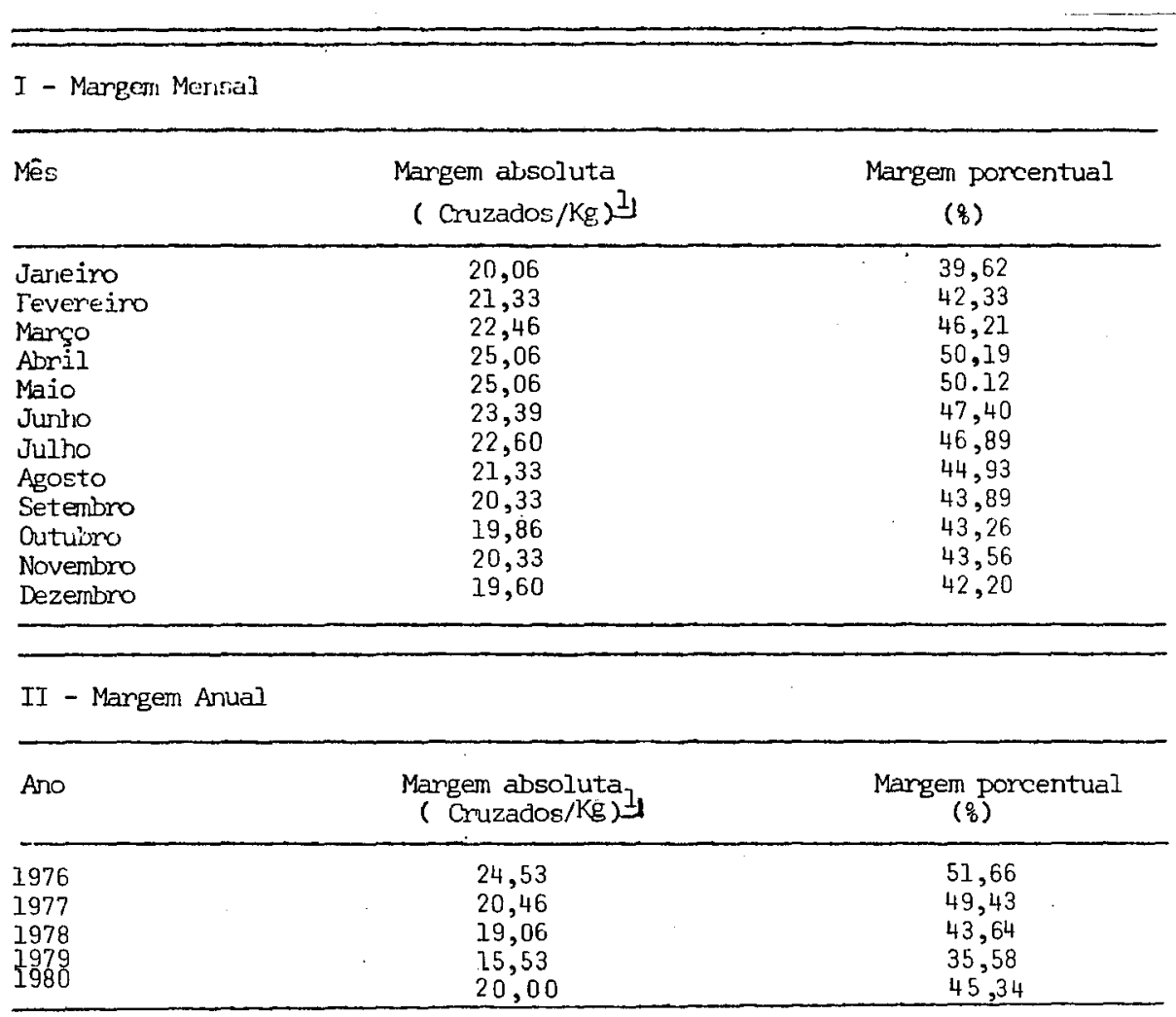

(1) Valor real en Cz\$(Dez/1987) 
Tabela 35. Margem corrente total de comercialização do arroz sem casca, tendo como região de produção o Estado do Rio Grande do Su1, no período 1981 a 1984

\begin{tabular}{|c|c|c|}
\hline \multicolumn{3}{|c|}{ I - Marge्गा Mencal } \\
\hline Mês & $\begin{array}{l}\text { Margem absoluta } \\
\text { (cruzados } / \mathrm{Kg}) \text { IJ }\end{array}$ & $\begin{array}{l}\text { Margem porcentual } \\
\text { ( }())\end{array}$ \\
\hline $\begin{array}{l}\text { Janeiro } \\
\text { Fevereiro } \\
\text { Março } \\
\text { Abril } \\
\text { Maio } \\
\text { Junho } \\
\text { Julho } \\
\text { Agosto } \\
\text { Setembro } \\
\text { Outubro } \\
\text { Novembro } \\
\text { Dezembro }\end{array}$ & $\begin{array}{l}21,20 \\
21,33 \\
20,13 \\
19,00 \\
19,00 \\
17,93 \\
19,00 \\
22,20 \\
21,80 \\
21,13 \\
19,60 \\
19,86\end{array}$ & $\begin{array}{l}48,46 \\
48,60 \\
48,44 \\
47,71 \\
48,35 \\
47,62 \\
48,50 \\
52,54 \\
57,75 \\
51,93 \\
49,51 \\
47,29\end{array}$ \\
\hline \multicolumn{3}{|c|}{ II - Margen Anual } \\
\hline Ano & $\begin{array}{l}\text { Margem absoluta } \\
(\text { Cruzados } / \mathrm{Kg})\end{array}$ & $\begin{array}{c}\text { Margen porcentual } \\
(\%)\end{array}$ \\
\hline $\begin{array}{l}1981 \\
1982 \\
1983 \\
1984\end{array}$ & $\begin{array}{l}17,73 \\
20,06 \\
22,93 \\
20,06\end{array}$ & $\begin{array}{l}47,78 \\
45,99 \\
50,95 \\
52,51\end{array}$ \\
\hline
\end{tabular}

(1) Valor real en $\mathrm{Cz} \$(\mathrm{Dez} / 1987)$ 
Tabela 36. Margem corrente tota1 de comercialização do fubá mimoso, tendo como região de produção o Estado de São Paulo, (DIRAs de Ribeirão Preto e Sorocaba), no período 1976 a 1985

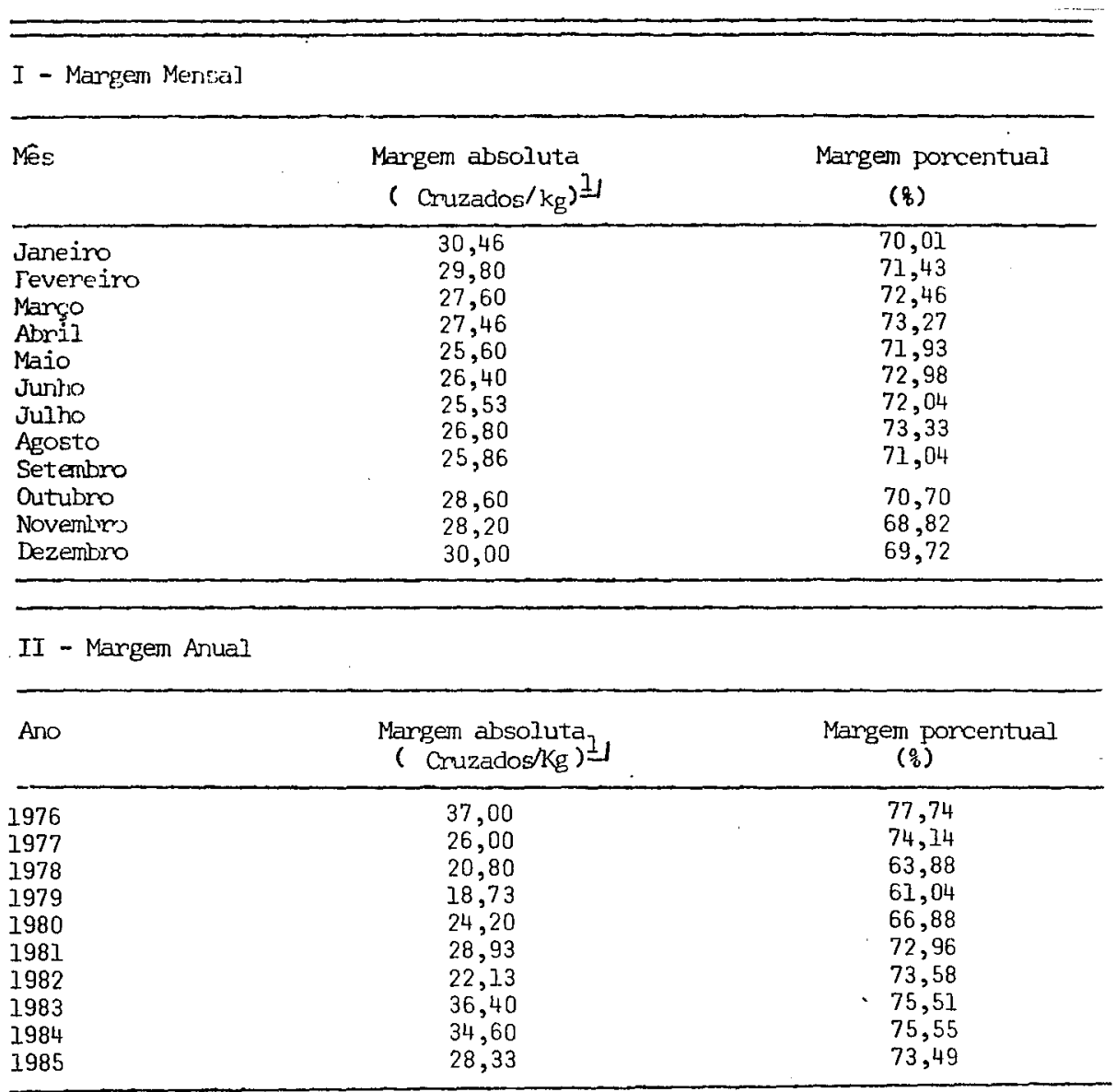

(1) Valor real em Cz\$ (Dez/1987) 
Tabela 37. Margem defasada ${ }^{1 /}$ total de comercialização do fubá mimoso, ten do como região de produção o Estado de São Paulo (DIRAs de Ribeirão Preto e Sorocaba), no período 1976 a 1985

\begin{tabular}{|c|c|c|}
\hline \multicolumn{3}{|c|}{ I - Margenı Meriejal } \\
\hline Mess & $\begin{array}{l}\text { Margem absoluta } \\
\left.(\text { Cruzados } / \mathrm{kg})^{2}\right)\end{array}$ & $\begin{array}{l}\text { Margem porcentual } \\
(\xi)\end{array}$ \\
\hline $\begin{array}{l}\text { Janeiro } \\
\text { Fevereiro } \\
\text { Março } \\
\text { Abril } \\
\text { Maio } \\
\text { Jurito } \\
\text { Julho } \\
\text { Agosto } \\
\text { Setenbro } \\
\text { Outubro } \\
\text { Novembro } \\
\text { Dezenbro }\end{array}$ & $\begin{array}{l}30,40 \\
28,60 \\
26,46 \\
27,06 \\
25,33 \\
26,26 \\
25,46 \\
27,33 \\
27,00 \\
29,26 \\
28,80 \\
30,40\end{array}$ & $\begin{array}{l}69,78 \\
68,46 \\
69,72 \\
72,19 \\
71,22 \\
72,73 \\
72,07 \\
74,54 \\
73,41 \\
72,74 \\
70,77 \\
70,87\end{array}$ \\
\hline \multicolumn{3}{|c|}{ II - Margem Anual } \\
\hline Ano & $\begin{array}{l}\text { Margem absoluta } \\
(\text { Cruzados } / \mathrm{Kg}) 21\end{array}$ & $\begin{array}{c}\text { Margem porcentual } \\
\left(\frac{0}{0}\right)\end{array}$ \\
\hline $\begin{array}{l}1976 \\
1977 \\
1978 \\
1979 \\
1980 \\
1981 \\
1982 \\
1983 \\
1984 \\
1985\end{array}$ & $\begin{array}{l}36,73 \\
26,00 \\
21,20 \\
18,53 \\
24,46 \\
28,53 \\
21,93 \\
37,06 \\
34,26 \\
28,33\end{array}$ & $\begin{array}{l}77,15 \\
74,35 \\
64,91 \\
60,59 \\
67,49 \\
72,27 \\
72,98 \\
76,95 \\
75,11 \\
73,63\end{array}$ \\
\hline
\end{tabular}

(1) Preço ao produtor defasado de 1 mês.

(2) Valor real en Cz\$ (Dez/1987) 
Tabela 38. Margem corrente total de comercialização do fubä mimoso, tendo como região de produção o Estado do Paranā, no período 1976 a 1984

\begin{tabular}{|c|c|c|}
\hline \multicolumn{3}{|c|}{ I - Margem Mensa] } \\
\hline Mês & $\begin{array}{l}\text { Margem absoluta } \\
\text { ( Cruzados/Kg) Jل }\end{array}$ & $\begin{array}{l}\text { Margem porcentual } \\
(q)\end{array}$ \\
\hline $\begin{array}{l}\text { Janeiro } \\
\text { Fevereiro } \\
\text { Manço } \\
\text { Abril } \\
\text { Maio } \\
\text { Jurio } \\
\text { Julho } \\
\text { Agosto } \\
\text { Setembro } \\
\text { Outubro } \\
\text { Noventuro } \\
\text { Dezenbro }\end{array}$ & $\begin{array}{l}39,26 \\
37,60 \\
33,86 \\
33,13 \\
30,73 \\
31,53 \\
30,86 \\
33,33 \\
33,40 \\
37,20 \\
37,40 \\
39,93\end{array}$ & $\begin{array}{l}89,96 \\
89,79 \\
89,78 \\
90,38 \\
89,71 \\
90,42 \\
90,35 \\
91,15 \\
90,89 \\
91,10 \\
90,37 \\
91,41\end{array}$ \\
\hline \multicolumn{3}{|c|}{ II - Margem Anual } \\
\hline Ano & $\begin{array}{l}\text { Margem absoluta } \\
(\text { Cruzados } / \mathrm{Kg})\end{array}$ & $\begin{array}{c}\text { Margem poncentual } \\
(\%)\end{array}$ \\
\hline $\begin{array}{l}1976 \\
1977 \\
1978 \\
1979 \\
1980 \\
1981 \\
1982 \\
1983 \\
1984\end{array}$ & $\begin{array}{l}42,13 \\
29,20 \\
27,66 \\
26,60 \\
32,80 \\
37,13 \\
27,53 \\
46,06 \\
44,59\end{array}$ & $\begin{array}{l}88,53 \\
83,94 \\
85,12 \\
87,81 \\
90,43 \\
93,79 \\
91,49 \\
94,87 \\
97,93\end{array}$ \\
\hline
\end{tabular}

(1) Valor real em Cz\$ (Dez/1987) 
Tabela 39. Margem corrente total de comercialização do fubá mimoso, tendo como região de produção o Estado de Minas Gerais, no perío do 1976 a 1984

\begin{tabular}{|c|c|c|}
\hline \multicolumn{3}{|c|}{ I - Margen Merisall } \\
\hline Mês & $\begin{array}{l}\text { Margem absoluta } \\
(\text { Cruzados } / \mathrm{Kg}) \text { If }\end{array}$ & $\begin{array}{l}\text { Margem porcentual } \\
\text { (q) }\end{array}$ \\
\hline $\begin{array}{l}\text { Janeiro } \\
\text { Fevereiro } \\
\text { Março } \\
\text { Abril } \\
\text { Maio } \\
\text { Juniso } \\
\text { Julho } \\
\text { Agosto } \\
\text { Setembro } \\
\text { Outubro } \\
\text { Novenbro } \\
\text { Dezenbro }\end{array}$ & $\begin{array}{l}38,46 \\
36,60 \\
33,00 \\
32,33 \\
30,13 \\
31,00 \\
30,26 \\
32,80 \\
32,73 \\
36,60 \\
36,80 \\
39,26\end{array}$ & $\begin{array}{l}87,83 \\
86,99 \\
87,15 \\
87,88 \\
87,63 \\
88,75 \\
88,53 \\
89,59 \\
89,01 \\
89,39 \\
88,77 \\
89,74\end{array}$ \\
\hline \multicolumn{3}{|c|}{ II - Margem Anual } \\
\hline Ano & $\underset{\text { ( Cruzados } / \mathrm{Kg})}{\text { Margem absoluta }}$ & $\begin{array}{c}\text { Margem porcentual } \\
\left(\frac{\%}{\delta}\right)\end{array}$ \\
\hline $\begin{array}{l}1976 \\
1977 \\
1978 \\
1979 \\
1980 \\
1981 \\
1982 \\
1983 \\
1984\end{array}$ & $\begin{array}{l}41,59 \\
28,80 \\
26,00 \\
25,46 \\
32,40 \\
36,33 \\
27,00 \\
45,53 \\
44,39\end{array}$ & $\begin{array}{r}87,36 \\
82,61 \\
79,81 \\
84,05 \\
89,38 \\
91,87 \\
89,88 \\
93,50 \\
97,50\end{array}$ \\
\hline
\end{tabular}

(1) Valor real en Cz\$ (Dez/1987) 
Tabela 40. Margem corrente do varejo de comercialização do ôleo de soja, no período 1973 a 1985

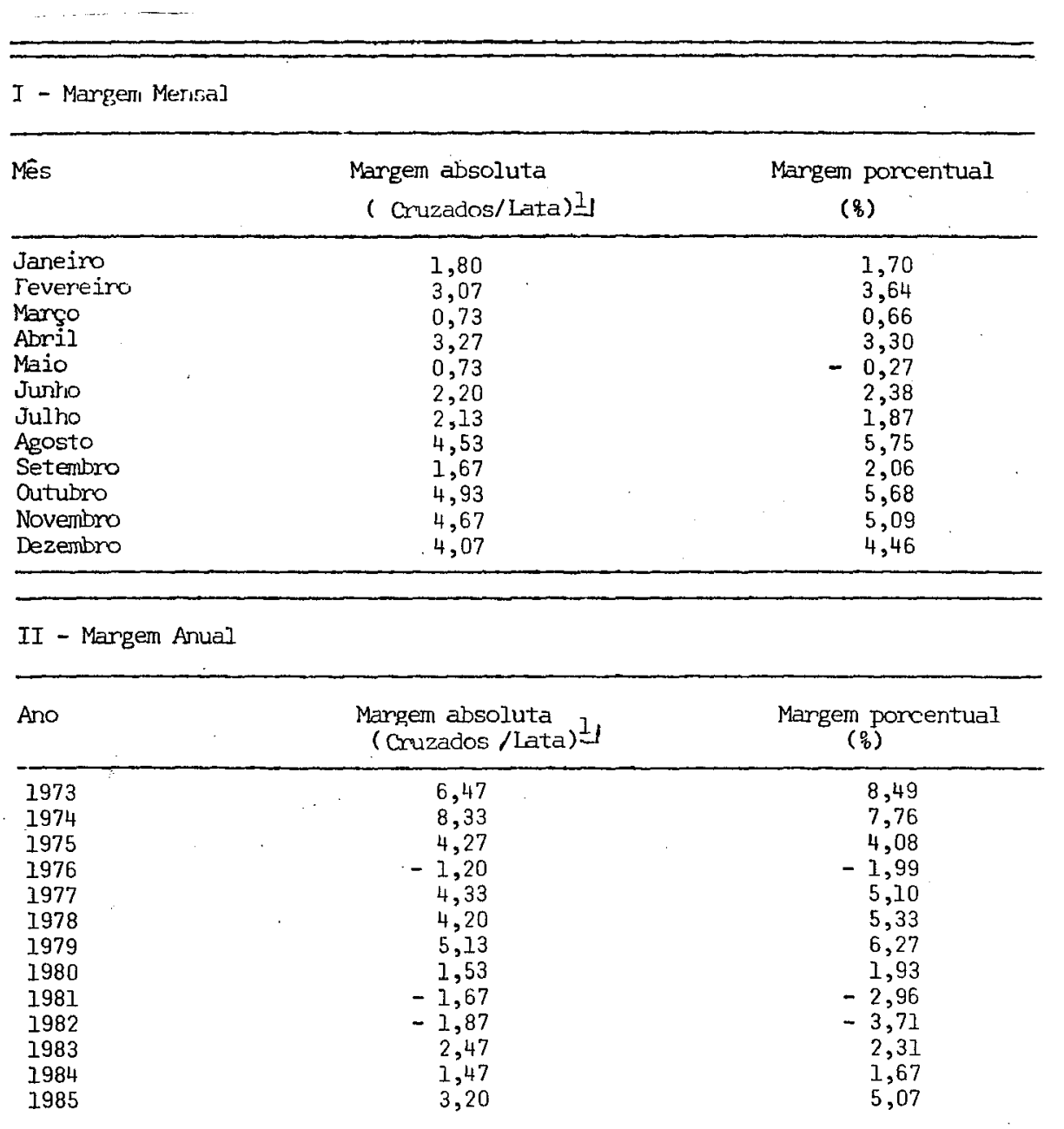

(1) Valor real en $\mathrm{Cz} \$$ (Dez/1987) pon lata de öleo (900 ml). 
Tabela 41. Margem defasada ${ }^{1 /}$ do varejo de comercialização do öleo de soja, no período 1973 a 1985

\begin{tabular}{|c|c|c|}
\hline \multicolumn{3}{|c|}{ I - Margem Mensä] } \\
\hline Més & $\begin{array}{l}\text { Margem absoluta } \\
(\text { Cruzados/Lata })\end{array}$ & $\begin{array}{l}\text { Mangem porcentual } \\
\text { (q) }\end{array}$ \\
\hline $\begin{array}{l}\text { Janeiro } \\
\text { Fevereiro } \\
\text { Março } \\
\text { Abril } \\
\text { Maio } \\
\text { Juntıo } \\
\text { Julho } \\
\text { Agosto } \\
\text { Setembro } \\
\text { Outubro } \\
\text { Novembro } \\
\text { Dezembro }\end{array}$ & $\begin{array}{r}1,27 \\
1,27 \\
-4,13 \\
-1,53 \\
-1,27 \\
1,80 \\
2,27 \\
5,00 \\
5,00 \\
0,80 \\
4,80 \\
2,40\end{array}$ & $\begin{array}{r}-0,21 \\
0,72 \\
-6,00 \\
-4,01 \\
-\quad 2,82 \\
1,07 \\
0,69 \\
0,51 \\
3,99 \\
6,76 \\
1,40 \\
-0,30\end{array}$ \\
\hline \multicolumn{3}{|c|}{ II - Margem Anual } \\
\hline Ano & $\begin{array}{l}\text { Margem absoluta. } \\
\text { ( Cruzados/Lata) }\end{array}$ & $\begin{array}{l}\text { Margem porcentual } \\
\left(\frac{\%}{\%}\right)\end{array}$ \\
\hline $\begin{array}{l}1973 \\
1974 \\
1975 \\
1976 \\
1977 \\
1978 \\
1979 \\
1980 \\
1981 \\
1982 \\
1983 \\
1984 \\
1985\end{array}$ & $\begin{array}{r}2,40 \\
2,73 \\
-3,93 \\
-3,67 \\
0,87 \\
1,80 \\
10,00 \\
-11,47 \\
-9,00 \\
-34,73 \\
13,33 \\
-0,04 \\
-5,27\end{array}$ & $\begin{array}{r}2,82 \\
25,33 \\
-4,52 \\
-\quad 6,28 \\
0,73 \\
2,02 \\
11,44 \\
-19,15 \\
-1,83 \\
-7,70 \\
13,71 \\
-1,21 \\
-9,08\end{array}$ \\
\hline
\end{tabular}

(1) Preço ao atacado defasado de 6 meses

(2) Valor real en $\mathrm{Cz} \$$ (Dez/1987) por lata de áleo (900 ml) 
Tabela 42. Margem corrente do atacado de comercialização do óleo de soja, tendo como região de produção o Estado de São Paulo (DIRAs de Marília é Ribeirão Preto), no período 1976 a 1985

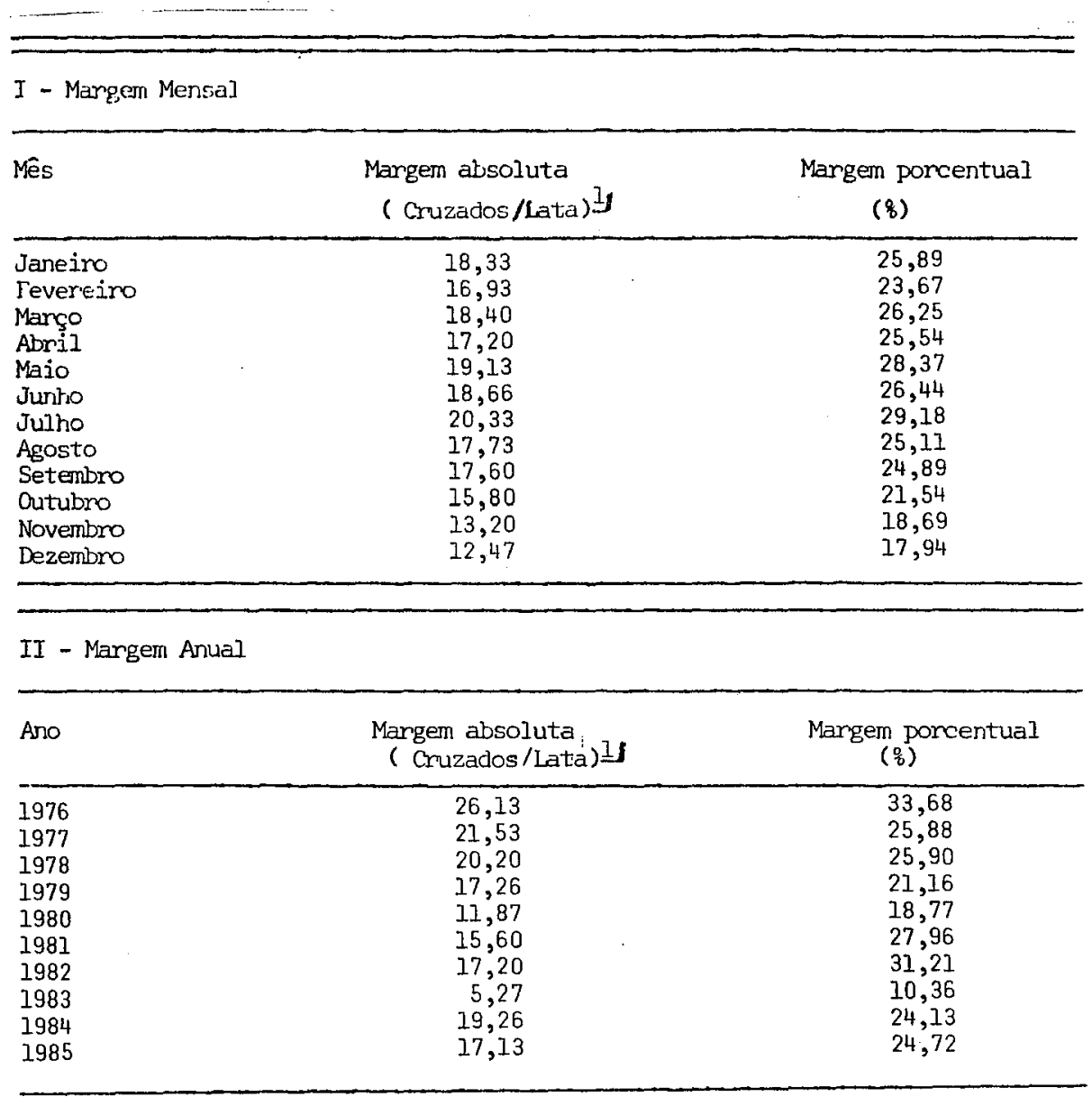

(1) Valor real em Cz\$ (Dez/1987) por lata de óleo (900 ml) 
Tabela 43. Margem corrente do atacado de comercialização do ōleo de soja, tendo como região de produção o Estado de Mato Grosso/Mato Grosso do Sul, no período 1975 a 1984

\begin{tabular}{|c|c|c|}
\hline I - Margem Merssal & & \\
\hline Mes & $\begin{array}{l}\text { Margem absoluta } \\
\text { ( Cruzados/Lata) IJ }\end{array}$ & $\begin{array}{l}\text { Margem porcentual } \\
\text { (8) }\end{array}$ \\
\hline $\begin{array}{l}\text { Janeiro } \\
\text { Fevere:iro } \\
\text { Março } \\
\text { Abril } \\
\text { Maio } \\
\text { Jurho } \\
\text { Julho } \\
\text { Agosto } \\
\text { Setembro } \\
\text { Outubro } \\
\text { Novembro } \\
\text { Dezembro }\end{array}$ & $\begin{array}{l}27,80 \\
26,40 \\
25,06 \\
22,80 \\
26,26 \\
25,86 \\
26,60 \\
23,20 \\
28,20 \\
27,13 \\
24,93 \\
24,53\end{array}$ & $\begin{array}{l}36,88 \\
34,85 \\
33,41 \\
30,79 \\
36,85 \\
34,91 \\
36,66 \\
31,81 \\
37,61 \\
35,29 \\
33,75 \\
33,92\end{array}$ \\
\hline \multicolumn{3}{|l|}{ II - Margem Anual } \\
\hline Ano & $\begin{array}{l}\text { Margen absoluta } \\
\text { ( Cruzados/Lata) } 1 \text { I }\end{array}$ & $\begin{array}{l}\text { Margem porcentual } \\
\left(\frac{\%}{6}\right)\end{array}$ \\
\hline $\begin{array}{l}1975 \\
1976 \\
1977 \\
1978 \\
1979 \\
1980 \\
1981 \\
1982 \\
1983 \\
1984\end{array}$ & $\begin{array}{l}42,93 \\
34,66 \\
30,20 \\
27,60 \\
21,06 \\
15,86 \\
19,20 \\
22,80 \\
15,33 \\
27,73\end{array}$ & $\begin{array}{l}44,51 \\
43,90 \\
36,08 \\
35,51 \\
26,09 \\
25,32 \\
34,54 \\
41,42 \\
25,10 \\
34,83\end{array}$ \\
\hline
\end{tabular}

(1) Valon real en Cz\$ (Dez/1987) por lata de öleo (900 ml) 
Tabela 44. Margem corrente do atacado de comercialização do óleo de soja, tendo como região de produção o Estado de Minas Gerais, no período de 1975 a 1984

\begin{tabular}{|c|c|c|}
\hline \multicolumn{3}{|c|}{ I - Margenı Mensal } \\
\hline Mês & $\begin{array}{l}\text { Margem absoluta. } \\
\text { ( Cruzados/Lata) }\end{array}$ & $\begin{array}{l}\text { Margem porcentual } \\
(\$)\end{array}$ \\
\hline $\begin{array}{l}\text { Janeiro } \\
\text { Fevereiro } \\
\text { Março } \\
\text { Abril } \\
\text { Maio } \\
\text { Junto } \\
\text { Julho } \\
\text { Agosto } \\
\text { Setenbro } \\
\text { Outubro } \\
\text { Novembro } \\
\text { Dezembro }\end{array}$ & $\begin{array}{l}22,20 \\
20,73 \\
21,26 \\
19,73 \\
22,60 \\
23,20 \\
23,33 \\
22,53 \\
23,26 \\
22,53 \\
21,13 \\
19,66\end{array}$ & $\begin{array}{l}29,04 \\
27,16 \\
28,06 \\
26,10 \\
31,50 \\
31,56 \\
32,05 \\
30,84 \\
31,24 \\
29,29 \\
28,92 \\
27,08\end{array}$ \\
\hline \multicolumn{3}{|c|}{ II - Margem Anual } \\
\hline Ano & $\begin{array}{l}\text { Margem absoluta } \\
\text { ( Cruzados/lata)」 }\end{array}$ & $\begin{array}{c}\text { Margem porcentual } \\
(\delta)\end{array}$ \\
\hline $\begin{array}{l}1975 \\
1976 \\
1977 \\
1978 \\
1979 \\
1980 \\
1981 \\
1982 \\
1983 \\
1984\end{array}$ & $\begin{array}{r}37,46 \\
31,60 \\
23,60 \\
23,60 \\
21,73 \\
14,86 \\
17,93 \\
17,60 \\
7,93 \\
22,26\end{array}$ & $\begin{array}{l}38,92 \\
40,48 \\
28,16 \\
30,22 \\
26,59 \\
24,03 \\
32,16 \\
31,77 \\
13,70 \\
28,00\end{array}$ \\
\hline
\end{tabular}

(1) Valor real em Cz $\$$ (Dez/1987) por lata de óleo (900 ml). 
Tabela 45. Margem defasada $\stackrel{1}{ }$ / do atacado de commercialização do óleo de soja, tendo como região de produção o Estado de Minas Gerais, no período de 1975 a 1984

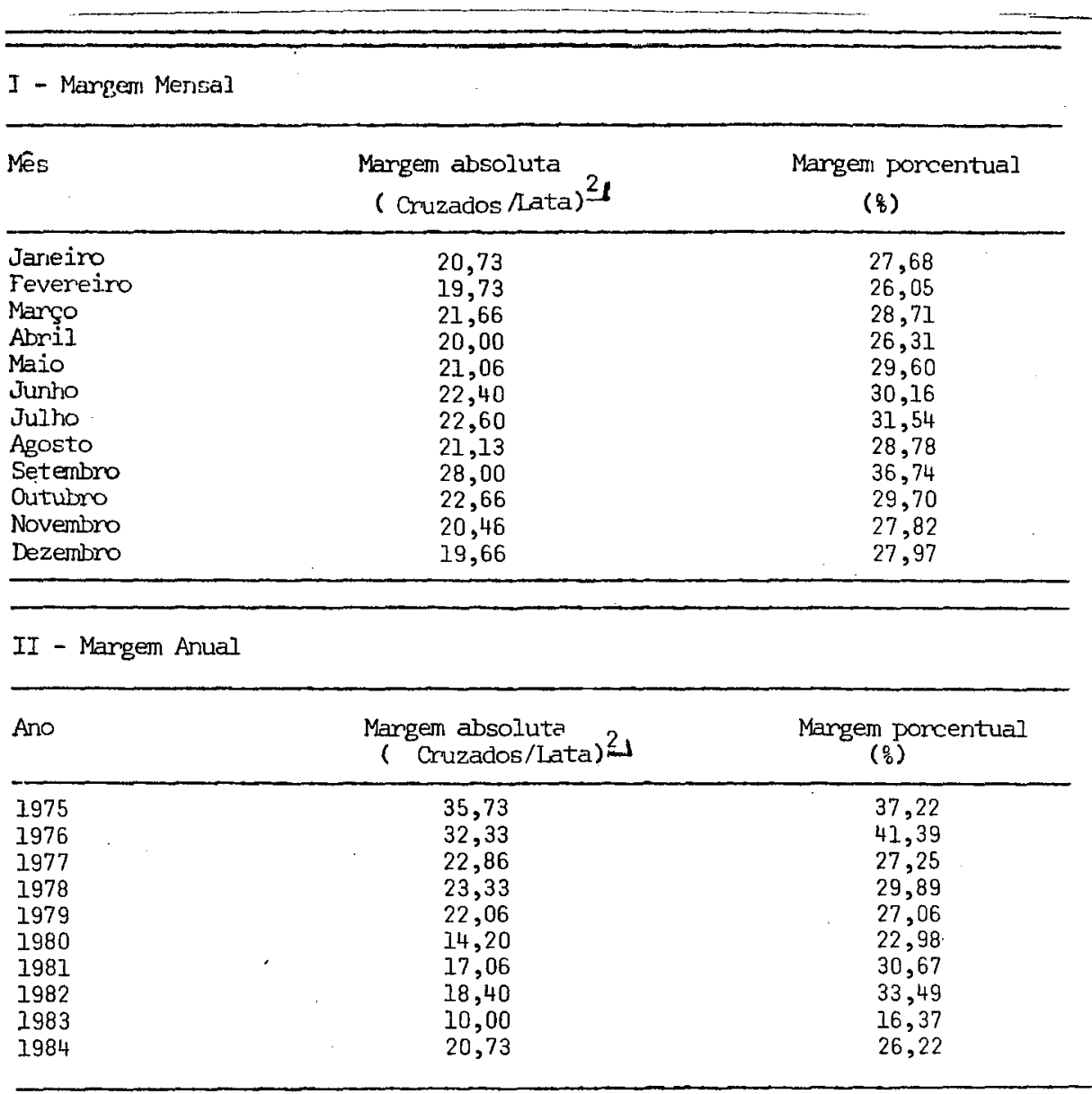

(1) Preço ao produtor defasado de 1 mês.

(2) Valor real en $\mathrm{Cz} \$(\mathrm{Dez} / 1987)$ por lata de óleo (900 ml). 
Tabela 46. Margem defasada ${ }^{1 /}$ do atacado de comercialização do óleo de so ja, tendo como região de produção o Estado de Minas Gerais, no período de 1975 a 1984

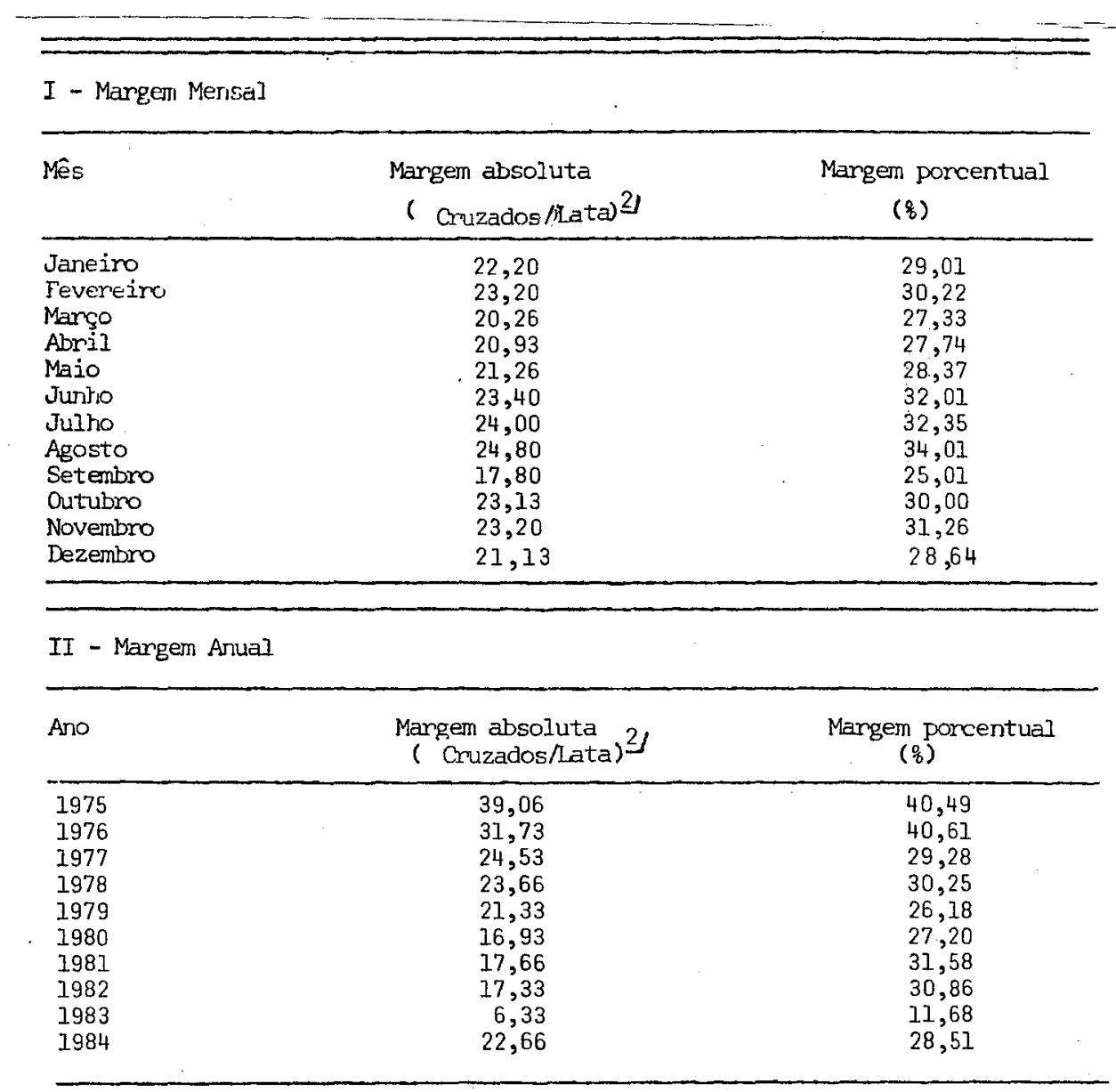

(1) Preço ao atacado defasado de 1 mês

(2) Valor real em Cz\$ (Dez/1987) por lata de óleo (900 ml). 
Tabela 47. Margem corrente total de comercialização do óleo de soja, tendo como região de produção o Estado de São Paulo (DIRAs de Ma rília e Ribeirão Preto), no período de 1975 a 1985

\begin{tabular}{|c|c|c|}
\hline I - Margem Mensal & & \\
\hline Mês & $\begin{array}{l}\text { Margem absoluta } \\
\left(\text { ( Cruzados/Lata) }{ }_{1}\right.\end{array}$ & $\begin{array}{l}\text { Margem porcentual } \\
(\xi)\end{array}$ \\
\hline $\begin{array}{l}\text { Janeiro } \\
\text { Fevereiro } \\
\text { Março } \\
\text { Abril } \\
\text { Maio } \\
\text { Jurito } \\
\text { Julho } \\
\text { Agosto } \\
\text { Setembro } \\
\text { Outubro } \\
\text { Novembro } \\
\text { Dezembro }\end{array}$ & $\begin{array}{l}20,60 \\
22,20 \\
21,60 \\
21,33 \\
21,20 \\
22,46 \\
23,06 \\
22,73 \\
19,53 \\
21,13 \\
18,00 \\
17,00\end{array}$ & $\begin{array}{l}26,72 \\
28,54 \\
28,37 \\
27,69 \\
28,33 \\
29,72 \\
31,01 \\
31,06 \\
26,90 \\
27,55 \\
23,81 \\
22,77\end{array}$ \\
\hline \multicolumn{3}{|l|}{ II - Margem Anual } \\
\hline Ano & $\begin{array}{l}\text { Margem absoluta } \\
\text { ( Cruzados/ Lata) }\end{array}$ & $\begin{array}{c}\text { Margem porcentual } \\
\left(\frac{o}{b}\right)\end{array}$ \\
\hline $\begin{array}{l}1975 \\
1976 \\
1977 \\
1978 \\
1979 \\
1980 \\
1981 \\
1982 \\
1983 \\
1984 \\
1985\end{array}$ & $\begin{array}{r}40,93 \\
24,93 \\
25,86 \\
24,33 \\
22,33 \\
13,40 \\
13,93 \\
15,33 \\
7,80 \\
20,73 \\
20,33\end{array}$ & $\begin{array}{l}41,96 \\
31,69 \\
30,97 \\
31,23 \\
27,44 \\
20,70 \\
25,00 \\
27,51 \\
12,67 \\
25,81 \\
29,79\end{array}$ \\
\hline
\end{tabular}

(1) Valor real en $\mathrm{Cz} \$$ (Dez/1987) por lata de óleo (900 ml). 
Tabela 48. Margem corrente total de comercialização do óleo de soja, tendo como região de produção o Estado de Mato Grosso / Mato Grosso do Sul, no período de 1975 a 1984

\begin{tabular}{|c|c|c|}
\hline \multicolumn{3}{|c|}{ I - Margen Mensal } \\
\hline Mēs & $\begin{array}{l}\text { Margem absoluta } \\
\text { (Cruzados/lata ) I }\end{array}$ & $\begin{array}{l}\text { Margem porcentual } \\
\text { (q) }\end{array}$ \\
\hline $\begin{array}{l}\text { Jarieiro } \\
\text { Fevereiro } \\
\text { Março } \\
\text { Abril } \\
\text { Maio } \\
\text { Junho } \\
\text { Julho } \\
\text { Agosto } \\
\text { Setenbro } \\
\text { Outubro } \\
\text { Novembro } \\
\text { Dezembro }\end{array}$ & $\begin{array}{l}26,80 \\
28,33 \\
24,66 \\
26,66 \\
27,80 \\
29,33 \\
30,80 \\
29,40 \\
30,73 \\
32,93 \\
29,80 \\
28,73 \\
\end{array}$ & $\begin{array}{l}34,67 \\
37,13 \\
32,48 \\
33,69 \\
36,55 \\
37,64 \\
38,94 \\
37,48 \\
38,58 \\
40,03 \\
37,25 \\
36,62 \\
\end{array}$ \\
\hline \multicolumn{3}{|c|}{ II - Margèn Anual } \\
\hline Ano & $\begin{array}{l}\text { Margem absoluta } \\
\text { ( Cruzados / Lata) If }\end{array}$ & $\begin{array}{c}\text { Margem porcentual } \\
\left(\frac{q}{q}\right)\end{array}$ \\
\hline $\begin{array}{l}1975 \\
1976 \\
1977 \\
1978 \\
1979 \\
1980 \\
1981 \\
1982 \\
1983 \\
1984\end{array}$ & $\begin{array}{l}47,19 \\
33,40 \\
34,53 \\
31,80 \\
26,20 \\
17,40 \\
17,60 \\
20,93 \\
17,86 \\
29,13\end{array}$ & $\begin{array}{l}48,58 \\
41,92 \\
41,17 \\
40,84 \\
32,36 \\
27,26 \\
31,58 \\
37,71 \\
27,40 \\
36,50\end{array}$ \\
\hline
\end{tabular}

(I) Valon real em Cz\$ (Dez/1987) por lata de öleo (900 ml). 
Tabela 49. Margem corrente total de comercialização do óleo de soja, ten do como região de produção o Estado de Minas Gerais, no período de 1975 a 1984

I - Margem Mensal

\begin{tabular}{|c|c|c|}
\hline Mês & $\begin{array}{l}\text { Margem absoluta } \\
\text { ( Conuzados/Lata) ل ل }\end{array}$ & $\begin{array}{l}\text { Margem porcentual } \\
\qquad(\xi)\end{array}$ \\
\hline $\begin{array}{l}\text { Janeiro } \\
\text { Fevereiro } \\
\text { Março } \\
\text { Abril } \\
\text { Maio } \\
\text { Junho } \\
\text { Julho } \\
\text { Agosto } \\
\text { Setenbro } \\
\text { Outubro } \\
\text { Novenbro } \\
\text { Dezenbro }\end{array}$ & $\begin{array}{l}19,73 \\
20,80 \\
18,80 \\
21,73 \\
22,06 \\
25,33 \\
26,46 \\
29,26 \\
26,26 \\
29,46 \\
26,86 \\
23,93\end{array}$ & $\begin{array}{l}24,87 \\
26,50 \\
24,33 \\
27,33 \\
28,99 \\
32,92 \\
33,54 \\
36,96 \\
32,82 \\
35,19 \\
33,30 \\
30,10\end{array}$ \\
\hline \multicolumn{3}{|c|}{ II - Margem Anual } \\
\hline Aro & $\begin{array}{l}\text { Margem absolyta } \\
\text { ( Cruzados }{ }_{\mathrm{L} a t a)} \text { I }\end{array}$ & $\begin{array}{c}\text { Margem porcentual } \\
\left(\frac{\%}{\%}\right)\end{array}$ \\
\hline $\begin{array}{l}1975 \\
1976 \\
1977 \\
1978 \\
1979 \\
1980 \\
1981 \\
1982 \\
1983 \\
1984\end{array}$ & $\begin{array}{l}41,73 \\
30,33 \\
27,93 \\
27,73 \\
26,80 \\
16,40 \\
16,26 \\
15,73 \\
10,46 \\
23,66\end{array}$ & $\begin{array}{l}43,00 \\
38,50 \\
33,26 \\
35,55 \\
32,86 \\
25,96 \\
29,20 \\
28,06 \\
16,01 \\
29,67\end{array}$ \\
\hline
\end{tabular}

(1) Valor real en Cz\$ (Dez/1987) por lata de óleo (900 ml). 
Tabela 50. Margem corrente do varejo de comercialização da laranja de mesa, no período 1972 a 1985

\begin{tabular}{|c|c|c|}
\hline \multicolumn{3}{|c|}{ I - Margem Mensal } \\
\hline Mes & $\begin{array}{l}\text { Margem absoluta } \\
\left.(\text { Cruzados/Kg })^{1}\right]\end{array}$ & $\begin{array}{l}\text { Margem porcentual } \\
(8)\end{array}$ \\
\hline $\begin{array}{l}\text { Janeiro } \\
\text { Fevereiro } \\
\text { Março } \\
\text { Abril } \\
\text { Maio } \\
\text { Jurho } \\
\text { Julho } \\
\text { Agosto } \\
\text { Setenbro } \\
\text { Outubro } \\
\text { Novenbro } \\
\text { Dezembro }\end{array}$ & $\begin{array}{l}13,00 \\
12,93 \\
13,00 \\
12,93 \\
13,13 \\
12,33 \\
11,80 \\
10,87 \\
10,73 \\
11,07 \\
13,06 \\
13,60\end{array}$ & $\begin{array}{l}51,03 \\
48,91 \\
50,20 \\
55,66 \\
60,05 \\
59,21 \\
58,36 \\
53,33 \\
50,32 \\
48,87 \\
51,51 \\
51,57\end{array}$ \\
\hline \multicolumn{3}{|c|}{ II - Margem Anual } \\
\hline Ano & $\begin{array}{l}\text { Margen absoluta } \\
\text { ( Cruzados/Kg } 1 \text { I }\end{array}$ & $\underset{(s)}{\text { Margem porcentual }}$ \\
\hline $\begin{array}{l}1972 \\
1973 \\
1974 \\
1975 \\
1976 \\
1977 \\
1978 \\
1979 \\
1980 \\
1981 \\
1982 \\
1983 \\
1984 \\
1985\end{array}$ & $\begin{array}{r}9,13 \\
12,80 \\
13,33 \\
12,07 \\
13,33 \\
15,06 \\
13,66 \\
12,87 \\
9,87 \\
11,07 \\
12,27 \\
9,60 \\
14,06 \\
14,26\end{array}$ & $\begin{array}{l}42,59 \\
47,58 \\
52,60 \\
56,56 \\
59,93 \\
53,09 \\
54,10 \\
55,67 \\
52,26 \\
50,73 \\
56,09 \\
56,38 \\
53,85 \\
54,10\end{array}$ \\
\hline
\end{tabular}

(1) Valor real en $\mathrm{Cz} \$(\mathrm{Dez} / 1987)$. 
Tabela 51. Margem defasada $1 /$ do varejo de comercialização da laranja de mesa, no período 1974 a 1985

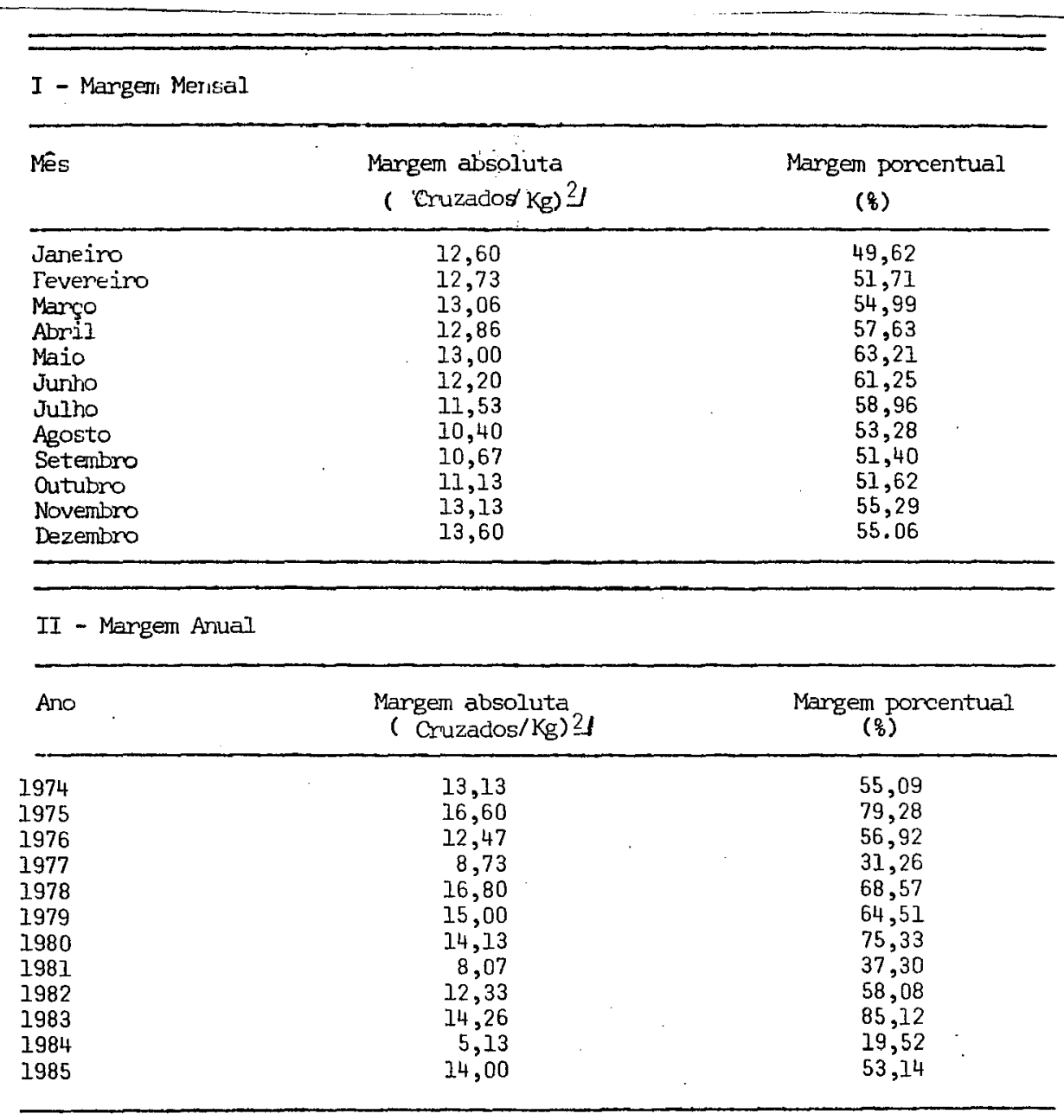

(1) Preço ao varejo defasado de 12 meses

(2) Valor real en Cz\$ (Dez/87) 
Tabela 52. Margem corrente do atacado de comercialização da laranja de mesa, tendo como região de produção o Estado de São Paulo, no período de 1978 a 1985

\begin{tabular}{|c|c|c|}
\hline \multicolumn{3}{|c|}{ I - Margen Mensal } \\
\hline Mes & $\begin{array}{l}\text { Margem absoluta } \\
\text { (Cruzados } / \mathrm{kg}) \text { J }\end{array}$ & $\begin{array}{l}\text { Margem porcentual } \\
(\xi)\end{array}$ \\
\hline $\begin{array}{l}\text { Jarleiro } \\
\text { Fevereiro } \\
\text { Março } \\
\text { Abril } \\
\text { Maio } \\
\text { Jurito } \\
\text { Julho } \\
\text { Agosto } \\
\text { Setembro } \\
\text { Outubro } \\
\text { Novembro } \\
\text { Dezembro }\end{array}$ & $\begin{array}{l}6,80 \\
7,20 \\
6,07 \\
4,27 \\
3,33 \\
3,20 \\
3,40 \\
4,07 \\
4,40 \\
6,27 \\
6,73 \\
7,00\end{array}$ & $\begin{array}{l}26,36 \\
27,11 \\
23,48 \\
19,65 \\
16,12 \\
16,28 \\
17,84 \\
20,76 \\
22,92 \\
29,78 \\
28,88 \\
30,57\end{array}$ \\
\hline \multicolumn{3}{|c|}{ II - Margem Anual } \\
\hline Ano & $\begin{array}{l}\text { Margem absoluta } \\
(\text { Cruzados } / \mathrm{Kg})^{1}\end{array}$ & $\begin{array}{c}\text { Margem porcentual } \\
\left(\frac{0}{8}\right)\end{array}$ \\
\hline $\begin{array}{l}1978 \\
1979 \\
1980 \\
1981 \\
1982 \\
1983 \\
1984 \\
1985\end{array}$ & $\begin{array}{l}6,33 \\
5,60 \\
5,27 \\
6,00 \\
5,13 \\
4,33 \\
4,80 \\
4,47\end{array}$ & $\begin{array}{l}24,65 \\
23,98 \\
27,80 \\
26,81 \\
24,00 \\
24,21 \\
18,28 \\
16,75\end{array}$ \\
\hline
\end{tabular}

(1) Valor real en Cz\$ (Dez/1987). 
Tabela 53. Margem corrente total de comercialização da laranja de mesa, tendo como região de produção o Estado de São Paulo, no período de 1978 a 1985 .

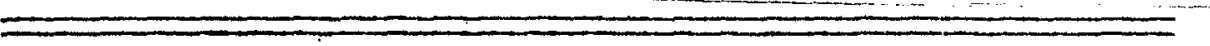

I - Margem Mensal

\begin{tabular}{|c|c|c|}
\hline Mês & $\begin{array}{l}\text { Margem absoluta } \\
(\text { Cruzados } \mathrm{Kg}) \text { If }\end{array}$ & $\begin{array}{l}\text { Margen porcentual } \\
\text { ( } 8)\end{array}$ \\
\hline $\begin{array}{l}\text { Janeiro } \\
\text { Fevereiro } \\
\text { Março } \\
\text { Abril } \\
\text { Maio } \\
\text { Junho } \\
\text { Julho } \\
\text { Agosto } \\
\text { Setembro } \\
\text { Outubro } \\
\text { Novembro } \\
\text { Dezembro }\end{array}$ & $\begin{array}{l}20,66 \\
21,46 \\
20,33 \\
17,53 \\
16,33 \\
15,46 \\
14,80 \\
15,13 \\
14,93 \\
16,26 \\
18,06 \\
18,06\end{array}$ & $\begin{array}{l}79,64 \\
79,63 \\
77,96 \\
77,36 \\
77,33 \\
77,04 \\
76,82 \\
76,09 \\
74,85 \\
77,67 \\
77,84 \\
77,29\end{array}$ \\
\hline \multicolumn{3}{|c|}{ II - Margem Anual } \\
\hline Ano & $\begin{array}{l}\text { Margem absoluta } \\
(\text { (cruzados } / \mathrm{Kg})\end{array}$ & $\begin{array}{c}\text { Margem porcentual } \\
\left(\frac{\%}{0}\right)\end{array}$ \\
\hline $\begin{array}{l}1978 \\
1979 \\
1980 \\
1981 \\
1982 \\
1983 \\
1984 \\
1985\end{array}$ & $\begin{array}{l}19,93 \\
18,46 \\
15,13 \\
17,00 \\
17,40 \\
13,86 \\
18,86 \\
18,73\end{array}$ & $\begin{array}{l}78,76 \\
79,65 \\
80,06 \\
77,53 \\
80,09 \\
80,60 \\
72,13 \\
70,86\end{array}$ \\
\hline
\end{tabular}

(1) Valor real en $\mathrm{Cz} \$(\mathrm{Dez} / 1987)$. 